Andrews University

Digital Commons @ Andrews University

\title{
A Structural Equation Model of the Influence of Personal, Behavioral, and Environmental Factors on the Writing Performance of First-year Students at a Selected Michigan Community College
}

Thula I. Norton Lambert

Andrews University, thula@andrews.edu

Follow this and additional works at: https://digitalcommons.andrews.edu/dissertations

Part of the Curriculum and Instruction Commons, and the Educational Assessment, Evaluation, and Research Commons

\section{Recommended Citation}

Lambert, Thula I. Norton, "A Structural Equation Model of the Influence of Personal, Behavioral, and Environmental Factors on the Writing Performance of First-year Students at a Selected Michigan Community College" (2015). Dissertations. 1580.

https://digitalcommons.andrews.edu/dissertations/1580

https://dx.doi.org/10.32597/dissertations/1580

This Dissertation is brought to you for free and open access by the Graduate Research at Digital Commons @ Andrews University. It has been accepted for inclusion in Dissertations by an authorized administrator of Digital Commons@ Andrews University. For more information, please contact repository@andrews.edu. 


\section{Andrews \$university}

Seek Knowledge. Affirm Faith. Change the World.

Thank you for your interest in the

\section{Andrews University Digital Library of Dissertations and Theses.}

Please honor the copyright of this document by not duplicating or distributing additional copies in any form without the author's express written permission. Thanks for your cooperation. 


\begin{abstract}
A STRUCTURAL EQUATION MODEL OF THE INFLUENCE OF PERSONAL, BEHAVIORAL, AND ENVIRONMENTAL FACTORS ON THE WRITING PERFORMANCE OF FIRST-YEAR STUDENTS AT A SELECTED MICHIGAN COMMUNITY COLLEGE
\end{abstract}

by

Thula I. Norton Lambert

Chair: Elvin Gabriel 


\title{
ABSTRACT OF GRADUATE STUDENT RESEARCH
}

Dissertation

\author{
Andrews University \\ School of Education
}

\section{Title: A STRUCTURAL EQUATION MODEL OF THE INFLUENCE OF PERSONAL, BEHAVIORAL, AND ENVIRONMENTAL FACTORS ON THE WRITING PERFORMANCE OF FIRST-YEAR STUDENTS AT A SELECTED MICHIGAN COMMUNITY COLLEGE}

Name of researcher: Thula I. Norton Lambert

Name and degree of faculty chair: Elvin Gabriel, Ed.D.

Date completed: December 2015

\section{Problem}

While previous writing performance studies have examined a range of motivational variables such as self-efficacy or writing apprehension, certain contextual variables and variables related to current writing pedagogy and practice have not been included, which has resulted in gaps in the research literature.

\section{Method}

A non-experimental, correlational, cross-sectional, ex post facto, survey research design was used to examine the personal, behavioral, and environmental factors that had been identified as being of potential influence to students' writing performance. A census 
was conducted among the 233 students enrolled in English Composition on the two campuses of a small two-year college in Michigan. The final sample consisted of 125 participants enrolled in 14 sections of a first-semester Freshman English course. Instrumentation for this study consisted of three questionnaires: The Writing Survey (TWS), the Writing Tasks Scale (WTS), and three researcher-developed measures, The Student Information Form (SIF), and two survey record reviews, the Previous Writing Achievement Spreadsheet (PWAS), and the Writing Performance Spreadsheet (WPS). The Statistical Package for the Social Sciences (SPSS) was used to store and organize the data, and generate descriptive statistics. The research hypothesis was tested using structural equation modeling (SEM) with IBM SPSS Amos 21 (Arbuckle, 2012).

\section{Results}

Structural equation modeling hypothesis-testing procedures indicated an acceptable fit between the theoretical covariance matrix and the observed covariance matrix. The chi-square test of the model was not statistically significant $\chi^{2}(33, N=125)$ $=41.11, p=.157$, which in SEM indicates that the model fits the data. The model yielded acceptable fit indices for all indices except one. The other fit measures attained the recommended target values. The value of the GFI was .94, which indicates a good fit. The NFI was .80, which is below the target value of .95. The CFI was .95, and the RMSEA was .045. The null hypothesis was therefore retained, indicating empirical support for the theoretical model. Non-significant correlations were found between Personal Factors (PF) and Environmental Factors (EF), $r=.29, p=.359$, Behavioral Factors (BF) and Environmental Factors (EF), $r=.29, p=.325$, and Personal Factors $(\mathrm{PF})$ and Behavioral Factors $(\mathrm{BF}), r=.19, p=.105$. Personal Factors $(\mathrm{PF})$ was the only 
significant predictor of writing performance. The path coefficient of .26 indicated a large effect size ( $>$.25, Kieth, 2006). Writing performance was influenced by the direct effect of Personal Factors (PF), which accounted for approximately $7 \%$ of the variance in writing performance.

\section{Conclusions}

The theoretical model of writing performance was supported by the findings. In addition, the causal contribution of Personal Factors, consisting of previous writing achievement, self-regulatory efficacy, and self-efficacy for writing tasks to first-year composition students' writing performance was validated, achieving both statistical and practical significance. Overall, the findings point to the important predictive role of personal factors in students' writing performance. The findings of this exploratory study hold implications for classroom practice, and point to the necessity of continued interdisciplinary writing research. 
Andrews University

School of Education

\title{
A STRUCTURAL EQUATION MODEL OF THE INFLUENCE OF PERSONAL, BEHAVIORAL, AND ENVIRONMENTAL FACTORS ON THE WRITING PERFORMANCE OF FIRST-YEAR STUDENTS AT A SELECTED MICHIGAN COMMUNITY COLLEGE
}

\author{
A Dissertation \\ Presented in Partial Fulfillment \\ of the Requirements for the Degree \\ Doctor of Philosophy
}

by

Thula I. Norton Lambert

December 2015 
(C) Copyright by Thula I. Norton Lambert 2015 All Rights Reserved 


\title{
A STRUCTURAL EQUATION MODEL OF THE INFLUENCE OF PERSONAL, BEHAVIORAL, AND ENVIRONMENTAL FACTORS ON THE WRITING PERFORMANCE OF FIRST-YEAR STUDENTS AT A SELECTED MICHIGAN COMMUNITY COLLEGE
}

\author{
A dissertation \\ presented in partial fulfillment \\ of the requirements for the degree \\ Doctor of Philosophy
}

by

Thula I. Norton Lambert

APPROVAL BY THE COMMITTEE:

Chair: Elvin Gabriel

Member: Tevni Grajales Guerra

Member: Larry D. Burton

Member: Ivan Davis

External: Lionel Matthews
Dean, School of Education

Robson Marinho 
To Thélor and William for your love, patience, and support along this journey.

To the memory of my father William Egbert Norton, whose untimely death left an unfilled void in the heart of our family.

To my mother Eileen Inetha Norton, who kept his memory alive, and who has been a model of grace and resilience in my life.

To my siblings Bernadette, Christine, John, James, and Trevor who set a high bar, and on whose shoulders I stand.

To my Heavenly Father for His constant reminder that His strength is made perfect in my weakness. 
TABLE OF CONTENTS

LIST OF ILLUSTRATIONS ..................................................................... ix

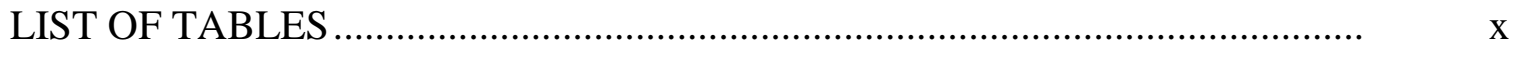

LIST OF ABBREVIATIONS ................................................................... xi

ACKNOWLEDGEMENTS ..................................................................... xii

Chapter

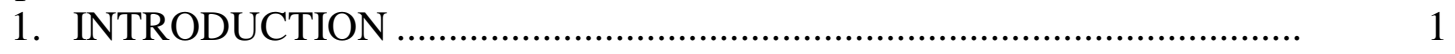

The Importance of Writing ................................................................. 1

A History of Interdisciplinary Collaboration in Contemporary

Composition Studies ..................................................................... 1

Learning Outcomes of the First-Year Writing Course .......................... 3

History, Mission and Characteristics of the

Community College .........................................................................

Background to the Problem ..................................................................... 6

Statement of the Problem.......................................................................... 13

Purpose of the Study …………………….......................................... 15

Research Question ............................................................................ 15

Hypothesis.................................................................................. 16

Significance of the Study ................................................................... 19

Conceptual Framework .......................................................................... 19

Overview of the Research Methodology ………………….................. 26

Delimitations of the Study ................................................................ 26

Definition of Terms......................................................................... 26

Summary .................................................................................. 27

Organization of the Study ………………………….......................... 28

2. REVIEW OF RELEVANT LITERATURE ............................................... 29

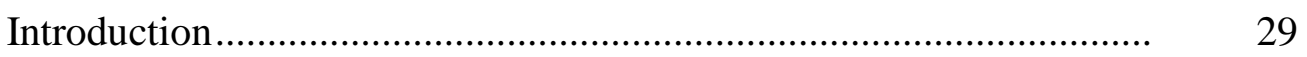

Definition and Measurement of Writing Performance ......................... $\quad 30$

CCCC Statement on Writing Assessment...................................... $\quad 30$

A Brief History of Postsecondary Writing Assessment................... 31

Reliability, Validity, and Writing Assessment ................................ 32 
Measuring Writing Performance........................................................

Holistic Scoring ........................................................................ 32

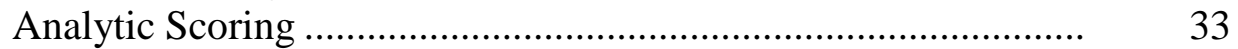

Performance Measures................................................................. 34

Timed Essays ............................................................................ 34

The Single Take-Home Paper ................................................... 35

Course Grades .................................................................... 36

Summary ............................................................................. 36

Personal Factors and Writing Performance ........................................... 37

Introduction...............................................................................

Previous Writing Achievement and Writing Performance ............. 37

Motivation and Writing....................................................................... 38

Introduction............................................................................. 38

Historical Overview of Research on

Writing Motivation ..................................................................... $\quad 39$

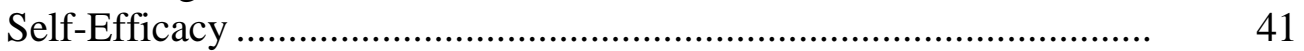

Writing Self-Efficacy Beliefs and Writing Performance...................... 44

Methodological Considerations ........................................................ 48

Measuring Writing Self-Efficacy................................................... 48

Limitations of First-Generation Self-Efficacy Scales ...................... 51

Self-Regulated Learning ..................................................................... 53

Self-Regulation, Academic Motivation, and Achievement .............. 53

Self-Regulation and Self-Efficacy .................................................. 55

Self-Regulation of Writing ............................................................. 55

Writing Self-Regulatory Efficacy and Writing Performance .......... 57

Behavioral Factors and Writing Performance....................................... 59

Introduction ............................................................................ 59

Adaptive Help-Seeking................................................................ 59

Instructor-Student Conferences and Writing Performance............. $\quad 60$

The Writing Center ....................................................................... 63

History of the Writing Center .................................................... 63

Frequency of Writing Center Visits

and Writing Performance.................................................. 64

Time on Task and Writing Performance.......................................... 66

Environmental Factors and Writing Performance ................................. 68

Introduction ............................................................................. 68

Gender and Writing Performance .................................................... 68

Language Background and Writing Performance............................ 69

Socioeconomic Status ...................................................................

Definition and Measurement of Socioeconomic Status............. 71

Measuring Socioeconomic Status .............................................. 71

Socioeconomic Status and Academic Achievement................. 74

Socioeconomic Status and Writing Achievement...................... $\quad 76$ 


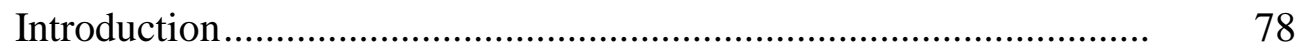

Research Design......................................................................... $\quad 78$

Description of the Quantitative Approach ..................................... $\quad 78$

Design of the Study ....................................................................

Population and Sample ................................................................ 80

Research Hypothesis ...................................................................... 81

Definition of Variables .................................................................. 81

Participant ID Number (ID) ...................................................... 81

Previous Writing Achievement (PWA_ACTz)............................. 82

Writing Self-Regulatory Efficacy (WRSE) ................................. 83

Self-Efficacy for Writing Tasks (SEFWT) ..................................... 83

Frequency of Writing Center Visits (FWCV).............................. 83

Frequency of Instructor-Student Conferences (FISC) .................. 84

Time on Task (TOT) ............................................................... 84

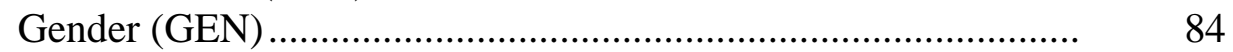

Language Background (LB) ...................................................

Socioeconomic Status (SES_EDL)............................................... 85

Writing Performance (WP) .......................................................... 85

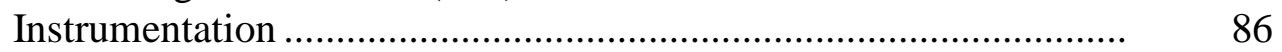

Instrument 1: The Writing Survey (TWS) ................................... 86

Instrument 2: The Writing Tasks Scale (TWTS) ......................... 87

Instrument 3: Student Information Form (SIF)............................ 87

Instrument 4: Structured Record Review....................................... 87

Previous Writing Achievement Form (PWAF) ...................... 87

Writing Performance Form (WPF) ........................................ 87

Data Collection Procedures............................................................... 88

The Use of the Survey Method ....................................................... 88

Research Involving Human Subjects ........................................... 88

Phase 1: Administration of Surveys............................................. 89

Phase 2: Administration of Structured Record Reviews.............. $\quad 90$

Data Analysis Procedures .............................................................. 90

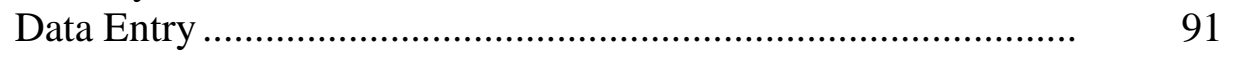

Data Cleaning............................................................................. 91

Structural Equation Modeling ...................................................... 91

Rationale for the Use of Structural Equation Modeling ......... 91

Sample Size Recommendations for the Use of Structural

Equation Modeling.......................................................... 93

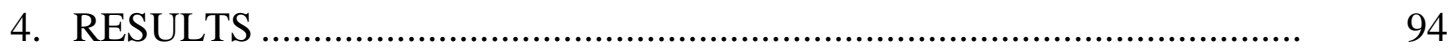

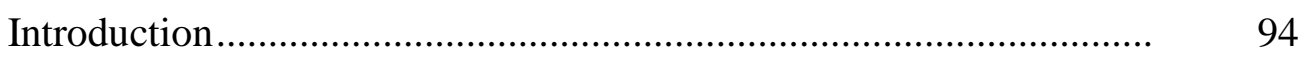

Response Rate ............................................................................. 94

Description of the Sample................................................................ 95

Participants............................................................................... 


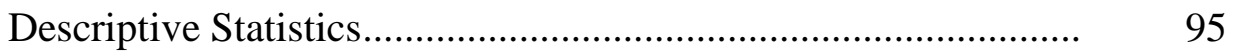

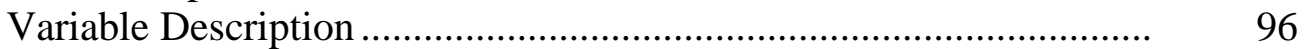

Previous Writing Achievement ..................................................... 97

Writing Self-Regulatory Efficacy .................................................. 98

Time on Task .......................................................................... 102

Frequency of Writing Center Visits .............................................. 102

Frequency of Instructor-Student Conferences ............................... 102

Writing Performance...................................................................... 104

Variable Correlation............................................................................. 104

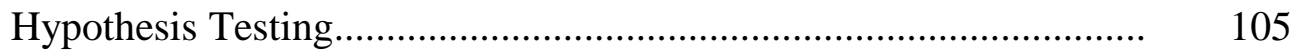

Hypothesis........................................................................... 105

Summary of Major Findings ............................................................. 109

5. SUMMARY, DISCUSSION, CONCLUSIONS AND

RECOMMENDATIONS ...................................................................... 111

Introduction ................................................................................. 111

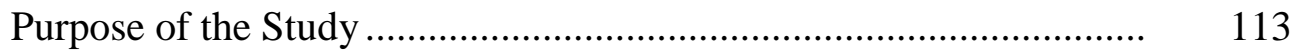

Summary of the Problem .................................................................... 113

Summary of the Literature Review ...................................................... 115

Measurement of Writing Performance.......................................... 115

Personal Factors ......................................................................... 115

Behavioral Factors ..................................................................... 117

Environmental Factors ............................................................. 118

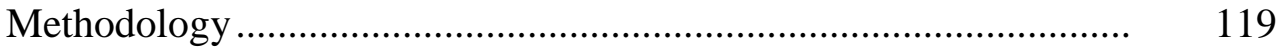

Population and Sample ........................................................... 119

Research Question ............................................................... 119

Research Design................................................................ 120

Summary of Findings................................................................... 120

Hypothesis................................................................................. 121

Conclusions .......................................................................... 121

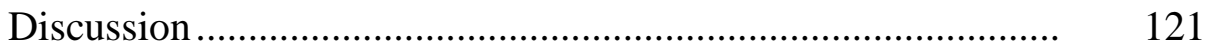

Other Related Findings ................................................................... 125

Limitations of the Study.................................................................. 128

Recommendations for Practice ....................................................... 129

Recommendations for Research .................................................... 130

Appendix

A. RESEARCH INSTRUMENT ..................................................................... 133

B. TABLE OF SPECIFICATIONS .............................................................. 138

C. INFORMED CONSENT FORM ............................................................. 148

D. CORRESPONDENCE ........................................................................ 150 
E. OBSERVED MODEL DATA ………………………………………...... 158

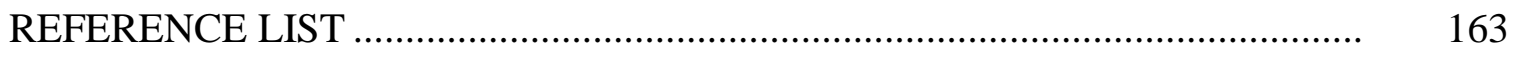

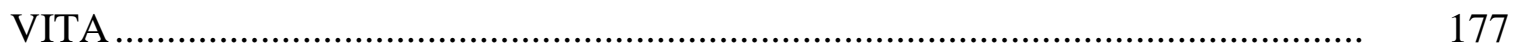




\section{LIST OF ILLUSTRATIONS}

1. $\quad$ ACT State and National Results, 2010-2014 ............................................ 10

2. Percentages of Students Meeting ACT English Benchmarks in 2014 by Ethnicity ................................................................................ 11

3. Theoretical Model of Writing Performance............................................... 18

4. The Relationships among the Three Main Categories of Determinants in Triadic Reciprocal Causation................................................................... $\quad 20$

5. Phases and Sub-Processes of Self-Regulation ......................................... 56

6. $\quad$ Observed Model of Writing Performance................................................... 109 


\section{LIST OF TABLES}

1. Demographic Characteristics ............................................................ 97

2. Mean and Standard Deviation for Writing Self-Regulatory Efficacy ........... 100

3. Mean and Standard Deviation for Self-Efficacy for Writing Tasks .............. 102

4. Time on Task, Frequency of Writing Center Visits, and Frequency of Instructor-Student Conferences ....................................................... 104

5. Mean, Standard Deviation, and Correlation among Variables ..................... 107

6. Fit Indices of the Observed Model......................................................... 108

7. Inter-correlations among Latent Variables in the Structural Model .............. 110

8. Path Coefficients for the Structural Model ............................................... 110 


\section{LIST OF ABBREVIATIONS}

\begin{tabular}{ll} 
BF & Behavioral Factors \\
FWCV & Frequency of Writing Center Visits \\
FISC & Frequency of Instructor-Student Conferences \\
EF & Environmental Factors \\
GEN & Gender \\
ID & Participant Identification \\
LB & Language Background \\
PF & Personal Factors \\
PWA_ACTz & Previous Writing Achievement \\
PWAF & Previous Writing Achievement Form \\
SEFWT & Self-Efficacy for Writing Tasks \\
SES_EDL & Educational Level of the Head of Household \\
SIF & Student Information Form \\
TOT & Time on Task \\
TWS & The Writing Survey \\
WSRE & Writing Self-Regulatory Efficacy \\
WP & Writing Performance \\
WPF & Writing Performance Form \\
WTS & Writing Tasks Scale \\
\hline W &
\end{tabular}




\section{ACKNOWLEDGEMENTS}

“It takes a whole village to raise a child”, says an old African proverb. It has also taken a proverbial village to support me as I have completed the most formative experience of my academic life. I would like to express my thanks and appreciation to the members of my dissertation committee. Dr. Gabriel, thank you for your leadership, for your timely feedback, your belief in me, and for making me laugh at the most unlikely moments. Dr. Grajales, thank you for guiding me through every step of the research process, and for helping me see the 'big picture' when my research project was still in its embryonic stage. Dr. Burton, thank you for sharing your research experience, for your timely advice on formatting the manuscript, and for your mentorship. Dr. Davis, thank you for providing me with the teaching experience out of which my research project grew, for your timely feedback, and for sharing your knowledge of the composition field.

I owe a debt of gratitude to the administration, faculty, and students at the research site for their participation in my research, and for the kindness and hospitality extended to me. I also wish to acknowledge the administration, faculty, and staff of Andrews University, my colleagues, students in my PhD cohort, and the many kind friends and well-wishers who have supported me along the way.

A special note of thanks is extended to Mrs. Amy Waller for patiently formatting the manuscript. I also wish to thank Dr. and Mrs. Christon and Carmelita Arthur, Dr. Anneris Coria-Navia, Dr. and Mrs. Kenneth and Lynette Riley, Mr. and Mrs. John and 
Lucy Randall, Dr. and Mrs. Lionel Matthews, Mrs. Hazel Joy Brown Patterson, Mrs. Anna Piskozub, Mrs. Michelle Bacchiochi, Ms. Vicki Thompson, Mr. Terrance Mann, Dr. Vivienne Quarrie, Mrs. Stacey Noriega and family, Ms. Olivia Spence, Ms. Jemma McLeish, Ms. Shanter Alexander, Ms. Avril Cassimy, Mrs. Lenier Henley, Ms. Fatimah Al Nasser, Ms. Rachel Wilson, Mr. and Mrs. Robert Benjamin, and Mr. and Mrs. Daniel and Isabel Verduzco. 


\section{CHAPTER 1}

\section{INTRODUCTION}

\section{The Importance of Writing}

The ability to communicate effectively in writing is fundamentally important to one’s personal, academic, and professional development, and to one’s ability to function in a literate society. This fundamental belief in the importance of writing has driven each stage of this research project, from its inception to the conclusions that will be drawn once the project is completed. Simply stated, writing matters.

Yet, despite its importance, there is ample evidence, both anecdotal and empirical, that large numbers of students complete high school and enter college and the workforce without the ability to express their thoughts in writing beyond a basic level. On the other hand, there is also evidence that many students master writing beyond a basic level by the time they enter college or the workforce. Understanding this difference in outcome is the catalyst of this study.

\section{A History of Interdisciplinary Collaboration in Contemporary Composition Studies}

Stock (2012) has traced the history of contemporary composition studies in America to the field of English education in an anthology of essays entitled Composition's Roots in English Education. She observes, “Just as the field of composition studies' roots are deeply imbedded in English education, so too are the fields of English education's roots deeply imbedded in composition studies” (p. 1). Stock has 
also described English as a scholarly field and school subject as relatively young, citing the fact that English professorships were only created at Harvard in 1876, Oxford in 1904, and Cambridge in 1911. The relative youth of the field of contemporary composition studies, its origins in English education, and its history of collaboration with the field of education make a strong argument for continued collaboration and underscores the necessity of engaging in an "interdisciplinary conversation" (Fleischer, 2012) in writing research and practice.

Several essays in Composition's Roots in English Education discuss the collaborative, interdisciplinary nature of English education and composition research and practice. Zebroski’s (2012) essay explores the history of contemporary composition studies between 1960 and 2000. According to Zebroski, previous histories have neglected the dual contributions of both colleges of education and the field of English education to the field of composition studies. Fleischer's (2012) essay A Case for Collaboration: Intertwined Roots, Interwoven Futures argues in favor of interdisciplinary collaboration in the fields of writing and writing education. In the author's view, the collaborative effort involved in the drafting of the guiding document Framework for Success in Postsecondary Writing is an illustration of interdisciplinary collaboration in action. This work is a joint effort between compositionists and English educators at both secondary and college levels. Fleischer writes,

In our case, these connections arose in part from our similar roots, but also from the recognition of our similar interests. What we saw was that the intersections are natural ones and that the end results - when we take care to recognize and celebrate these intersections - can be vitally important for literacy teaching and learning. p. 161 
Fleischer's (2012) second illustration describes her scholarly encounters with the work of Lev Vygotsky, Paolo Freire, John Dewey, Maxine Greene, and others. The influence of these scholars on her theoretical orientation and pedagogy can also be considered as an argument in favor of interdisciplinary collaboration in writing research and practice. Fleischer's call for an "interdiscipline of composition” (p. 162) is illustrated in the following quote:

Right now we need to take advantage of our shared passions and expertise; right now is the time to bring to the table all of what we know and - in the company of smart and caring others - try to get this work, the literacy education of our students, done right. (p. 163)

This research project draws on Fleischer's vision for an interdiscipline of composition and her call for continuing the interdisciplinary conversation by adopting an approach which integrates the disciplines of composition, education, and psychology.

\section{Learning Outcomes of the First-Year Writing Course}

The Writing Program Administrators (WPA) Writing Outcomes Statement for First-Year Composition (2014) outlines the learning outcomes for first-year composition programs in higher education. The statement provides an overview of "writing knowledge, practices, and attitudes that undergraduate students develop in first-year composition” (p. 1). These outcomes are also aligned with the Framework for Success in Postsecondary Writing (2010). The following is an abridged version of the intended learning outcomes students are expected to attain by the end of first-year composition:

Students are expected to acquire rhetorical knowledge, defined by the WPA as "the ability to analyze contexts and audiences and then to act on that analysis in comprehending and creating text” (p. 1). Students are also expected to develop critical thinking, or "the ability to analyze, synthesize, interpret, and evaluate, information, 
situations, and texts” (p. 2). Thirdly, students are expected to develop an understanding of the composing process or writing strategies, including drafting and revising their writing. Finally, students are expected to acquire a knowledge of conventions, or "formal rules and informal guidelines that define genres and...shape readers' and writers' perceptions of correctness or appropriateness” (p. 3).

However, the WPA Outcomes Statement should be read with one important caveat. The Statement does not equate 'outcomes' with 'standards' or "precise levels of achievement” (p. 1). Specific standards for assessing these outcomes are determined by individual writing programs and institutions.

Isaacs and Knight (2013) have elaborated on the autonomy exercised by individual writing programs with regard to how they apply the recommendations of the WPA Outcomes Statement in developing curricula and choosing teaching methodology. In their chapter entitled Assessing the Impact of the Outcomes Statement, Isaacs and Knight (2013) observed that the stated goal of the WPA Outcomes Statement was to foster agreement on learning outcomes for first-year composition. The authors note, however, that first-year writing programs often do not refer to the principles outlined in the WPA Outcomes Statement. This has resulted in "an overly large spectrum of approaches” in first-year writing instruction. However, despite the fact that the WPA

Outcomes Statement has not been widely implemented, its guidelines provide a frame of reference with regard to the general expectations of the first-year writing course.

\section{History, Mission and Characteristics of the Community College}

An understanding of the history, mission, and characteristics of the community college or public two-year college is essential in order to lay the groundwork for, and 
establish the context in which this research project will take place. The mission of the community college has evolved with time, from a mission of workforce and economic development in the 1960s, to one of adult education and community services in the 1970s.

In recent years, the mission of the community college has again evolved from being a gateway to four-year institutions. Some states have granted them permission to confer their own bachelor’s degrees (Dougherty \& Townsend, 2006). Douherty and Townsend further observe that despite the changing and sometimes conflicting missions of the community college, that the current "transfer and baccalaureate missions” will likely increase in the future.

In defining the role of the community college, the Community College Research Center (CCRC) at Columbia University Teacher's College views the community college as fulfilling "multiple missions - from workforce training, to remediating students in preparation for higher education, to community enrichment” (The Role of the Community College section, para. 2).

The following is a description of key institutional and student characteristics of public two-year colleges. According to information obtained from the U.S. Department of Education, National Center for Statistics, 7.2 million students were enrolled in public two-year colleges in 2012. This figure represents $40 \%$ of all undergraduate students enrolled in postsecondary institutions. Approximately 98\% of all public two-year colleges with first-year undergraduates had open admissions policies in 2012-2013. Forty-one percent of the students attending two-year institutions were enrolled full-time. 
Information obtained from the Michigan Community College Network indicates that approximately 200,000 students were enrolled in 28 community colleges during the 2014 fall semester in Michigan. Of this number, approximately 67\% were enrolled fulltime. Michigan community colleges also practice open admissions. Students include recent high-school graduates, non-traditional adult students, and students who have not obtained their high-school diplomas.

According to the Directory of Michigan Public Community Colleges (2014), during the 2012-2013 school year, the majority of student contact hours (53.8\%) were reported in general education courses, followed by occupational courses (35.7\%), developmental education (9.5\%), and personal interest courses (0.9\%). Courses are offered on-site, as well as at extension sites on weekdays, evenings, and on weekends.

English Composition is a general education course which is transferable to participating four-year colleges and universities statewide. According to the Michigan Association of Collegiate Registrars and Admissions Officers, participating four-year institutions may accept up to 6 English Composition transfer credits. These transfer courses include English Composition 1 and 2, or English Composition 1 and one communications course.

\section{Background to the Problem}

The transition from high-school writing to college-level writing can be challenging for entering first-year college students. Commenting on the level of complexity of college-level writing, Carroll (2002) proposed the term literacy task instead of writing assignment as more accurately reflective of college-level writing expectations. Carroll observed, "What are often called "writing assignments" in college 
are, in fact, complex "literacy tasks" calling for high-level reading, research, and critical analysis” (p. xix).

Sullivan (2006) makes a similar observation in his essay entitled An Essential Question: What Is College-Level Writing? He has suggested expanding the term collegelevel writer to college-level reader, writer, and thinker, and has proposed that these three skills be jointly evaluated in students’ writing. He observes, "Good writing can only be the direct result of good reading and thinking ...” (p. 16).

Sullivan (2006) has outlined several criteria in view of arriving at a definition of college-level writing. Firstly, students should be able to thoughtfully engage with, and respond to abstract ideas, such as are contained in an article, essay or reading excerpt. Students should also be able to thoughtfully analyze ideas and topics, engage in higherorder thinking, arrange their ideas in an organized manner, be able to synthesize source material, and adhere to the conventions of standard written English.

There is, however, a lack of consensus in the field as to what constitutes "collegelevel” writing. The task of defining "college-level” writing and coming to a common understanding of standards, expectations and outcomes has been described as "daunting" (Sullivan, 2006, p. 1). In addition to the lack of consensus, Sullivan has also commented on the challenges which have resulted from certain current enrollment trends, particularly at the community college. Among the trends he references are an increasing number of nontraditional students and English as a Second Language students who may be unprepared for college-level writing.

Recent reforms reflect attempts at increasing students' readiness for the complex literacy tasks they will encounter in college. The adoption of the Common Core State 
Standards Language Arts and Literacy is a major reform aimed at improving students’ “college and career readiness”, a phrase which has gained increasingly widespread use since the launching of the Common Core State Standards (CCSS) in 2009. College- and career-readiness standards are intended to "address what students are expected to know and understand by the time they graduate from high school” (Common Core State Standards Initiative Development Process section, para. 3).

The Common Core State Standards for Language Arts and Literacy were developed using existing standards. However, three major changes were introduced that aim to align high school standards with college-level outcomes as follows:

1. Regular practice with complex texts and their academic language.

2. Reading, writing, and speaking grounded in evidence from texts, both literary and informational.

3. Building knowledge through content-rich nonfiction. (Common Core State Standards Initiative, Key Shifts in English Language Arts section, para. 2) An alternative reform, the Framework for Success in Postsecondary Writing (2010) which was discussed earlier, was developed as a joint effort by the Council of Writing Program Administrators (CWPA), the National Council of Teachers of English (NCTE), and the National Writing Project (NWP). The Framework was developed in response to the perceived absence of educators’ voices in the discussion regarding the development of the Common Core State Standards (O’Neill, Adler-Kassner, Fleischer \& Hall, 2012, p. 520).

The Framework outlines "the rhetorical and twenty-first-century skills as well as habits of mind and experiences that are critical for college success” (p. 525). The habits 
of mind deemed essential for developing college readiness and success include curiosity, openness, engagement, creativity, persistence, responsibility, flexibility, and metacognition (p. 525).

Beyond the broad definitions and goals of college readiness outlined in the Common Core State Standards and the Framework for Success in Postsecondary Writing, college-readiness has been more narrowly defined and used as a basis for college admissions. The Michigan Department of Education has defined college-readiness in English as the percentage of students who obtain a minimum score of 18 in English on the ACT standardized test. This benchmark of 18 is "the minimum score needed on an ACT subject-area test to indicate a $50 \%$ chance of obtaining a B or higher or about a $75 \%$ chance of obtaining a C or higher in the corresponding credit-bearing college course” (ACT Profile Report, 2014, p. 6).

What then has been the impact of recent reforms on the college readiness of entering first-year college students, and has it facilitated the transition from high-school to college-level writing? As McComiskey (2012) has observed, the influence of the Common Core State Standards and the Framework should be reflected in the preparedness of high school students for college-level writing. He observed,

If the Framework is viewed as additional support for the CCSS or as a guide to developing assessment instruments based on the CCSS, then it should have some impact on secondary education and the preparation of high school students for the rigors of college writing. (p. 538)

An examination of the results of the American College Testing (ACT) results over the last five years indicates that there remains considerable variation among entering first-year college students with regard to their readiness for college-level writing (see Figure 1). National results of ACT indicate that between 2010 and 2014, the percentages 
of those who were considered ready for college-level writing ranged from $64 \%$ to $67 \%$. During this time period between 1,568,835 and 1,845,747 students were assessed nationally. In the state of Michigan these percentages ranged from 56\% to 59\% during the same period (Michigan ACT Profile Report, 2014). These percentages are based on the more than 100,000 students assessed annually in the state of Michigan.

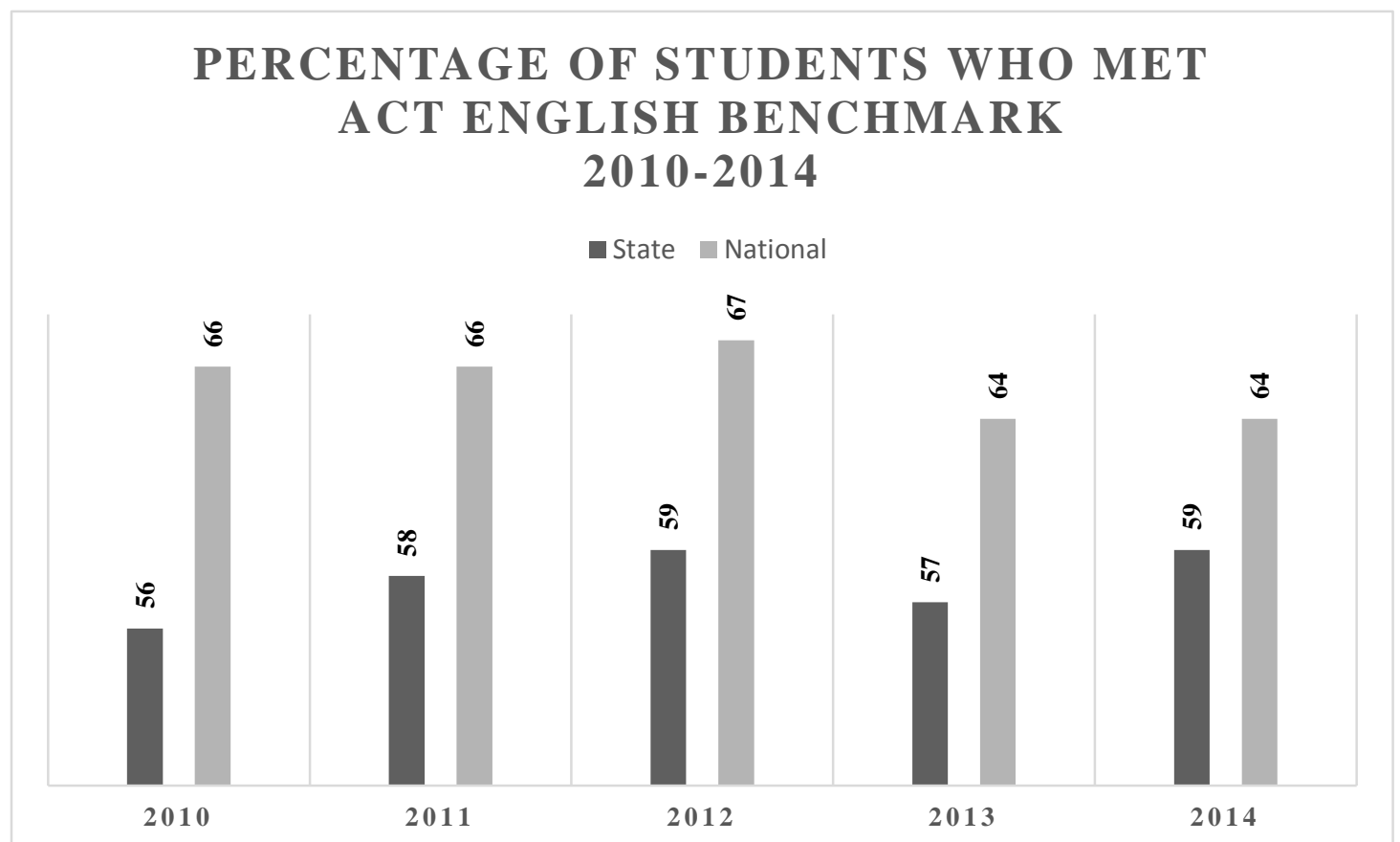

Figure 1. ACT English state and national results, 2010-2014. Data from the ACT Profile Report - State, Graduating Class 2014, Michigan (p. 7), by ACT Inc., 2014, Iowa City, IA: ACT Inc.

The variation in initial level of writing attainment is further illustrated by the ethnic composition of students who met the ACT English benchmarks in 2014. As Figure 2 shows, large percentages of students of African American, American Indian, Pacific Island, and Hispanic origin did not meet the ACT benchmark in English in 2014. 
The recent report from the ACT, The Condition of College and Career Readiness

2015: National, discussed the implications of the non-attainment of the ACT benchmarks overall:

Graduates who enrolled in 2-year colleges or pursued other options after high school were more likely to have met fewer Benchmarks. For the sizeable number of 2014 graduates who did not meet any Benchmarks, their post-high school opportunities appear to have been limited compared to their college-ready peers. (p. 16)

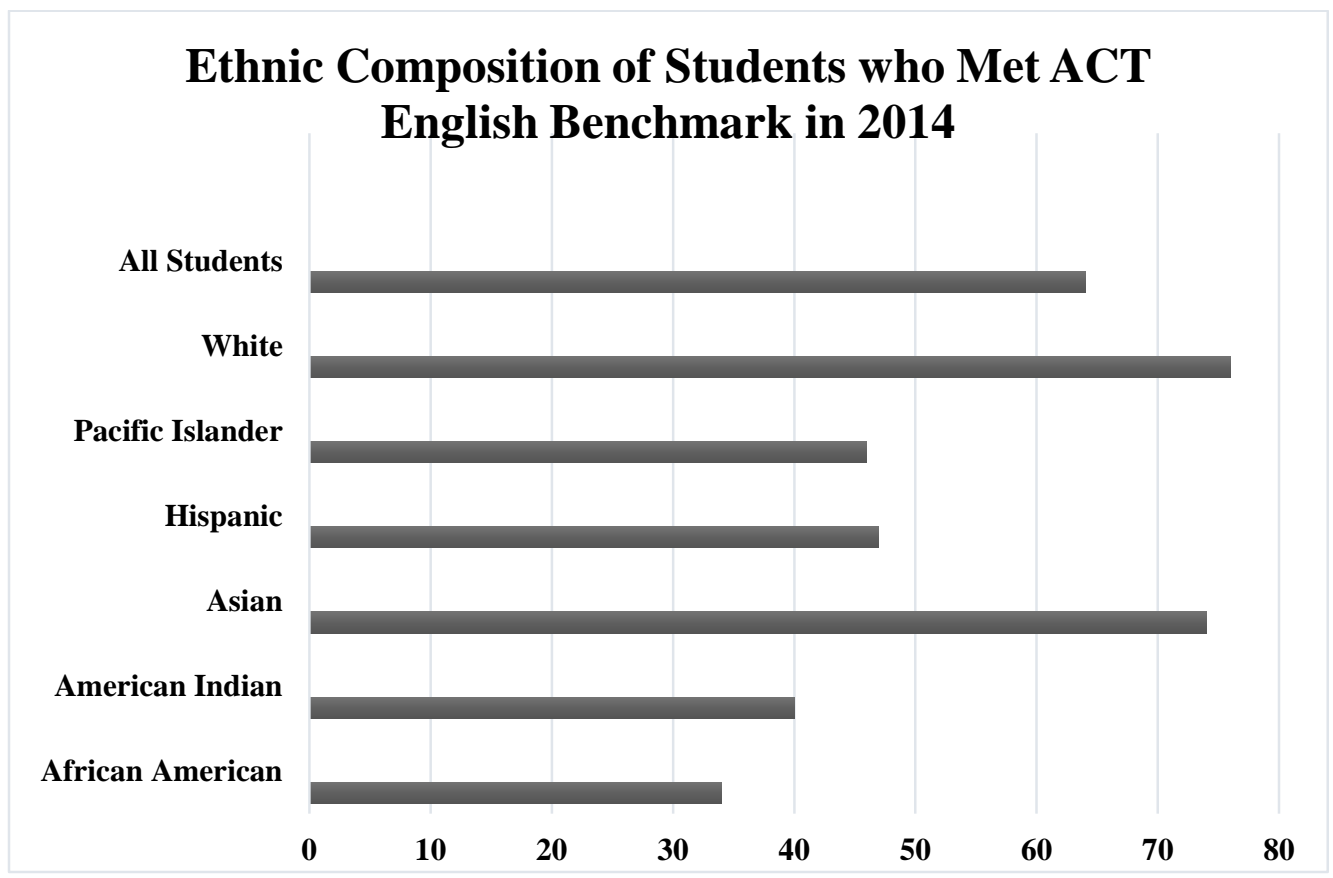

Figure 2. Percentages of students meeting ACT English benchmarks in 2014 by ethnicity. Data from The Condition of College and Career Readiness 2014: African American Students (p. 7), by ACT Inc., UNCF, 2014, Iowa City, IA: ACT Inc.

As the results of standardized tests such as the ACT show, students enter the firstyear writing classroom with varying degrees of preparedness for college-level writing. The variation is important, especially when one considers that colleges which practice an 
open enrollment policy such as community colleges generally accept a range of applicants, including high-school graduates, students who have completed the GED, or who have a high-school completion certificate. Community colleges also provide remediation for entering students who may not have attained required levels at the time of college entry. Any given first-year writing class can therefore consist of students with varying initial levels of writing ability.

Several national studies have drawn public attention to the need for excellence in writing instruction (e.g. Graham \& Perin, 2007; National Commission on Writing in America’s Schools and Colleges 2003; 2004; 2005; 2006). These studies have also provided an overall assessment of the writing skills of the nation's students and workers. The 2003 report entitled The Neglected " $R$ ": The Need for a Writing Revolution states that although most students have acquired basic writing skills they "cannot write well enough to meet the demands they face in higher education and the emerging work environment” (p. 16).

The 2004 report summarized the results of a survey of 120 major corporations. Approximately a third of these corporations reported that a third or less of their workers displayed the level of writing skill that was valued by these firms. The report also found that employers considered writing as an essential skill for employment and promotion. Similar results were reported in the 2005 report of the survey of state employers. Although writing was reported to be a "critical skill” for state employees to possess, state employers reported that "significant numbers of their employees do not meet states' expectations (p. 3). 
Arum and Roska’s (2011) national study, Academically Adrift: Limited Learning on College Campuses analyzed the results of the College Learning Assessment (CLA) from 2005 to 2007, and concluded that students did not show significant improvement in their critical thinking, analytical reasoning, and writing skills during their first two years of college. The study found that during the first two years of college, $45 \%$ of sophomores had made no "measurable gains in critical thinking, analytical reasoning, and writing skills as assessed by the CLA” (Roska and Arum, 2011, p. 35). Roska and Arum also reported significant variation in student learning, and explored factors which contributed to improvement in students' scores on the CLA. These factors included time spent studying, mode of studying, whether alone or in a group, faculty expectations and approaches, and course requirements.

\section{Statement of the Problem}

Writing Studies research has been enriched by the contribution of the field of educational psychology, which has considered the role of both social and cognitive factors in students' attainment of writing outcomes. Previous studies have been conducted within a social cognitive theoretical framework, which allows for the consideration of multiple variables contributing to students' writing performance. These studies have investigated the role of motivational variables such as previous writing achievement (e.g. Zimmerman \& Bandura, 1994), self-efficacy (eg. Pajares \& Johnson, 1994), self-efficacy for self-regulation (e.g. Sanders-Reio, 2010), writing apprehension (e.g. Sanders-Reio, Alexander, Reio, \& Newman, 2010), and locus of control (e.g. Jones, 2008) in students’ writing performance. 
While these studies have examined a range of motivational variables, they have tended to exclude certain contextual variables, and variables related to current writing pedagogy and practice. This has resulted in gaps in the research literature. There is a need to enlarge the scope of variables considered as contributing factors to the writing performance of undergraduate students. For example, few studies have considered the contribution of socioeconomic factors, although socioeconomic status has been studied in relation to overall academic performance within a social cognitive framework (e.g. Bandura, Barbaranelli, Caprara \& Pastorelli, 1996).

Another emerging area of interest is students' contribution to their own learning through help-seeking behaviors such as writing center visits and instructor-student conferences. Only a few studies have been conducted on writing center visitation as a help-seeking behavior (e.g. Williams \& Takaku, 2011; Williams, Takaku \& Bauman, 2006). Also, previous studies on instructor-student conferences have tended to be qualitative and have focused on their effectiveness on the quality of revisions students make to their writing, or the interactions between instructors and students during conferencing (e.g. Gulley, 2012; Hewett, 2006). However, few studies have investigated the role of frequency of instructor-student conferences, or the influence of time spent engaged in writing tasks on students' writing performance. There is therefore a need for studies which measure the effectiveness and contribution of these activities to students' learning within a quantitative paradigm.

There is also a need for more studies which examine the writing performance of students from language backgrounds other than English once they are placed in mainstream composition classes. Studies on English as a Second Language (ESL) 
students' perceptions of the mainstream writing classroom have been conducted (e.g. Braine, 1996). However, few studies have investigated how these students perform once they are placed in mainstream composition classes. Doolan’s (2013; 2014) studies have been enlightening in that they found significant differences in error patterns and holistic quality between native English speakers and students whose first language is not English. However, because this is an emerging area of interest there is still a need for additional studies to expand the knowledge base in this area.

Previous quantitative studies on writing achievement have tested their theoretical models using multivariate data analysis procedures including hierarchical regression (e.g. Jones, 2008; Prat-Sala \& Redford, 2012; Sanders-Reio, 2010; Tanyer, 2015) and path analysis (e.g. Williams \& Takaku, 2011; Zimmerman \& Bandura, 1994). However, to date, no prior studies which have examined writing performance within a social cognitive framework have applied Bandura’s $(1977 ; 1978)$ theoretical model of triadic reciprocal causation, nor used structural equation modeling (SEM), which allows for the analysis of latent constructs.

\section{Purpose of the Study}

The primary purpose of the study was to test a theoretical model of the influence of personal, behavioral, and environmental factors on the writing performance of firstyear community college students. The study also examined the relationships among the three latent variables specified in the model, as well as their contribution in predicting the independent variable. 


\section{Research Question}

Due to the exploratory nature of the study, a holistic approach to framing the research question and testing the hypothesis was taken. In this exploratory study of the personal, behavioral and environmental factors which may influence the writing performance of first-year community college students, the research question sought to investigate whether the theoretical model was supported by the empirical data. The following research question was answered: Is the theoretical covariance matrix equal to the observed covariance matrix?

\section{Hypothesis}

Statistical modeling allows for the description of the latent structure which underlies a grouping of observed variables. Statistical models can be represented graphically, or as a set of mathematical equations, and can provide an explanation of the relationship between the observed and latent variables. A researcher generally bases the hypothesized statistical model on his or her knowledge of the relevant theory, on previous research, or on a combination of both. After specifying the model, the researcher tests its validity using sample data that includes all of the observed variables which comprise the model.

The main purpose of model-testing is to calculate the goodness of fit between the theoretical model and the observed or empirical data. The structure of the theoretical model is imposed on the empirical data, and is tested to determine the goodness of the fit with the restricted model. As one might expect, exact fit between the empirical data and the theoretical model is not very likely to occur. The residual is the dissimilarity between 
the models. The model-fitting procedure can be expressed by the following equation: Data $=$ Model + Residual (Byrne, 1994).

The hypothesis to be tested relates to the pattern of causal structure linking several predictors that bear on the construct of the other latent variable or variables. Causal relations among all variables on the hypothesized model must be grounded in theory or empirical research or both. Typically, the hypothesis to be tested argues for the validity of postulated causal linkages among the variables of interest.

Figure 3 shows a graphical representation of the hypothesized theoretical model of writing performance. Ellipses represent the latent, or unobserved variables. Straight lines with arrows represent the direction of influence or causal effect. Paths generally have a corresponding path coefficient. Path coefficients are beta weights which indicate the strength of the predictor variables, when all of the other relationships in the model are controlled. Curved lines represent correlations among latent variables. (Meyers, Gamst, \& Guarino, 2013; Schrieber, Stage, King, Nora \& Barlow, 2006). The dependent variable is an observed variable represented by a square.

The theoretical model of writing performance is constituted by the following observed variables. Personal Factors (PF) consists of three indicators: Previous Writing Achievement (PWA_ACTz), Writing Self-Regulatory Efficacy (WSRE), and SelfEfficacy for Writing Tasks (SEFWT); Behavioral Factors (BF) consists of Frequency of Writing Center Visits (FWCV), Frequency of Instructor Student Conferences (FISC), and Time on Task (TOT); Environmental Factors (EF) consists of Gender (GEN), Language Background (LB), and Education Level of the Head of Household (SES_EDL). 
The theoretical model suggests bivariate correlations among the latent variables Personal Factors (PF), Environmental Factors (EF), and Behavioral Factors (BF), and direct causal relationships between the latent variables and the dependent variable Writing Performance (WP): The theoretical model represents three proposed bivariate correlations and three predictors, as in a multiple linear regression.

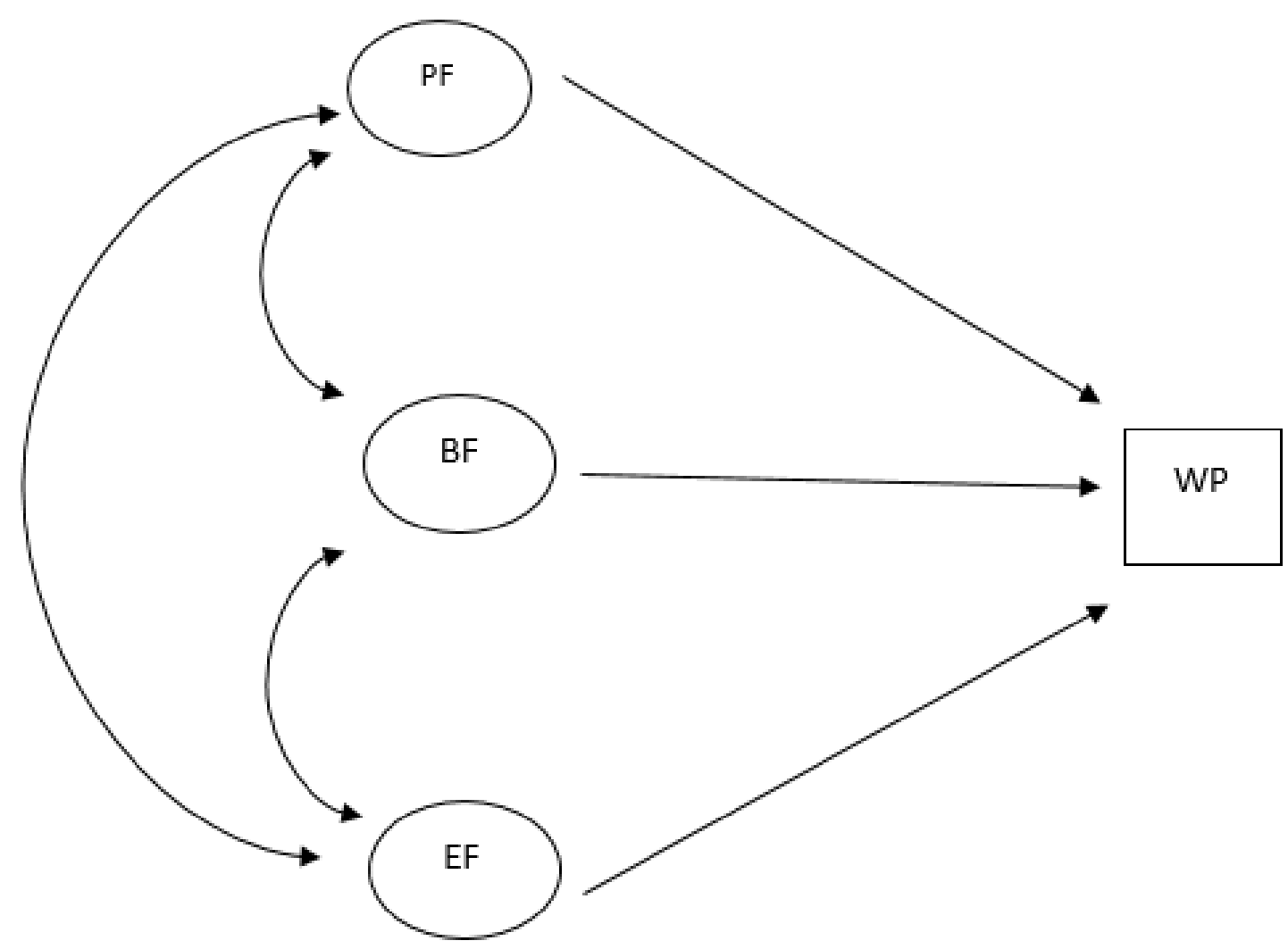

Figure 3. Hypothesized theoretical model of writing performance. Latent constructs are shown in ellipses. Lines with arrows represent the path or direction of influence. Curved arrows represent correlations among latent variables. The dependent variable is an observed variable represented by a square. 


\section{Significance of the Study}

This study contributes to writing studies research by exploring factors which may influence the writing performance of first-year college students. The findings of this study could serve as a basis for instructional design and curriculum development. The study is of potential benefit to writing instructors and Writing Program Administrators. Curricula could be developed that would include instructional units in areas which are found to significantly influence students' writing performance. An awareness of the personal, behavioral, and environmental factors which influence students' writing performance could also inform writing instructors and serve as a basis for targeted instruction. Student success centers could also use the findings of the study to plan interventions. The findings of the study could also inform writing centers and serve as a measure of their effectiveness.

\section{Conceptual Framework}

A conceptual framework links the research questions to overarching theoretical constructs. It explains how the variables in the study inform broader issues, and how they contribute to the larger body of knowledge in the field (Marshall \& Rossman, 2011). The conceptual framework used to explain the relationship among the variables in this study was drawn from Bandura’s $(1977 ; 1978)$ social cognitive theory. The conceptual framework was developed by the researcher based on a review of relevant literature and empirical studies.

Social cognitive theory is based on the underlying assumption that humans' ability to play a role in their own development, or human agency, is a fundamental aspect of being human (Bandura 2001; 2006). Bandura has identified four core characteristics of 
human agency: Intentionality, forethought, self-reactiveness and self-reflectiveness.

Intentionality refers to the ability to act and make choices in an intentional manner.

Forethought refers to one's ability to set goals, prepare for, and plan expected outcomes.

Self-reactiveness refers to one's capacity to shape suitable actions and to self-motivate and self-regulate these actions. Self-reflectiveness refers to one's ability to reflect on one's actions, and to adjust one's actions as needed.

Social cognitive theory proposes a model of triadic reciprocal causation consisting of personal, behavioral, and environmental factors (Figure 4). As Bandura has observed,

Persons are not autonomous agents nor simply mechanical conveyors of animating environmental influences. Rather, they make causal contribution to their own motivation and action within a system of triadic reciprocal causation. In this model of causation, action, cognitive, affective, and other personal factors, and environmental events all operate as interacting determinants. (p. 1175)

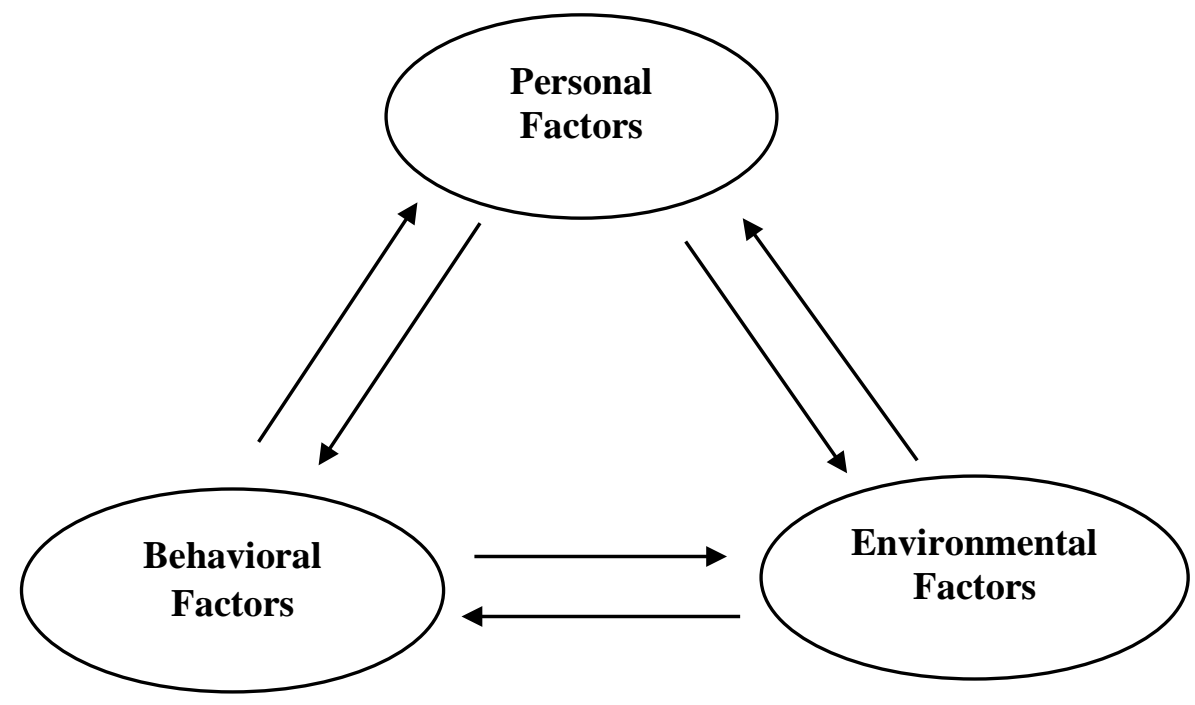

Figure 4. The Relationships among the three main categories of Determinants in Triadic Reciprocal Causation. Adapted from Self-efficacy: The exercise of control (p. 6), by Albert Bandura, 1997, New York, NY: W. H. Freeman. 
However, Bandura (1989) does not attribute equal weight to the three components of the model. He observed that each component may differ in strength, and that their influence may not be exercised in a simultaneous manner.

Zimmerman (1989) identified triadic reciprocal causation as one of three underlying assumptions of social cognitive theory. In addition to triadic reciprocal causation, social cognitive theory assumes that self-efficacy influences self-regulated learning and that self-regulation consists of three categories of sub-processes: "selfobservation, self-judgment, and self-reaction” (Bandura, 1986, as cited in Zimmerman, 1989, p. 331).

Social cognitive theory has framed the study of academic motivation, learning, and achievement in educational research. Over the last three decades, some areas educational researchers have studied include the role self-efficacy beliefs in relation to self-regulation (e.g. Ryan \& Pintrich, 1997; Zimmerman \& Bandura, 1994); modeling (e.g. Schunk, 1981); academic performance and career options (e.g. Lent, Brown, \& Larkin, 1986); academic performance, persistence and retention (e.g. Multon, Brown \& Lent, 1991); and self-regulation and academic achievement (e.g. Zimmerman, 1990).

Social cognitive theory has also framed research on writing motivation and writing achievement. Zimmerman and Bandura (1994) posited that "In social cognitive theory, regulation of one's own motivation and learning is codetermined by many interacting factors that would be expected to affect the self-management of writing activities” (p. 847). Boscolo \& Hidi (2007) have highlighted three motivational variables that have been studied in relation to writing: interest, self-efficacy, and self-regulation. 
The conceptual model which frames the current study will apply Bandura's (1977; 1978) concept of triadic reciprocal causation, which consists of personal, behavioral and environmental factors, to explain the relationships among the variables. Given its centrality in social cognitive theory with regard to its role in the examination of fearful or avoidant behavior (Bandura, 1977), or as influencing self-regulated learning (Zimmerman, 1989), the variable self-efficacy will be examined as a personal factor in the present study.

Bandura (1977) posited that the strength of one’s self-efficacy beliefs, or one’s perceived ability to accomplish a given task, will influence whether or not an individual initiates and persists in coping behaviors. Further, applied to the academic domain, selfefficacy has been theorized as playing "an influential mediational role in academic attainment” (Bandura, 1997, p. 216). Students' self-efficacy beliefs, both with regard to their writing ability and their ability to regulate their writing activities, would therefore be expected to influence their writing performance in the present study.

Performance accomplishments, which are based on personal mastery experiences, have been identified as one of four main sources of efficacy information (Bandura, 1977; Pajares, Johnson \& Usher, 2007). Successful or failed performance accomplishments are a determinant of an individual's level of self-efficacy. Given the mediational role of selfefficacy in academic attainment, it would therefore be expected that students' previous writing achievement would influence their writing performance.

Behavioral factors are examined within the context of academic self-regulation. As a self-regulatory process (Zimmerman, 1998), adaptive help-seeking mediates the relationship between challenging academic tasks and task completion (Newman, 1994). 
Adaptive help-seekers engage in self-evaluation and self-monitoring and know when input from others is necessary (Newman, 2008). Ryan and Pintrich (1997) also found that students with low levels of self-efficacy tend to avoid seeking help. Therefore, adaptive help-seekers would be expected to seek help from the writing center and from their instructors when necessary.

The manner in which students engage with writing tasks is also an indication of their motivation. According to Winne and Hadwin (2008) students exercise conscious control of their learning, which in turn determines their level of engagement and persistence on a given task. The amount of time students schedule for writing is also a function of their ability to manage their time. Since time-management has been identified as a self-regulatory process (Zimmerman, 1998), self-regulated students would therefore be expected to set aside regular time to plan, organize and revise their writing (Zimmerman \& Kitsantas, 2002). In this study students' level of engagement is measured by the amount of time they spend on writing tasks, following the work of Astin (1993), who found time on task to be correlated with academic achievement.

Zimmerman (1989) identified two main categories of environmental influences which have been gleaned from theory and research on social cognitive theory: Those originating from the physical environment and those originating from social experience. Based on these categories, the environmental variables in this study - gender, language background, and educational level of the head of household - fall into the category of variables originating from the social environment.

With regard to gender and writing performance, empirical studies reviewed for this study found mixed results that included both gender differences (e.g. Williams \& 
Takaku) and no gender differences (e.g. Arum \& Roska, 2011; Pajares \& Johnson, 1994) with regard to writing performance. However, in the studies that found significant gender differences, females tended to outperform males. Therefore, it would also be expected that if significant gender differences were found, the difference would favor females.

As a contextual variable, language background would be expected to influence students’ writing performance. Doolan (2013) found significant differences in holistic quality and error patterns between students whose first language is English (L1) and students from a non-English speaking (L2) backgrounds. L1 students would therefore be expected to have better writing performance than L2 students.

Socioeconomic status has been studied in relation to the academic performance of children within a social cognitive framework (e.g. Bandura, Barbaranelli, Caprara \& Pastorelli, 1996). Few studies have included the variable socioeconomic status as a predictor of students' writing performance. However, based on the correlation found between socioeconomic status and academic achievement (e.g. Sirin, 2005), socioeconomic status would be expected to influence students’ writing performance.

Applied to the present study, social cognitive theory holds that students' motivation, learning, and achievement in writing operate within the parameters of personal, behavioral, and environmental factors. Personal factors, as measured by students' previous writing achievement, writing self-regulatory efficacy, and self-efficacy for writing tasks would be expected to influence the dependent variable writing performance because (a) previous writing achievement has been found to be a significant predictor of writing performance (e.g. Arum \& Roska, 2011; Jones, 2008; Pajares \& Johnson, 1994; Zimmerman \& Bandura, 1994); (b) writing self-regulatory efficacy 
correlated with writing performance in several studies (e.g. Sanders-Reio, 2010, 2014;

Zimmerman \& Bandura, 1994; (c) significant associations have been found between selfefficacy for writing and writing performance (e.g. Prat-Sala \& Redford, 2012; Tanyer, 2015; Williams \& Takaku, 2011).

In the present study, behavioral factors as measured by frequency of writing center visits, frequency of instructor conferences, and time on task are expected to explain the dependent variable writing performance since (a) significant correlations between frequency of writing center visits and writing performance have been found (e.g. Grinnell, 2003; Williams \& Takaku, 2011; Williams, Takaku \& Bauman, 2006); (b) as a self-regulated learning strategy, adaptive help-seekers will seek help from their instructors when necessary (Newman, 2008); (c) time on task correlated with overall academic performance (e.g. Astin, 1993; McClenney \& Marti, 2006).

Environmental factors relative to students’ writing performance are measured by students' gender, language background, and education level of the head of household as an indicator of socioeconomic status. These factors are expected to influence students' writing performance since (a) significant gender effects have been found in writing performance (e.g. Williams \& Takaku, 2011) and writing self-efficacy (e.g. Pajares \& Johnson, 1994); (b) significant differences have been found relative to language background and writing performance (e.g. Doolan, 2013; 2014); (c) socioeconomic status as indicated by parental education level has been found to influence the writing performance of undergraduate students (e.g. Arum \& Roska, 2011). 


\section{Overview of the Research Methodology}

This study of the factors which influence the writing performance of first-year community college students $(n=125)$ was conducted in two phases using survey research methodology. In Phase 1, participants completed three survey instruments. In Phase 2, participants’ ACT English scores, ACT COMPASS Writing Placement Test scores, SAT scores and final grades on a persuasive essay were collected from the participating institution. A theoretical model was developed by the researcher based on a review of relevant literature. This theoretical model was tested using structural equation modeling (SEM) as the method of data analysis.

\section{Delimitations of the Study}

The study was delimited to students enrolled in a first-year College Writing course at a selected community college in Michigan. Michigan provides a unique academic context, given the percentage of students who have scored below the benchmark of 18 on the ACT English test, when compared to the national average.

\section{Definition of Terms}

Previous writing achievement is defined as the scores students obtained on standardized tests of written English (ACT, COMPASS, SAT), and which are used for placement purposes (Zimmerman \& Bandura, 1994).

Self-efficacy is defined as “one’s capabilities to organize and execute the courses of action required to produce given attainments” (Bandura, 1997, p. 3).

Self-regulation is defined as "self-generated thoughts, feelings, and actions, for attaining academic goals” (Zimmerman, 1998, p. 73).

Self-regulation of writing is defined as "self-initiated thoughts, feelings and 
actions that writers use to produce texts and to improve their writing” (Hidi \& Boscolo, 2007, p. 11).

Socioeconomic status is defined as the educational level of participants' head of household (Arum \& Roska, 2011).

Time on task is defined as the number of hours students spend on their writing assignments outside of regular class time (Astin, 1999; Wagner \& Schober, 2014). Writing self-efficacy refers to an individual's confidence in his or her writing abilities (Pajares, Hartley \& Valiante, 2001).

Writing self-regulatory efficacy is defined as "belief in one's capabilities to regulate one’s writing activities” (Zimmerman \& Bandura, 1994).

Writing performance refers to the grade students obtain on their final major writing assignment, a persuasive research essay (Sanders-Reio, Alexander, Reio \& Newman, 2014).

\section{Summary}

There is a lack of consensus on a definition of college-level writing. Recently published national and state reports have drawn attention to the under-preparedness of many entering first-year students for the expectations of college-level writing. There is a need for an interdisciplinary approach to writing research and practice as a result of the shared history and concerns of the fields of contemporary composition and education. This study proposes an interdisciplinary approach, as it is informed by the fields of composition and rhetoric, education, and psychology. Bandura’s (1989) social cognitive theory allows for such an approach. His proposed model of triadic reciprocal causation consisting of personal factors, behavioral, and environmental factors provides a 
conceptual framework for investigating the factors which may influence students' writing performance.

\section{Organization of the Study}

Chapter1 presents the background of the problem, the statement of the problem, the conceptual framework, research question and hypothesis, the purpose, significance of the study, a definition of key terms, and delimitations of the study.

Chapter 2 provides a review of theoretical and empirical literature pertaining to the independent and dependent variables.

Chapter 3 presents the methodology that will be used in the study. Sections include a description of the population, sampling procedures, and a description of the variables, and instrumentation. Data collection and data analysis procedures are also presented.

Chapter 4 reports on the response rate of the survey, presents descriptive statistics of the sample and the variables used in the study, and presents inferential statistics which address the research hypothesis.

Chapter 5 summarizes the research findings, interprets them in light of relevant literature, discusses the implications and limitations of the study, makes recommendations for applying research findings, and suggests directions for further research. 


\section{CHAPTER 2}

\section{REVIEW OF RELEVANT LITERATURE}

\section{Introduction}

In preparing the review of the literature, several criteria were chosen for including

or excluding sources: Research articles were selected if they had been published in peerreviewed journals. Dissertations were selected if they had been published in the ProQuest database. Because of the foundational nature of early studies, no time limit for inclusion was set. More recent research studies were included if they were published within the last ten years. Although the focus of the proposed review is higher education, studies from K-12 were also included if they had the potential to inform the current study.

A combination of database searching and "snowballing” was used to identify relevant literature. Searches were conducted in Academic Search Complete, Sage Journals, PsychInfo, Education Resource Information Center (ERIC), Google Scholar, and Proquest databases using the following search terms or combinations of terms: Previous writing achievement and writing performance; self-efficacy and writing performance; self-regulated learning; self-regulation and writing; socioeconomic status and writing performance; gender and writing performance; ethnicity and writing performance; ESL and mainstream composition and writing performance; help-seeking and writing performance; teacher-student conferences and writing performance; writing center and writing performance. The snowballing technique, which consists of reading 
the reference lists of studies that I located in the databases, was particularly effective in locating additional sources that were relevant to the review.

The review is organized both thematically and chronologically. A chronological approach will be used to distinguish early research from more recent advances. The review is divided into five major sections as follows: (a) The introduction discusses the criteria for inclusion and exclusion of sources and the organization of the review. The first section discusses how the construct of writing performance has been measured in previous studies with the goal of providing the definition that will be used in this study. The three remaining sections discuss students' writing performance in light of (b) personal factors (c) behavioral factors, and (d) environmental factors.

\section{Definition and Measurement of Writing Performance}

\section{CCCC Statement on Writing Assessment}

The Conference on College Composition and Communication (CCCC) Position Statement (2014) states that writing assessment is used for multiple purposes, including assigning grades, or for assessing proficiency. The CCCC views the writing that occurs in the college classroom as a social activity between faculty and students, and has recommended the following:

- a period of ungraded work (prior to the completion of graded work) that receives response from multiple readers, including peer reviewers,

- assessment of texts - from initial through to final drafts-by human readers, and

- more than one opportunity to demonstrate outcomes. (Assessment in the Classroom section, para. 2)

The CCCC has also made several recommendations with regard to assessing for proficiency that are outlined in the excerpt below: 
Proficiency or exit assessment involves high stakes for students. In this context, assessments that make use of substantial and sustained writing processes are especially important.

Judgments of proficiency must also be made on the basis of performances in multiple and varied writing situations (for example, a variety of topics, audiences, purposes, genres).

The assessment criteria should be clearly connected to desired outcomes. When proficiency is being determined, the assessment should be informed by such things as the core abilities adopted by the institution, the course outcomes established for a program, and/or the stated outcomes of a single course or class. Assessments that do not address such outcomes lack validity in determining proficiency.

The higher the stakes, the more important it is that assessment be direct rather than indirect, based on actual writing rather than on answers on multiple-choice tests, and evaluated by people involved in the instruction of the student rather than via machine scoring. To evaluate the proficiency of a writer on other criteria than multiple writing tasks and situations is essentially disrespectful of the writer. (Assessment of Proficiency section, para. 1- 4).

Writing performance will be measured in this study by the grades students obtain on the final persuasive research essay. It is assumed that by the time students have written this essay, they would have had varied writing experiences. Also, as a take-home assignment, it is assumed that students would have had the opportunity to revise multiple drafts.

\section{A Brief History of Postsecondary Writing Assessment}

The history of writing assessment has been described as "a narrative of incomplete and uncomplete waves” (Yancey, 2009, p. 146). The first period dates from the 1950 s to the 1970s, when writing was assessed primarily through objective tests. During the second period from 1970 to 1986 holistically scored essays were introduced. The third period from 1986 to the present has been characterized by portfolio and program assessment (Yancey, 2009). 
According to Yancey (2009), the history of writing assessment can also be viewed through the lens of two major concepts: validity and reliability. This history can be interpreted in terms of the conflicting views and understanding of these concepts by psychometric experts and practitioners.

\section{Reliability, Validity, and Writing Assessment}

Writing assessment is not an exact science, as there is inherent difficulty in assigning a quantitative score to material that is distinctly qualitative in nature. Measuring writing performance has been described as "perhaps the most salient limitation of any study of writing” (Pajares and Johnson, 1994, p. 319), as it is open to subjective interpretation.

Reliability has been defined as the consistency with which a test measures what it aims to measure. Validity refers to the test measuring what it is supposed to measure. Reliability issues have been identified in the field of writing assessment since Starch and Eliot's (1912) study, which found significant disagreement among teachers with regard to grading essays written by the same students (Huot \& O’Neill, 2009).

\section{Measuring Writing Performance}

\section{Holistic Scoring}

Writing performance has been assessed using holistically scored essays (e.g. Pajares and Johnson, 1994). Holistic scoring has been described as a "quick, impressionistic qualitative procedure for sorting or ranking samples of writing... a set of procedures for assigning a value to a writing sample according to previously established criteria” (Charney, 1984, p. 67). 
In Pajares’ (1994) study, the rationale given for using holistically scored essays was that it reduced bias, as essays scored by expert raters are accessible to inter-rater reliability checks. Pajares and Johnson also observed that on condition that standardized procedures are adhered to, holistically scored essays result in consistent scores.

However, the shortcomings of holistic assessment have also been underscored in the writing assessment literature (e.g. Cherry and Meyer, 2009). The authors have argued, for example, that interrater reliability by itself cannot be used to support the practice of holistic assessment. The authors further argue that interrater reliability provides only a partial picture of the reliability of holistic assessment. Interrater reliability does not account for the overall reliability of the assessment, only that raters have the ability to consistently assess the quality of a piece of writing.

As Cherry and Meyer (2009) have observed, "Because most holistic assessments purport to measure writing ability (rather than the quality of a writing sample or the consistency of the raters), instrument reliability should be of greater concern to evaluators than interrater reliability” (p. 34). The authors conclude that whether or not raters are consistent in their scoring, if the writing prompt is flawed, or if writers do not write consistent responses to it, holistic scores would not accurately reflect writing ability.

\section{Analytic Scoring}

In analytic scoring a piece of writing is evaluated based on certain traits or dimensions, with a separate score allotted to each trait (Arter \& McTighe, 2001). Student performance on an essay may be analyzed for traits such as idea development, organization, thesis development, or use of conventions. 
White (2009) has discussed the advantages and disadvantages of analytic scoring. Unlike holistic scoring, analytic scoring has the advantage of providing diagnostic information. White has also pinpointed what he views as several major shortcomings of analytic scoring. Firstly, analytic scoring is built on the assumption that writing can be viewed and assessed as the total of its separate traits. White observes, “...analytic scoring imagines a model of writing that is neatly sequential and comfortably segmented” (p. 26). White also argues that there is little consensus among professionals, as to the separate traits which exist in writing.

\section{Performance Measures}

Writing performance has been measured in the literature in several ways. These include using holistically scored essays (e.g. Jones 2008; Pajares \& Johnson, 1994; 1996; Shell et al., 1989), using the number of writing tasks successfully completed by students (e.g. Meier, McCarthy, \& Schmeck, 1984), final course grades (e.g. Jones, 2008; Williams \& Takaku, 2011; Zimmerman \& Bandura, 1994), timed essays (Arum \& Roska, 2011; Doolan, 2013; 2014), or as a single take-home paper (Sanders-Reio, 2010; 2014). The following section will discuss the advantages and shortcomings of three of these performance measures: Timed essays, a single take-home paper, and course grades.

Timed essays

Timed essays are the most commonly used method of assessment in standardized tests such as the ACT and SAT, which are used for college admission and placement purposes. Hillocks (2002) has pointed out several shortcomings of timed essays: “The prompts offer little background information for test-takers to use in constructing their responses, but this lack of background information is intentional because essays are 
graded for their structure and mechanics more than for their content” (as cited in Coker and Lewis, 2008, p. 247).

Murphy and Yancey (2008) have pinpointed several challenges associated with timed essays as a measure of writing performance. They argue, for example, that the validity of the test can be diminished if certain groups within the population are favored or disadvantaged by the testing conditions. Murphy and Yancey observe, "In such cases, a test's results speak more to who can perform a task within an allotted time and less to who is capable of performing the task” (p. 371)

Timed essays have also been criticized because they do not provide opportunities for feedback and revision, as has been recommended by the Conference on College Composition Position Statement on Writing Assessment:

Essay tests that ask students to form and articulate opinions about some important issue... without time to reflect, talk to others, read on the subject, revise, and have a human audience promote distorted notions of what writing is. They also encourage poor teaching and little learning. (Guiding Principles of Assessment section, para. 2)

The single take-home paper

The single take-home paper has several advantages compared to timed essays. Unlike the timed essay, students are given time to complete the assignment and gather background information. The take-home paper also provides the opportunity for reflection and revision. Take-home papers also have one limitation, however, in that they may not capture the range of variation in students' overall writing performance.

Hayes, Hatch and Silk (2000) found little correlation (0.16) between students' performance on a single take-home essay and their subsequent performance on successive take-home essays. Hatch et al. concluded that strong conclusions should not 
be drawn from a student's performance on a single writing task. "Correlations as low as those we found indicate that knowing how well a student did on one essay allows us to predict very little about the quality of another essay that the student writes for the same class" (p. 16).

Course grades

Zimmerman and Bandura (1994) measured writing performance using regular course grades. Their rationale was that course grades can be used by students to establish course goals. Course grades also encompass more activities than a project, and constitute the existing measure of academic success in composition courses.

Course grades, on the other hand, especially when scored by multiple raters, may not constitute an objective measure of writing performance. In addition, course grades generally consist of other components such as participation and attendance. Jones (2008) observed,

While grades provide some drawbacks as a measure of academic achievement, in that it is unlikely that all the instructors in the writing program would follow the same criteria for scoring essays, they have the great advantage of measuring achievement in the way that both students and schools recognize most readily. (p. 219)

\section{Summary}

There is inherent difficulty in assessing writing by assigning a quantitative score to an activity that is qualitative in nature. Issues of reliability and validity have persisted in the field of writing assessment. Limitations in both scoring methods and performance measures have been acknowledged. Shortcomings have been identified in holistic and analytic scoring, as well as commonly used performance measures such as timed essays, the single take-home paper, and course grades. 


\title{
Personal Factors and Writing Performance
}

\author{
Introduction
}

This section of the review will present studies that have examined the influence of students' personal factors on their writing performance. Literature relevant to the role of previous writing performance, writing self-efficacy and writing self-regulatory efficacy will be discussed.

\section{Previous Writing Achievement and Writing Performance}

The influence of students' previous writing achievement on their subsequent writing performance has been investigated in several studies (e.g. Pajares \& Johnson, 1994; Zimmerman \& Bandura, 1994; Jones, 2008; Williams \& Takaku, 2011; Arum \& Roska, 2011). Pajares and Johnson's (1994) study of 30 teacher education students measured their previous writing performance using a timed 30-minute essay administered at the beginning of the term. Pajares and Johnson found a moderate correlation $(.57, p<.001)$ between preand posttest scores on the timed essay.

Previous writing achievement as measured by verbal SAT scores was found to be moderately correlated with writing performance in Zimmerman \& Bandura’s (1994) study of first-year composition students. Zimmerman and Bandura found a weak correlation between verbal SAT scores and final grades $(.25, p<.05)$.

Jones (2008) found previous writing achievement to significantly predict writing performance among 118 students enrolled in a basic writing section of College English. Students’ previous writing achievement was measured by their self-reported high-school English grade and a holistically scored essay, the Writing Proficiency Test. Jones found weak correlations between the pre- and posttest results of the Writing Proficiency Test 
$(.22, p<.05)$ as well as between students' self-reported grades and their grades in College English (.28).

Arum and Roska (2011) used students ACT/SAT scores as a measure of students' academic preparation in their national evaluation study of 2300 freshmen and sophomores attending 24 colleges in the United States. This study reported the results of a standardized test, the Collegiate Learning Assessment (CLA). Arum and Roska reported and discussed the results of the performance task, a written response to a prompt which evaluates' students' ability to use evidence to support an argument, analyze and synthesize evidence, and make inferences from evidence. The CLA also aims to evaluate students' ability to organize and present their ideas in a logical manner, as well as their use of mechanics and vocabulary (Collegiate Learning Assessment, City University of New York, Performance Task section, para. 7). The study found that students whose ACT/SAT scores were in the top quintile obtained higher mean scores on the CLA (1330.34) than those who scored in the bottom quintile of the ACT/SAT (1008.09). Williams and Takaku's (2011) study contradicted the findings of previous studies. They found that previous writing achievement, as indicated by SAT writing score and a pretest, was not related to composition grade.

\title{
Motivation and Writing
}

\author{
Introduction
}

This section of the review will discuss the literature relative to the two remaining personal factors which have been hypothesized to influence writing performance within a social cognitive framework in this study: Self-efficacy and self-regulation. In order to 
establish a context for the discussion, a brief historical overview of research on writing motivation will be provided.

Historical Overview of Research on Writing Motivation

Hidi \& Boscolo (2006) have described writing as a “motivational problem” (p. 145). According to the authors, one unique motivational challenge faced by writers is that they typically create texts with little external input. When writers are provided with a topic, the ideas and text that they produce depend on the extent of their knowledge of the topic. De Bernardi and Antolini (2007) have observed that argumentative writing is one of the most common forms of writing engaged in by students in middle school and beyond, and may affect students' motivation. "Production of this text type is often a compulsory rather than a chosen task frequently presenting a high level of "distance" between the writer and the product, which leads to a lack of motivation and personal involvement” (p. 183).

This view of the relationship between writing and motivation has not always been reflected in the literature. Much of early contemporary composition research tended to focus on the cognitive domain of writing. Several landmark composition studies (e.g. Emig, 1971; Flower \& Hayes, 1981; Perl, 1980; Sommers, 1980) have examined the composing process and have largely contributed to our current understanding of writing as a recursive process.

Writing motivation has been studied since the 1970s (eg. Daly \& Miller, 1975), and mainly investigated the role of writing apprehension on the writing performance of first-year composition students. Hidi and Boscolo (2006) have observed that interest decreased in these early studies on writing apprehension during the 1980s. The authors 
attribute this decrease in interest to a renewed focus on studies related to cognition and writing. They write, "Due to the focus on cognition, the motivational and affective dimension of writing tended to be neglected or ignored by writing researchers in the 1980s” (p. 144).

Hidi and Boscolo (2006) have further observed that research on motivation in the 1980s, particularly in the domains of interest research and self-efficacy research, in turn influenced writing research. According to the authors, self-efficacy and interest research showed writing to be “... a complex activity involving not only cognitive and metacognitive processes but also affective components” (p. 144). For example, McLeod (1987) proposed expanding composition research beyond purely cognitive process approaches, and argued for a holistic approach that examines both cognitive and affective domains in the writing process. McLeod viewed the psychological constructs of motivation and beliefs as affecting the manner in which students engage with writing tasks.

According to Troia, Shankland and Wolbers (2012), the focus of early research on writing motivation underwent a shift with the development of the social cognitive theory of learning (p. 12). The social cognitive framework included the more recently formulated theoretical constructs comprising academic motivation. Troia, Shankland and Wolbers (2012) have identified four major elements of achievement motivation that have been studied within the social cognitive framework: Self-efficacy beliefs, goal orientations, personal and situational interest, and attributions for outcomes (p. 6).

Similarly, Boscolo and Hidi (2007) have identified three major areas of research on motivation and have discussed how each area relates to writing. The first area relates 
to motives, such as an individual's goal orientations, needs, values, and interests. The second area relates to the individual's perceptions of his or her ability to accomplish certain tasks and includes constructs such as self-efficacy, self-concept and selfperceptions of competence. The third area relates to self-regulation of various tasks. With regard to writing, strategies that writers use to self-regulate their writing include time spent planning, using metacognitive strategies, and persevering at writing tasks. From these three areas, the authors have highlighted three motivational variables that have been studied in relation to writing: Interest, self-efficacy, and self-regulation (p. 1).

\section{Self-Efficacy}

Bandura’s (1977) psychological construct of self-efficacy is at the core of a theoretical framework in which changes accomplished in fearful and avoidant behavior are analyzed. According to Bandura (1997), “perceived self-efficacy refers to beliefs in one's capabilities to organize and execute the courses of action required to produce given attainments” (p. 3). Schunk and Miller (2002) have provided what will be used in this review as a working definition for the construct of self-efficacy, as “one’s perceived capabilities for accomplishing a task” (as cited in Pajares \& Urdan, 2006, p. 32).

Bandura's theory is based on the premise that any mode of cognitive operation creates and strengthens one’s self-efficacy expectations. Bandura differentiated between efficacy expectations and outcome expectations. An efficacy expectation is "the conviction that one can successfully execute the behavior required to produce the outcomes”, whereas an outcome expectation is “a person's estimate that a given behavior will lead to certain outcomes” (p. 193). 
Bandura’s (1977) rationale for distinguishing between outcome expectations and efficacy expectations is the difference between an individual's knowledge that a certain action will result in a certain outcome, and the belief in his or her capacity to accomplish the necessary action. Bandura further posits that the strength of an individual's beliefs will influence whether or not they initiate and persist in coping behaviors. He writes, "People fear and tend to avoid threatening situations they believe exceed their coping skills, whereas they get involved in activities and behave assuredly when they judge themselves capable of handling situations that would otherwise be intimidating” (p. 194).

Expectancy outcomes originate from four main sources: "performance accomplishments, vicarious experience, verbal persuasion, and physiological states” (Bandura, 1977, p. 195). Bandura described performance accomplishments as a major factor in determining expectancy outcomes as they depend on an individual's mastery experiences. He writes, “This source of efficacy information is especially influential because it is based on personal mastery experiences. Successes raise mastery expectations; repeated failures lower them, particularly if the mishaps occur early in the course of events” (p. 195). Self-efficacy beliefs can be strengthened by providing mastery experiences, modeling, social persuasion, and learning to interpret their physiological states (Wood \& Bandura, 1989).

Bandura (2006) has also made a distinction between perceived self-efficacy and other psychological constructs such as self-esteem and locus of control. Whereas selfefficacy judges an individual's ability, self-esteem judges an individual's self-worth. Locus of control is concerned with whether or not outcomes come as a result of an 
individual's actions or whether one's actions are determined by external forces (as cited in Pajares \& Urdan, 2006, p. 309).

Bandura (1997) applied his conceptualization of self-efficacy to the academic domain. He wrote, "Efficacy beliefs play an influential mediational role in academic attainment” (p. 216). Bandura further posited that students' self-efficacy can better predict their academic performance than their previous academic achievement, knowledge and skills. Other theorists (e.g. Gore, 2006; Schunk 1991) have also discussed the role played by self-efficacy in academic motivation.

Pajares and Valiante (2006) discussed self-efficacy as it relates to academic performance. According to Pajares and Valiante, students' perceptions of their abilities influence their choices and the decisions they make. Students will show a tendency to choose tasks and activities about which they feel competent and confident, and steer clear of those about which they do not. Pajares and Valiante observed, "Students with a strong sense of personal competence in an academic task will approach difficult tasks as challenges to be mastered rather than as threats to be avoided” (p. 159). However, students with low levels of self-efficacy tend to avoid seeking help (Ryan and Pintrich, 1997), and experience anxiety (Meece, Wigfield \& Eccles, 1990).

Self-efficacy has been found to be a significant predictor of academic performance at both secondary and post-secondary levels. In a longitudinal study of 412 secondary students aged 13 to 19, Caprara, Vecchione, Alessandri, Gerbino, \& Barbaranelli, (2011) found academic self-efficacy beliefs were found to be a partial mediator of the association between junior high school grades $(r=.04, \mathrm{p}<.05)$ and senior high school grades $(r=.05, \mathrm{p}<.05)$. Similarly, Zajacova, Lynch \& Espenshade 
(2005) found self-efficacy to be a significant predictor of GPA ( $r=.25,0.07, p<.001)$ among 107 first-year college students.

\section{Writing Self-Efficacy Beliefs and Writing Performance}

Self-efficacy beliefs have been identified as one of four major elements of achievement motivation, along with goal orientations, interest, and outcome attributions (Troia, Shankland \& Wolbers, 2012). According to Piazza and Siebert (2008), although researchers have recognized that affective factors play an integral part in writing, the renewed research focus on the role of motivational constructs such as engagement, interest and attitudes in writing has been recent.

Several studies on writing self-efficacy have been conducted (e.g. Jones, 2008; McCarthy, Meier \& Rinderer, 1985; Meier, McCarthy \& Schmeck, 1984; Pajares and Johnson, 1994; Shell et al., 1989; Williams \& Takaku, 2011; Zimmerman \& Bandura, 1994). These studies have been classified as first- and second-generation studies based on the theoretical conceptualization of their instruments (Sanders-Reio, 2010).

The instruments used in first-generation studies (e.g. McCarthy, Meier, \& Rinderer, 1985; Meier, McCarthy \& Schmeck, 1984; Shell, Murphy \& Bruning, 1989) disproportionally addressed sentence-level concerns such as spelling, punctuation and usage, and tended to neglect more substantive skills. Second-generation studies (e.g. Jones, 2008; Zimmerman \& Bandura, 1994) measured writing self-efficacy using scales that addressed both mechanical and substantive writing skills. While these studies have contributed to the writing self-efficacy literature, there remains room for replicating the scales used in second-generation studies, given the dearth of studies at the college level that have used these instruments. 
Meier, McCarthy and Schmeck (1984) conducted one of the earliest studies which used Bandura’s (1977) self-efficacy theory as a framework for studying the writing performance of first-year composition students. The researchers' study of 121 college freshmen indicated that highly efficacious students tended to be better writers. Also, deep processors who experienced less anxiety were in general more efficacious and predicted their performance more accurately.

McCarthy, Meier \& Rinderer (1985) obtained similar results in their study of college freshmen enrolled in beginning writing classes. They found that among the 4 predictor variables, strength of perceived efficacy, perceived locus of control, anxiety, and cognitive processing, only strength of perceived efficacy was a significant predictor of writing performance $(r=.33)$ between self-efficacy and essay scores.

Shell, Murphy and Bruning’s (1989) study confirmed the findings of McCarthy et al. (1985). The study found a stronger relationship between self-efficacy for writing skills and subsequent writing scores $(r=.32)$ than self-efficacy for writing tasks $(r=.17)$ and outcome expectancy $(r=.13)$. Self-efficacy beliefs were found to be independent from actual writing skill.

In a study of 30 undergraduate pre-service teachers over the course of one semester, Pajares and Johnson (1994) found that students' confidence in their writing skills explained the relationship between writing beliefs and writing performance, not their confidence in their ability to perform writing tasks. As the researchers have noted, “This finding supports Bandura's (1986) proposition that the predictive power of self efficacy is dependent on the similarity between the confidence assessment and the criterial task” (p. 323). 
Zimmerman and Bandura's (1994) study of 95 college freshmen enrolled in regular and advanced sections of first-year composition found that students' academic self-efficacy for writing had both a direct and indirect influence on writing performance through its influence on personal goals $(r=.38, p<.05)$.

Jones (2008) conducted a study on writing self-efficacy as a predictor of success among basic writers in a first-semester composition course. The hypothesis that selfbelief would be a better predictor of writing performance than cognitive factors was partially supported by the study. The hypothesis that there would be a significant correlation between the measures of self-efficacy collected during the first half of the semester and those collected at the end was supported by the study. Pre- and postmeasures of writing self-efficacy were found to be highly correlated $(r=.75, p<.001)$.

More recent studies have also investigated the role of students' writing selfefficacy beliefs and writing performance in higher education. Sanders-Reio (2010) surveyed 286 pre-service teachers enrolled in six sections of an undergraduate educational psychology class. This study found that higher writing self-efficacy scores for mechanical skills (grammar, punctuation, and usage) were weakly correlated with higher grades $(r=.24, p<.01)$. This finding contradicted the results of what SandersReio has classified as second-generation studies. According to the researcher, these studies tended to report larger correlations between total writing self-efficacy (mechanical, substantive and self-regulatory writing self-efficacy) and writing performance. Sanders-Reio reported lower correlations for writing self-efficacy scores ( $r=.20, p=<.01)$, substantive self-efficacy scores $(r=.18, p<.01)$, and self-regulatory writing self-efficacy $(r=.17, p<.01)$ than mechanical self-efficacy $(r=.24, p<.01)$. 
Williams and Takaku (2011) examined secondary data collected from 6 freshman cohorts totaling 671 students over a period of eight years. The purpose of the study was to investigate the nature of the relationship between help-seeking behavior, self-efficacy, frequency of writing center visits, and their final grades. Williams and Takaku found the relationship between writing self-efficacy and writing performance to be mediated by the frequency of writing center visits. Williams and Takaku reported that despite lower selfefficacy levels, ESL students obtained higher grades than their native-speaking peers. Higher writing self-efficacy was also associated with higher grades $(\beta=.07, p<.05)$.

Prat-Sala and Redford (2012) studied the influence of undergraduate students' writing self-efficacy and reading self-efficacy on their writing performance. Participants were 145 first and second-year psychology students. They completed two self-efficacy scales, one for writing and one for reading. The writing performance of first-year students was assessed by a 500-word essay, while second-year students’ performance was assessed using a 1200-word essay. The study found that both self-efficacy for reading and writing had an influence on students' writing performance, although the relationship between writing self-efficacy and writing performance was stronger. The writing selfefficacy of first-year students moderately correlated with their writing performance ( $r=$ $.38, n=91, p<.001)$. Similar results were obtained for second-year students $(r=.43, n=$ $54, p<.001)$.

Tanyer (2015) replicated Prat-Sala and Redford's (2012) study with a sample of 116 English as a Foreign Language first-year students. Significant Pearson correlations were found between self-efficacy for writing and writing performance $(r=.35, p<.01)$. 
The results of the hierarchical linear regression indicated that self-efficacy for writing explained $7 \%$ of the variance $(F(2,113)=7.947 ; p=.001)$ in essay writing performance.

\section{Methodological Considerations}

The majority of the writing self-efficacy studies previously discussed used quantitative surveys to collect the data. Data were analyzed primarily using multiple regression analysis procedures (e.g. Jones, 2008; Pajares and Johnson, 1994; Zimmerman \& Bandura, 1994). Williams \& Takaku (2011) used path analysis. McCarthy, Meier \& Rinderer (1985); Meier, McCarthy \& Schmeck (1984); and Shell et al., (1989) conducted stepwise regression analyses to identify the most significant predictor of writing performance.

The parameters within which path analysis is to be used to describe causal relationships were previously discussed. These include testing theories and evaluating construct validity, and establishing causation when guided by theory. One of the shortcomings of stepwise regression procedure used in several of the preceding studies was discussed by Pajares and Johnson (1996). They noted, for example, that although Meier, McCarthy, and Schmeck (1984) found that writing self-efficacy predicted writing performance among undergraduates, the stepwise analysis procedure did not allow the researchers to investigate the nature of the relationships among all the variables in the study.

\section{Measuring Writing Self-Efficacy}

This section provides an overview of the literature that has informed the development of writing self-efficacy scales. Pajares and Valiante (2006) have identified three types of measures that have been used in writing self-efficacy research. The first 
type measures students' confidence in their ability to perform writing skills such as mechanical skills. Another type of scale assesses students' confidence in their ability to accomplish writing tasks such as writing a research paper. The third category includes writing self-efficacy scales consisting of confidence judgments by which students rate their confidence that they can obtain a particular grade. This result is then matched with the grades that students actually obtain.

Meier et al. (1984) developed what has been described as belonging to the first generation of instruments used to measure writing self-efficacy (Sanders-Reio, 2010). They developed a 19-item efficacy expectations measure to assess the writing performance of college freshmen. The magnitude of students' self-efficacy was measured by students' responding Yes or No to the 19-item efficacy expectations measure. The strength of students' writing self-efficacy beliefs was measured using a 100-point scale, where students indicated the level of certainty with which they could perform the tasks on the efficacy expectations measure.

McCarthy et al. (1985) also investigated the relationship between writing selfefficacy and writing performance among college students. They used the same SelfAssessment of Writing measure used in the study by Meier et al. (1984). The instrument used in both studies was designed primarily to measure mechanical writing skills. Sample questions from the instrument used by McCarthy et al. include, "Can you write an essay without major spelling errors?" "Can you write an essay without run-on sentences?" "Can you write an essay free of comma faults?" "Can you write an essay in which the ideas are clearly expressed?" (p. 468). 
Shell et al. (1989) developed a writing self-efficacy instrument consisting of 2 subscales: a 16-item task subscale and an 8-item component skill subscale. Students’ writing was assessed by a writing sample written in response to a timed 20-minute essay prompt: "What do you believe to be the qualities of a successful teacher?" Items form the task subscale included: " 1 . Write a letter to a friend or family member. 2 . List instructions for how to play a card game. 3. Compose a will or other legal document. Sample items from the skill subscale include: Correctly spell all words in a one page passage. 2. Correctly punctuate a one page passage. 3. Correctly use parts of speech (i.e. nouns, verbs, adjectives, etc.)” (p. 99).

Pajares' research in the area of writing self-efficacy has primarily relied on the Writing Self-Efficacy Scale (WSES; Pajares \& Johnson, 1994), which measures both writing skills and tasks. Zimmerman and Bandura (1994) developed two scales to measure perceived self-efficacy: 25-item Writing Self-Regulatory Efficacy Scale, and a Perceived Efficacy for Academic Attainment in the Writing Course. Students rated the strength of their beliefs that they could obtain one of a range of possible grades from A to F. Students used the Self-Evaluative Standards Scale to rate their levels of satisfaction or dissatisfaction if they received one of the 12 academic grades.

According to Bandura (2006) scales measuring perceived self-efficacy should be domain-specific, and should therefore be relevant to the domain being studied. Bandura writes, "The construction of sound efficacy scales relies on a good conceptual analysis of the relevant domain of functioning. Knowledge of the activity domain specifies which aspects of personal efficacy should be measured" (p. 310). Bandura further observes that if self-efficacy scales are constructed based on factors that are unrelated to a particular 
domain, research findings would not accurately reflect the different aspects of perceived self-efficacy within that domain.

In short, self-efficacy scales must be tailored to activity domains and assess the multifaceted ways in which efficacy beliefs operate within the selected domain of activity. The efficacy scales must be linked to factors that, in fact, determine quality of functioning in the domain of interest. (pp. $310-311$ )

\section{Limitations of First-Generation Self-Efficacy Scales}

Jones (2008) identified what he has described as a conceptual flaw in the instrumentation used in Pajares and Johnson's (1994) study. This flaw prevented the instrument from being used in Jones' study on the role of writing self-efficacy beliefs in predicting the performance of basic college writers. Jones observed,

The skills scale does not follow the model of writing that is in tune with the principles of composition pedagogy. The skills items focus almost exclusively on sentence-level skills such as spelling, punctuation, and the use of correct parts of speech (the last of which would be seen as almost irrelevant in determining whether someone knows how to write well); only one of the items focuses on the paragraph level and one on the essay level. Skills scales developed for all levels of students should include items both on the sentence level and on the level of the entire composition. (pp. 217, 218)

Zimmerman and Bandura (1994) developed a scale for measuring writing selfefficacy which is more closely aligned to current composition practice. This study has been classified as one of the first second-generation writing self-efficacy studies (Sanders-Reio, 2010). Zimmerman and Bandura reported Cronbach reliability coefficients of .91 and .87 respectively for these two self-efficacy scales.

Jones (2008) also developed scales that were more closely aligned to current composition practice. He applied Bandura's (2001) guidelines for creating contextspecific self-efficacy scales by aligning them with the College English 1 curriculum and the Writing Program Administrators’ (WPA, 2000) outcomes statement for first-year 
composition. In addition to sentence-level concerns, his writing skills scale also included items that addressed more global composition features such as thesis development and organization.

The second scale, the writing tasks scale, measured students' confidence in their ability to complete various writing tasks such as writing a persuasive essay that cites sources that present arguments that are different from the students' own. The third scale, a regulatory self-efficacy scale, focused on how students approached challenging writing assignments.

The reliability of the scale was tested by administering it at a three-week interval to 18 volunteers enrolled in a psychology course. The two datasets were highly correlated for the writing approach scale $(\mathrm{r}=.83, \mathrm{p}<.001)$, the writing task scale $(\mathrm{r}=.84, \mathrm{p}<.001)$, and the writing skills scale $(\mathrm{r}=.84, \mathrm{p}<.001)$. Cronbach's alpha measured .85 for writing approach, .94 for writing task, and .93 for writing skills.

Sanders-Reio, Aleander, Reio, and Newman’s (2014) Writing Self-Efficacy Index (WSI) expanded on Zimmerman \& Bandura’s (1994) writing self-regulatory efficacy scale. The scale addresses features not included in previous writing self-efficacy scales and are also more aligned to current composition pedagogy. In addition to sentence-level concerns, Sanders-Reio et al's scale includes items that consider elements of composition such as argumentation and analysis, audience, and the writing process.

The structure of the Writing Self-Efficacy Index (WSI) was examined using Principal Component Analysis (PCA) and varimax rotation. The WSI was found to contain three components: Writing self-efficacy for Substantive, Self-Regulatory and Mechanical skills. The eigenvalues for each of the components were 16.4, 10.9, and 10.2, 
respectively, and explained $26.9 \%, 18.5 \%$, and $17.9 \%$ of the variance individually, and a total of $63.3 \%$ combined. Cronbach’s reliability coefficients reported for each subscale ranged between .94 and .98 .

\section{Self- Regulated Learning}

Self-Regulation, Academic Motivation, and Achievement

Zimmerman \& Schunk (2008) have defined self-regulated learning as "the process by which learners personally activate and sustain cognitions, affects, and behaviors that are systematically oriented toward the attainment of learning goals” (p.vii). According to Zimmerman \& Schunk, research interest in the domain of self-regulation and academic achievement originated from findings which pointed to factors beyond students' skills and abilities in explaining student achievement, such as self-regulation and motivation.

The majority of the early studies on self-regulation in education investigated the use of cognitive strategies and behaviors, including monitoring, organization, rehearsal, time-management, and productivity. For the past thirty years the research focus has shifted to include motivational variables, including goals, attributions, self-efficacy, outcome expectations, self-concept, self-esteem, social comparisons, emotions, values, and self-evaluation (Zimmerman \& Schunk, 2008). As Zimmerman (1998) has observed, “... research on academic self-regulation grew out of efforts to explain proactive efforts of students to learn on their own - their personal initiative, resourcefulness, persistence, and sense of responsibility” (p. 73).

Winne \& Hadwin (2008) discussed the relationship between self-regulation and motivation. According to Winne and Hadwin, self-regulated learning is built on the 
assumption that students exercise conscious control of their learning. Students engage in goal-setting within the parameters set by their present abilities and environment. They observe, "Students also exercise agency by making choices about how they strive to reach those goals, including how intensely to engage in a task and how long to persist if the task cannot be completed almost instantly and effortlessly” (p. 298). Schunk (1989) viewed self-regulation and motivation as interconnected and impossible to understand as separate processes. Zimmerman (1989) has proposed a definition of self-regulated learning which includes three characteristics: Using self-regulated strategies, responding to self-directed feedback about one’s learning, and self-motivation.

Winne and Hadwin (1998, as cited in Winne \& Hadwin, 2008) have proposed a recursive four-phase model of self-regulated learning. During the first phase, task perception, students observe their environment. The environment includes teacherassigned tasks, textbook exercises, and their own self-knowledge. Students use this information to form an individualized portrait of a given task. This individualized portrait can affect motivation, including perceived self-efficacy. The second phase, goal-setting, is an outgrowth of phase 1, where students plan how to attain their goals. Students' goals can consist of behaviors, types of intellectual engagement, or motivational changes. The third phase, enacting, occurs as students implement their plan through the use of cognitive, behavioral, or motivational strategies. During the fourth phase, adaptation, students may consider their strategies for task completion, may modify these strategies to attain their goals, or eventually discontinue the task. 


\section{Self-Regulation and Self-Efficacy}

Zimmerman's (2002) proposed a three-phase self-regulation model consisting of the forethought phase, the performance phase, and the self-reflection phase. Self-efficacy is a self-motivation belief and has been classified in the forethought phase of Zimmerman's model (see Figure 5). Zimmerman (2000) has described self-efficacy as interacting with students' self-regulated learning processes, and mediating their academic performance.

Several studies (e.g. Zimmerman, Bandura, Martinez-Pons, 1992; Zimmerman and Martinez-Pons, 1990) have found that students’ self-efficacy for self-regulated learning impacted their belief in their academic ability, which in turn influenced their academic performance. Pajares (2008, in Schunk \& Zimmerman) observed, “Students self-efficacy beliefs influence their academic motivation through their use of selfregulatory processes such as goal-setting, self-monitoring, self-evaluation, and strategy use ...” (p. 121).

\section{Self-Regulation of Writing}

Self-regulation of writing is of particular importance within a process-oriented approach to writing. As Zimmerman and Kitsantas (2007) have observed,

Successful writing requires high levels of self-regulation and self-motivation. Although these self-discipline qualities of writers are often hidden from readers, they are widely reported in personal accounts of professional writers. Prominent theories of writing have identified a number of processes that are clearly selfregulatory in nature, such as textual planning, goal setting, organizing, evaluating, and revising. (p. 51)

Zimmerman (1998) identified self-regulatory processes that are applicable across several domains, including writing. These processes include goal-setting, task strategies, imagery, self-instruction, time-management, self-monitoring, self-evaluation, self- 
consequences, environmental structuring, and help-seeking. Applied to the domain of writing, goal-setting as described by expert writers includes, for example setting objectives for a number of words or pages.
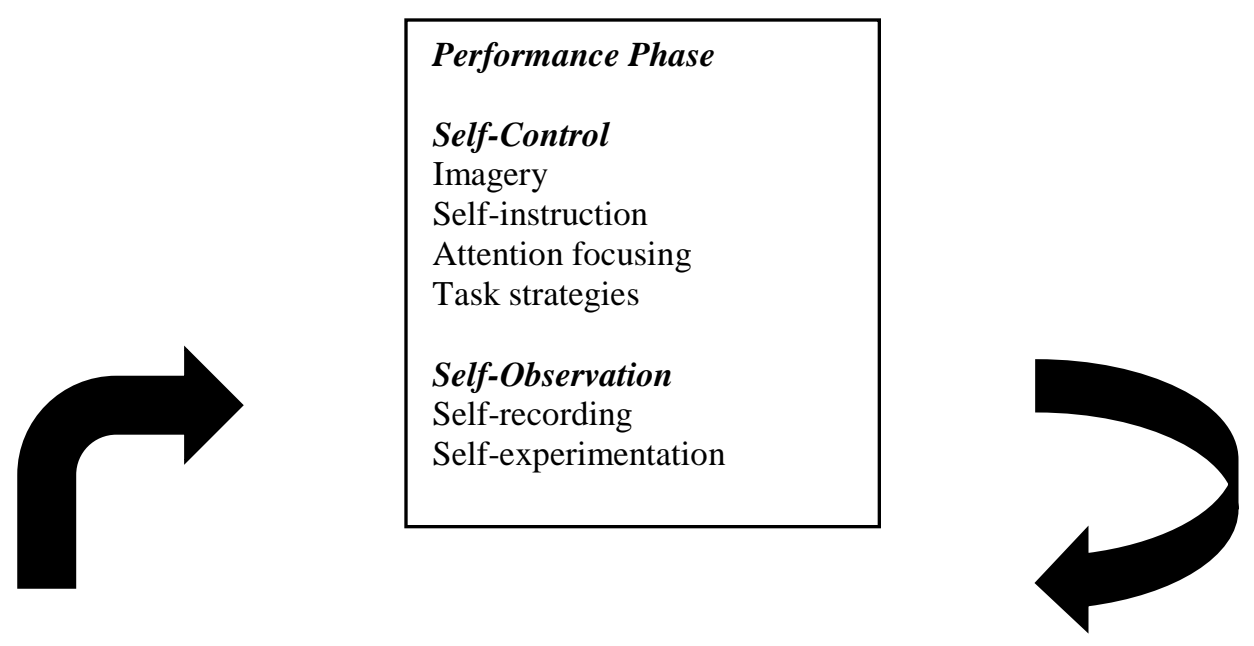

\section{Forethought Phase}

Task Analysis

Goal setting

Strategic planning

\section{Self-Motivation Beliefs}

Self-efficacy

Outcome expectations

Intrinsic interest/value

Learning goal orientation

\section{Performance Phase}

Self-Control

magery

Self-instruction

Attention focusing

Task strategies

Self-Observation

Self-recording

Self-experimentation

Figure 5. Phases and sub-processes of self-regulation. From Self-efficacy: An essential motive to learn. Contemporary Educational Psychology, 25, (p. 67), by B. J. Zimmerman, 2000. 


\section{Writing Self-Regulatory Efficacy and Writing Performance}

This section of the review will present studies that have investigated the relationship between self-efficacy to regulate one’s writing and writing performance. Zimmerman and Bandura (1994) investigated first-year composition students’ selfefficacy to regulate their writing activities and its influence on students’ writing performance. Zimmerman and Bandura have defined self-efficacy to regulate writing activities, or writing self-regulatory efficacy as “Belief in one’s capabilities to regulate one’s own writing activities” (p. 847). It was hypothesized that students’ perceived selfregulatory efficacy would influence their own personal standards and perceived academic self-efficacy. Students’ personal standards and perceived academic self-efficacy would have both a direct and indirect influence on their writing performance through the performance goals they set for themselves. These performance goals would in turn be influenced by students’ previous writing achievement, as measured by their SAT scores.

The results of a path analysis indicate that students enrolled in the advanced composition course had higher levels of self-regulatory efficacy $(M=4.42)$ than those enrolled the regular section $(M=4.15)$. The results of the path analysis also indicated that students' self-regulatory efficacy influenced their personal standards, and perceived academic self-efficacy, which were related to grade goals. Self-regulatory efficacy was weakly correlated with students' final grades $(r=.14, p>.05)$. However, the correlation was not statistically significant.

Sanders-Reio (2010) expanded on Zimmerman and Bandura’s (1994) study by using a modified version of the writing self-regulatory efficacy scale. Two hundred and seven undergraduates enrolled in an educational psychology class participated in this 
study. The purpose of the study was to investigate the influence of students' beliefs about writing, their writing self-efficacy, and writing anxiety on their writing performance. The results of hierarchical regression analyses indicated that writing self-regulatory efficacy was weakly correlated with writing performance $(r=.17, p<.01)$.

Sanders-Reio, Alexander, Reio, and Newman (2014) investigated whether the beliefs about writing of 738 undergraduates enrolled at a public university in Florida were related to their writing self-efficacy, and writing apprehension. Sanders-Reio et al. hypothesized that students' beliefs about writing would explain a larger percentage of variance in their final grades, than writing self-efficacy and writing apprehension. Writing self-efficacy was composed of three-subscales: Substantive, self-regulatory and mechanical.

The results of the hierarchical regression supported the hypothesis that students' beliefs about writing would explain the most variance in writing performance in the regression model. This study measured self-regulatory efficacy using Zimmerman and Bandura’s (1994) Writing Self-Regulatory Efficacy scale. Writing self-regulatory efficacy was found to explain $1.3 \%$ of the variance in writing performance. This was less than for the total self-efficacy measure consisting of three subscales: substantive, selfregulatory, and mechanical, which accounted for $3.3 \%$ of the variance.

Ekholm, Zumbrunn, \& Conklin (2015) found a significant correlation between writing self-regulation and writing self-efficacy $(r=.35, p<.001)$ in their study of 115 undergraduate students. Writing self-efficacy explained $11 \%$ of the variance in students' writing self-regulation. Students' attitudes toward feedback were also found to be significantly related to writing self-regulation. Students who perceived feedback in a 
positive manner tended to have higher self-regulation. Approximately $23 \%$ of the variance in writing self-regulation was explained by a combination of students’ writing self-efficacy and their attitudes toward feedback.

\section{Behavioral Factors and Writing Performance}

Introduction

This section of the review will review the literature relevant to behavioral factors and writing performance. It will begin by discussing the concept of adaptive helpseeking, and present studies relative to two help-seeking behaviors as they relate to writing: frequency of writing center visits and instructor-student conferences. This section will also discuss studies related to students' engagement in their own learning, and the relationship between the time students spend on writing tasks and their writing performance.

\section{Adaptive Help-Seeking}

Newman (2008) has described adaptive help-seeking as “a strategy of selfregulated learning” (p. 316). Newman (1994) conceptualized adaptive help-seeking as mediating the relationship between challenging academic tasks and successfully completing those tasks.

Newman (2008) has placed adaptive help-seeking within the framework of Vygotsky's sociocultural theory of learning. Within this framework, learners may need the assistance of a more knowledgeable person when completing an academic task. Commenting on what he has described a neglected component of Vygotsky’s theory Newman observes, “An important aspect of self-regulation is knowing when it is 
necessary to fall back to other-regulation. The self decides when it is time for input from the other ...” (p. 316).

Newman (2008) has also contrasted adaptive help-seeking with non-adaptive help-seeking. According to Newman adaptive help-seeking and non-adaptive helpseeking differ in two ways. Firstly, adaptive help-seekers engage in a process of selfreflection, and reflect on three types of questions when facing challenging academic tasks. They consider whether the request is necessary, its content, and the person from whom they should seek help. Adaptive help-seekers also differ from non-adaptive helpseekers with regard to affect and motivation. Newman writes,

Adaptive help seekers possess intrapersonal, self-system resources ... that support their effort and interest and allow them to persist in the face of factors that can inhibit or undermine help seeking (e.g. social comparison among peers, teachers and classrooms emphasizing grades rather than learning). (as cited in Schunk \& Zimmerman, 2008, p. 317)

The affective-motivational resources accessed by adaptive help-seekers are comprised of goals, self-beliefs, and emotions.

The following section will discuss two help-seeking behaviors that have become an integral part of writing pedagogy and practice: Instructor-student conferences, and writing center visitation.

\section{Instructor-Student Conferences and Writing Performance}

Lerner (2005) has provided a historical overview of instructor-student conferences, tracing their origin to the 1890s. Conferencing grew out of a need to meet the needs of individual students. Instructor-student conferences have become established best practices in fostering revision among student writers, and have been referred to as one of the most effective methods of writing instruction (Beck, 1939, as cited in Lerner, 
2005, p. 186). Lerner observed, “... one practice never collects dust: teacher-student conferencing. Advocates for conferencing have spanned each era of practice, from current-traditional rhetoric, through sociocognitive approaches, to post-modern sensibilities and post-modern realities” (p. 186).

The transactional nature of the instructor-student conference has been established in the literature. Murray (1985) described the instructor-student conference as "professional discussions between writers about what works and what needs work" (p. 140). This approach has been adopted to define the role of instructor and student during conferencing. During conferences students can be taught strategies for critically assessing and revising their writing (Beach, 1989), encouraged to make decisions about their writing, engage in self-evaluation Newkirk (1989), and initiate the conversation (Murray, 1985). Commenting on the benefit of instructor-student conferences Jacobs and Karliner (1977) observed,

By providing an opportunity for the student to talk with an interested listener about his topic, the conference often enables the student to discover and develop ideas which may have been vague or germinal. Such talk is usually translated into more coherent, interesting, and well-written papers. (p. 489)

Several studies on the effectiveness of instructor-student conferences have been conducted. These studies have focused on the effectiveness of the interaction between instructor and student on the quality of students' revisions (e.g. Eksi, 2012; Gulley, 2012; Hewett, 2006), or in developing of personal agency in beginning writers (e.g. Strauss \& Xiang, 2006), students' expectations of the instructor-student conference (e.g. Liu, 2009), the role of students' self-efficacy in instructor-student conferences (e.g. Bayraktar, 2009).

Eksi (2012) conducted a nine-week experimental study of 46 English as a Foreign Language majors who were enrolled in a first-year academic writing course. The purpose 
of the study was to compare the effectiveness of peer feedback and teacher feedback on students’ writing performance on five writing assignments. Participants were divided into two treatment groups. The experimental group of 23 participants received two weeks of training in peer review techniques which included giving feedback on the form and the content of essays. Students in the treatment group were also given a peer review checklist to assist them in their review. Students in the experimental group provided feedback to students on their first drafts. Students in this group also received feedback on their final drafts only from their instructor. The control group received instructor feedback during individual conferences on the first and final drafts of their essays. Students' revisions of their essays were analyzed for surface or deep revisions using Faigley and Witte’s (1981) taxonomy. The study found almost similar results in the number and quality of the revisions made in the two groups.

Hewett (2006) conducted a qualitative text analysis of synchronous online writing conferences. Instructors used an electronic whiteboard to provide synchronous feedback to 23 undergraduate first-year writing students. Fourteen online instructors who were trained in synchronous and asynchronous conferencing participated in this study. Interactions between students and instructors were coded. The researcher then carried out a textual analysis of students' writing to determine whether students' revisions could be attributed to the feedback they had received from their instructors during conferences. Of 52 instructor-student interactions analyzed, the researcher recorded 38 instances where students' had incorporated suggestions for revision from their instructor.

Gulley’s (2012) study of 70 developmental writing students enrolled at a community college explored the effect of the oral feedback students received during 
writing conferences on their subsequent revisions. Students were assigned to three treatment conditions: Oral feedback, written feedback and both oral and written feedback. This study found no differences in revisions on students' essays with regard to content, structure, grammar, or style among the treatment groups. The study concluded that students' revisions were not dependent on the type of feedback they had received.

As illustrated by the studies discussed, the literature on instructor-student conferences focuses on their effectiveness on the quality of revisions students make. Little is known, however, on the effect of the frequency of instructor conferences. Lerner (2005) observed, “For much of this history, the issue hasn’t been so much whether or not to use conferencing, but how to teach with regular conferencing” (p. 186). Little is also known about the effectiveness of student-initiated conferences when students seek help from their instructor.

\section{The Writing Center}

\section{History of the Writing Center}

Carino (1995) has traced the history of the writing center to the early 1900s and the development of writing laboratories. Writing laboratories originated in the highschool classroom, where the instructor would engage in individualized tutoring during class time. Separate writing labs were established at public colleges during the 1930s, primarily in response to an influx of students. A large number of these students were the children of immigrants, and were viewed as inadequately prepared for college work. By the 1940s writing labs were established in higher education, and expanded further with the arrival of military officers seeking intensive training in English. By the 1950s writing

labs or clinics had become part of many college writing programs. Writing labs and 
centers continued to increase during the 1960s in response to open admissions policies in higher education.

Haswell (2008) has discussed the evolution of the writing center from a place where remedial writing students were "sentenced" by their instructors to correct their writing to the present, where students at all levels of writing proficiency can consult with tutors. Today, writing centers are generally staffed by undergraduate and graduate tutors who assist students at various stages of their writing.

Despite the evolution of the writing center from a place of remediation, Rendleman (2013) observed that the practice of mandatory writing center visits remains a cause for concern among those who oppose this policy. Those who oppose the practice have argued that writing center visits would be more beneficial to students if the source of their motivation were intrinsic rather than extrinsic. According to Rendleman, mandatory writing center visits may result in students resisting these visits, developing negative attitudes toward writing centers, and ineffective sessions.

\section{Frequency of Writing Center Visits and Writing Performance}

Research on writing center visitation as a form of adaptive help-seeking is sparse (Williams \& Takaku, 2011). Rendleman (2013) made a similar observation in noting the lack of major scholarly reviews on writing center visitation. Rendleman further noted that the literature consists of empirical studies as well as theoretical articles, and articles of a more anecdotal nature. As Williams and Takaku have noted,

Writing centers ... appear to offer a rich source of information related not only to writing performance but also to help seeking and self-efficacy. Nevertheless, empirical research investigating writing center visitation as a manifestation of adaptive help seeking and self-efficacy is notably absent. (p. 4) 
Following is a discussion of the literature relevant to writing center visitation and its influence on students’ writing performance. Williams, Takaku, and Bauman (2006) conducted a four-year longitudinal study of 256 undergraduate ESL students to investigate the extent to which students' frequency of writing center use predicted their grades in their first and third year writing courses. The researchers hypothesized that highly self-regulated students would visit the writing center more frequently, and would obtain higher grades in their courses than those who did not. The results of the multiple regression analyses indicate that was a correlation between students SAT reading score and the frequency of writing center visits $(\beta=.23, p<.05)$.

Students who received lower scores on the SAT reading section tended to visit the writing center more frequently. Also, students’ grades in first-year composition were found to be predicted by the frequency with which they visited the writing center $(\beta=$ .34, $p<.05$.). Similarly, students' grades in their junior-level composition class were also predicted by the number of writing center visits $(\beta=.53, p<.05)$. In this study, the more frequently students visited the writing center, the better the grades they obtained in their first- and third-year composition courses.

Williams and Takaku (2011) investigated the relationship between help-seeking, self-efficacy, the number of writing center visits and the writing performance of 671 students from 6 undergraduate cohorts. The researchers hypothesized that the frequency of writing center visits would mediate students' self-efficacy, which would in turn influence their writing performance. The study found that frequency of writing center visits was a significant predictor of students' grades $(\beta=.26, p<.001)$. Frequency of 
writing center visits was also found to mediate the relationship between writing selfefficacy and course grades.

In another study entitled Gender, Writing Self-Efficacy and Help-Seeking, Williams and Takaku (2011) reported that writing center visits significantly predicted students' grades $(\beta=.19, p<.001)$. Students who had more frequent visits tended to have higher grades.

Grinnell (2003) conducted a quasi-experimental study of 202 students enrolled in 10 sections of a pre-Freshman Composition class. The purpose of the study was to investigate the effectiveness of two instructional methods used in a university writing center, one-on-one tutoring, and computer-assisted tutoring using the PLATO method, on students’ writing apprehension and writing performance. Students were randomly assigned to two treatment groups and a control group. Participants in the treatment groups received either one-on-one tutoring or computer-assisted tutoring. The participants in the control group received no tutoring. It was hypothesized that students who attended the writing center for one hour or more every week would have improved writing performance. The results of the between subjects MANCOVA indicate that there were significant group differences between the control group $(M=120,16)$ and those who had received one-on-one tutoring at the writing center ( $M=130.93)$.

\section{Time on Task and Writing Performance}

Astin (1999) presented a theory of involvement, in which he defined involvement as "the amount of physical and psychological energy that the student devotes to the academic experience” (p. 518). Astin also stated that involvement can be measured in quantitative terms by the number of hours students spend studying or time on task. Astin 
views student involvement as closely resembling the psychological construct of motivation, but considers it to be the "behavioral manifestation" of the psychological state of being motivated.

Several national evaluation studies have reported on student engagement both at four-year colleges and universities (e.g. Arum \& Roska, 2011; Astin, 1993) and at community colleges (Center for Community College Student Engagement, 2015; McClenney \& Marti, 2006). In Arum and Roska’s (2011) study, students reported spending an average of 12 hours every week studying and completing course assignments. $37 \%$ of students surveyed reported spending less than 5 hours every week working on course assignments. This study did not report on the relationship that was found between time on task and students' academic performance.

McClenney and Marti (2006) report entitled Exploring Relationships between Student Engagement and Student Outcomes in Community Colleges summarized the results of data collected from 9,725 students in 3 separate studies. The purpose of the study was to investigate the nature and extent of the relationship between student engagement, persistence into the second term or second year, active and collaborative learning, and academic achievement as measured by student GPA and credit completion. The study found that student engagement was highly correlated with persistence and had "some effect" on academic performance. Student effort as measured by the time spent reading, taking notes, class attendance, revising assignments through multiple drafts. Very little correlation between student effort and GPA for the Achieving the Dream study $\left(\mathrm{r}=.059^{*}\right)$, the HSS study $\left(\mathrm{r}=.119^{* *}\right)$, and the Florida study $\left(\mathrm{r}=.044^{*}\right)$. 


\title{
Environmental Factors and Writing Performance
}

\author{
Introduction
}

It is also important to examine the role of environmental factors on the attainment of writing outcomes in the college writing classroom. This section will discuss literature relative to the role of gender, ethnicity, language background and socioeconomic status on students' writing performance.

\section{Gender and Writing Performance}

Meier, McCarthy \& Schmeck (1984) found significant gender differences in writing performance during phase 1 of their study. Females tended to have better writing skills than males.

Pajares and Johnson (1994) found no significant gender effects with regard to previous writing achievement or writing performance. However, girls scored lower than boys on the writing self-efficacy scale.

Williams \& Takaku (2011) studied gender, writing self-efficacy, and help-seeking behaviors in undergraduate students. Gender differences were found in writing performance. Females had higher grades than males $(\beta=.11, p<.001)$.

Arum and Roska (2011) found no gender differences in the results of the Collegiate Learning Assessment (2005, 2007). Male and female students demonstrated similar performance on measures of critical thinking, complex reasoning, and writing skill.

Villalon, Mateos and Cuevas (2013) investigated the nature of the relationship between gender, writing conceptions, writing self-efficacy and writing performance among 111 tenth-grade students at a Madrid public school. The researchers hypothesized 
that there would be no gender differences in writing self-efficacy beliefs. They also hypothesized that girls would differ in their conception of writing, and that girls would outperform boys on a writing task. The study reported gender differences in the way in which boys and girls conceived writing. Girls demonstrated greater sophistication in the way they conceived of writing than boys. The study did not find gender differences in writing self-efficacy. Girls also performed better on the writing task than boys.

\section{Language Background and Writing Performance}

The Conference on College Composition and Communication (2009) Statement on Second Language Writing and Writers has recognized that there is an increasing diversity in college and university classrooms in the United States. The statement describes several of the challenges some students with different language backgrounds may face when they integrate the mainstream writing classroom: "Some students may have difficulty adapting to and adopting North American discursive strategies because the nature and function of discourse, audience, and rhetorical appeals often differ across cultural, national, linguistic, and educational contexts” (para. 2). The CCCC also recognized the presence of bilingual students who grew up speaking other languages in their home, community, and school environments.

Doolan (2013) compared the linguistic features of three groups of students in first-year composition classes: Generation 1.5 students, or U.S educated students who speak a non-English language at home, L1 or students whose first language is English, and L2 or ESL students. The purpose of this study was to determine whether the writing of Generation 1.5 students differed from that of their L1 and L2 peers. 237 writing samples were analyzed for errors, holistic quality, and language development. The study 
found significant differences in holistic quality among Generation 1.5 students ( $M=7.39$, $\mathrm{SD}=1.84)$, L1 students $(\mathrm{M}=8.02, \mathrm{SD}=1.96)$ and $\mathrm{L} 2$ students $(\mathrm{M}=5.59, \mathrm{SD}=1.79)$. No significant differences in error patterns were found between Generation 1.5 and L1 students. Significant differences in error patterns were found among L1 and L2 students. No differences were found for linguistic quality when Generation 1.5 and L1 students were compared. The most significant differences were found between Generation 1.5 and L2 students and L1 and L2 students.

Doolan's (2014) study of 149 Generation 1.5 students, 201 L1 students and 55 L2 students found similar results. Significant differences were found between Generation 1.5 students and L2 students with regard to holistic quality, errors, and linguistic development. There were also significant differences between Generation 1.5 students and L1 students with regard to academic language use. The study concluded that the writing of these two groups may share more similarities than previous research might have indicated.

Williams \& Takaku (2011) study found that international non- native English speaking students had lower writing self-efficacy than their native English speaking counterparts, sought help more frequently, and had better writing performance in terms of grades. Arum and Roska (2011) found that students who spoke a language other than English had only slightly lower performance than native English speaking students on the Collegiate Learning Assessment in terms of their critical thinking, complex reasoning, and writing skills.

Di Gennaro’s (2009) study Investigating Differences in the Writing Performance of International and Generation 1.5 students aimed to find evidence of difference in the 
writing of these two groups of students. Three raters analyzed writing samples from 97 undergraduate students for differences in grammar usage, rhetorical control, cohesiveness, essay length, and sociolinguistic and content control. Results indicate that generation 1.5 students had greater rhetorical control in areas such as organization. No differences were found in their use of grammar or cohesiveness. Generation 1.5 students wrote longer essays but had difficulty with content control.

\section{Socioeconomic Status}

\section{Definition and Measurement of Socioeconomic Status}

Socioeconomic status has been described as "probably the most used contextual variable in education research” (Sirin 2005, p. 417). However, there has been a lack of consensus among social science researchers regarding its conceptual definition. As Bradley and Corwyn (2002) have observed, "There has been something of a tug-of-war between proponents of SES as representing class (or economic position) and proponents of SES as representing social status (or prestige)” (p. 372). Bradley and Corwyn further observe that Coleman's (1988) concept of capital, which consists of both resources and assets, has gained wider acceptance among social scientists as a conceptual definition of socioeconomic status. Bradley and Corwyn have explained this acceptance as follows:

Capital (resources, assets) has become a favored way of thinking about SES because access to financial capital (material resources), human capital (nonmaterial resources such as education), and social capital (resources achieved through social connections) are readily connectible to processes that directly affect well-being. (p. 372)

\section{Measuring Socioeconomic Status}

Bradley and Corwyn (2002) have noted that the manner in which socioeconomic status is measured is determined by the population being investigated, the data collection 
method, and research question. Socio-economic status has been operationalized in the literature in various ways. One of the most common measures consists of three indicators: parents' income, level of education, and occupation. Parents' income indicates the economic and social resources to which the student has access. Parents' education itself indicates parental income. Occupation is categorized based on the level of education needed for a specific type of employment (Sirin, 2005, p. 419).

However, Wardle, Robb, and Johnson (2001) have pointed to low response rates and higher incidence of missing and invalid data among adolescents in surveys collecting data on parents' characteristics. Wardle et al. observe, “One approach is to utilize other information on household circumstances as a basis for deriving SES. There has been an increasing use of material indicators of socioeconomic deprivation, such as car ownership and housing tenure...(p. 595).

Some studies have measured socioeconomic status using two indicators. Some studies have used parents' education and educational materials in the home (e.g. Willens, 1981), parental education and income (e.g. Davis, 2008), or parental education and occupation (e.g. Arum and Roska, 2011; Grbic, Jones, and Case, 2013).

Other studies have used financial aid awards as a single indicator of socioeconomic status. Cutolo (2007) used Federal Pell Grants and the Tuition Assistance Program (TAP) from the state of New York. The use of Pell Grants as an indicator of socioeconomic status has also been recommended by Gribic, Jones and Case (2013) and Borman, Halperin, and Tyson (2010). Borman et al. have noted, "Because Pell Grants are based on economic need, they can serve as a proxy indicator of socioeconomic status” (p. 
150). Bandura, Barbaranelli, Caprara, and Pastorelli (1996) used one indicator - father's occupation, although they also reported the mother's occupation.

Sirin’s (2005) meta-analysis of studies, conducted between 1990 and 2000, found that among four indicators of socioeconomic status - parental education, parental occupation, parental income, and eligibility for free or reduced-lunch programs - the most commonly used indicator was parental education $(k=30)$.

Grbic, Jones, and Case (2013) have suggested that the criteria used to determine which indicators should be used as a reliable measure of socioeconomic status should include intuitiveness, validity of the concept being investigated, accuracy, ease of collection, and long-term stability. Grbic et al. (2013) have also observed that although personal or family income have been widely used as an indicator of socioeconomic status, that it is not an adequate measure. The authors have provided several reasons for this. Students may be unwilling to provide this information due to considerations of confidentiality. Also, they may be unable to provide this information due to a lack of knowledge. Thirdly, family income may fluctuate over time. Grbic et al. recommend using education and occupation as a more reliable measure of socioeconomic status, as these do not fluctuate to the extent that income might.

In conclusion, the American Psychological Association has cautioned against developing a composite measure of socioeconomic status. Rather, investigating the contribution of individual indicators to a particular phenomenon is preferable to merging measures (APA Task Force, 2006). 


\section{Socioeconomic Status and Academic Achievement}

Sirin (2005) conducted a meta-analysis of 207 studies published between 1990 and 2000. The purpose of the study was to investigate the extent of the relationship between socioeconomic status and academic achievement, to evaluate the degree to which the relationship was impacted by the methodologies used and student characteristics, and to replicate White’s (1982) meta-analysis using more recent data. The results indicated a moderate to correlation (.299) between socioeconomic status and academic performance.

A significant finding of this study was that students' family SES showed one of the highest correlations with academic achievement. The study also found that the relationship between SES and academic achievement was influenced by factors such as the measure of SES or achievement used, students’ grade level, status as an ethnic minority, and school location. The results indicate that the strength of the relationship between SES and achievement was modified, with lower correlations obtained when neighborhood characteristics were used to indicate family SES than when home resources were used. The study also found that SES more strongly predicted achievement among white students than among minorities. The study found indicators such as parents’ income, occupation, or education to be "less predictive" of academic achievement for minority students (p. 439).

Based on the findings of this study Sirin (2005) recommended that in operationalizing SES, researchers should examine four factors: “(a) the unit of analysis for SES data; (b) the type of measure used; (c) the range of the SES variable; (d) the source of SES data” (p. 439). 
Several previous studies have investigated the influence of socioeconomic status on student achievement at the elementary level (e.g. Bandura, Barbaranelli, Caprara \& Pastorelli, 1996) and undergraduate level (e.g. Astin, 1993). Bandura et al. found an indirect link between family socioeconomic status and children's academic achievement. Family socioeconomic status was found to influence children's academic achievement through its effect on their parents' academic aspirations and children's prosocial behavior.

Astin’s (1993) landmark evaluation study of undergraduates, entitled What Matters in College? Four Critical Years Revisited investigated the effect of college environments on various college outcomes. The study found socioeconomic status to most strongly influence students' completing the bachelor's degree. SES was found to impact GPA and students’ pursuit of graduate education. Participants also reported improvement in their ability to think critically, analyze and solve problems, knowledge of their area of study and general academic progress. The study concluded that higher SES students could anticipate "more positive outcomes in college, regardless of their abilities, academic preparation, and other characteristics” (p. 6).

Dubow, Boxer and Huesmann (2009) conducted a longitudinal study of participants interviewed at ages 8, 19, 30, 48. Parents' educational level indirectly predicted participants' educational level and professional prestige at age 48. Educational aspirations and educational level at age 19 mediated participants’ educational level and professional prestige at age 48 .

In Hahs-Vaughn’s (2004) study, path coefficients indicated that college experiences more strongly predicted the educational outcomes of first-generation students 
( $\beta=.42)$ than pre-collegiate traits $(\beta=.28)$. College experiences consisted of nonacademic experiences, academic experiences and intensity of enrollment. Pre-collegiate traits consisted of father and mother's education, expected highest education level, and entrance exam scores. Educational outcomes consisted of degree obtained, cumulative GPA, and aspirations for education.

\section{Socioeconomic Status and Writing Achievement}

Only a few older studies were located that have investigated socioeconomic status in relation to writing achievement in higher education (e.g. Kirschner and Poteet, 1973; Shaugnessy, 1977; Willens, 1981). Overall, these studies have found that students' use of non-standard English forms was related to their socioeconomic status.

Commenting on the dearth of studies that have included socioeconomic status as a factor in students' writing performance, Pajares and Johnson (1996) observed, "Variables such as socioeconomic status (SES) would have been strong predictors of academic performance and would have provided a strong control for the influence of self-efficacy ... and we recommend that subsequent studies include it” (p. 173). Pajares’ and Johnson's recommendation seems to have gone unheeded, as only one recent study was found which has included socioeconomic status as a factor in students’ writing performance.

Arum and Roska’s (2011) national evaluation study used parental education and parental occupation as indicators of socioeconomic status. This study found that parents who had graduate or professional degrees outperformed their peers by a 60-point margin on the 2007 Collegiate Learning Assessment test. 
According to the ACT annual report entitled First-Generation Students: The Condition of College and Career Readiness 2014, 42\% of students whose parents had not attended college met the ACT benchmark in English compared to $60 \%$ for students whose parents had attended some college, $76 \%$ for students whose parents had bachelor's degrees, and $86 \%$ for students whose parents had graduate degrees. 


\section{CHAPTER 3}

\section{RESEARCH METHODOLOGY}

\section{Introduction}

The primary purpose of the study was to test a theoretical model of the influence of personal, behavioral, and environmental factors on the writing performance of firstyear community college students by examining the relationships among the three latent variables specified in the model, as well as their contribution in predicting the independent variable. This chapter presents the research methodology consisting of (a) the research design, (b) population and sample, (c) hypotheses, (d) variable definitions, (e) instrumentation (f) data collection procedures (g) data analysis procedures.

\section{Research Design}

\section{Description of the Quantitative Approach}

The research design for the study is quantitative. According to Kraska (2010), the underlying philosophical worldview of quantitative research design is positivism. The positivist approach to research assumes the use of objective, scientific methods to gain knowledge. The scientific method requires the use of measurement, and an empirical or scientific basis for carrying out research on populations and samples. The scientific method involves the formulation of hypotheses, and the collection of observable and quantifiable data. In addition, hypotheses are tested following mathematical procedures and statistical analyses. 
Creswell (2009) recommends using a quantitative approach to address research problems which require "(a) identification of factors that influence an outcome, (b) the utility of an intervention, or (c) understanding the best predictors of outcomes” or testing a theory (p. 18). In this study, the research problem requires the identification of factors that influence students' writing performance, an understanding of which of these factors best predict writing performance, and the testing of a theoretical model, thereby justifying the use of a quantitative approach.

\section{Design of the Study}

This study used a non-experimental, correlational, cross-sectional, ex post facto survey research design. This study is non-experimental, in that it relies on measurement, and does not involve the intervention of the researcher. Non-experimental designs are aimed at examining variation among the participants in the sample. Non-experimental designs allow for the investigation of the relationships among variables. McMillan and Schumacher (2010) have provided several reasons which establish the importance of relationships in educational research. Relationships enable the researcher to "make a preliminary identification of possible causes of important educational outcomes... identify variables that need further investigation...predict one variable from another” (p. 222).

This study is also correlational. According to Creswell (2012) a correlational design is appropriate if the goal of the research is to relate two or more variables to examine their influence on each other. Creswell has identified two types of correlational designs: Those which are useful in predicting outcomes or prediction design, and those used to explain relationships among variables or explanatory design. This study will use 
an explanatory research design. An explanatory research design is used to "explain the association between or among variables” (p. 341).

Creswell (2012) has identified two types of survey designs: cross-sectional and longitudinal. This study will use a cross-sectional survey design, as data will be collected at one point in time. According to Creswell, cross-sectional survey designs are useful in collecting data relative to “current attitudes, opinions, or beliefs” (p. 377).

Ex post facto designs are used "to investigate whether one or more pre-existing conditions have possibly caused subsequent differences in the groups of subjects” (McMillan \& Schumacher, 2010). This study will examine the possible influence of students’ previous writing achievement on their subsequent writing performance.

\section{Population and Sample}

The target population for this study consisted of 233 students enrolled in 14 sections of English Composition at a two-year community college in Michigan. Convenience sampling was used in this study. Fink (2003) has defined a convenience sample as "a group of individuals who are ready and available" (p. 41). Convenience sampling was used based on the results obtained on the ACT English test in the state of Michigan over the past five years, which were below the national average. A census was conducted among all 233 students currently enrolled in English Composition at the two campuses of the same institution. Students were invited to participate on condition that they were 18 years or older. The sample consisted of 147 participants, based on the number of students present when the survey was administered. After the data were cleaned, the final sample consisted of 125 participants. 


\section{Research Hypothesis}

The research hypothesis will test whether the theoretical model of writing performance is supported by the empirical data, and is presented below:

Hypothesis: The theoretical covariance matrix equals the observed covariance matrix.

The theoretical model suggests bivariate correlations among the latent variables Personal Factors (PF), Environmental Factors (EF), and Behavioral Factors (BF), and direct causal relationships between the latent variables and the dependent variable Writing Performance (WP): The theoretical model represents three proposed bivariate correlations and three predictors as it is in a multiple linear regression.

\section{Definition of Variables}

The conceptual, instrumental, and operational definition of the variables that were included in this study are outlined below. These variables consist of one demographic variable, eleven independent variables, and one dependent variable. Appendix E includes a table of specifications listing the variables and their definitions.

\section{Participant ID Number (ID)}

Participant ID number (ID) is conceptually defined as the researcher-assigned number used to identify each questionnaire collected from student participants. It is operationally defined as consecutive Arabic numerals. This variable will be entered as categorical data, and is used to organize the data. 


\section{Previous Writing Achievement (PWA_ACTz)}

Following the work of Zimmerman \& Bandura (1994), Previous Writing Achievement (PWA), is conceptually defined as ACT English, ACT COMPASS Writing Skills Placement Test scores, and SAT verbal scores. The rationale for using these three standardized tests as measures of previous writing achievement was determined by the current placement practices of the participating educational institution, which accepts

scores from all three standardized tests. Students are placed in regular sections of English Composition if they obtain minimum scores of 18 on the ACT English test, 70 on the ACT COMPASS, and 470 on the SAT verbal test.

The ACT verbal aptitude score is instrumentally defined as consisting of 75 multiple choice questions. The maximum score possible to be obtained on the ACT English Test is 36. This variable is operationally defined as Arabic numerals and was entered as continuous data.

The ACT COMPASS Writing Skills Placement Test is instrumentally defined as multiple choice questions which test students' ability to identify and correct errors in sentences and paragraphs in eight areas. The ACT COMPASS Writing Skills Placement Test is scored on a scale from zero to 100.

The SAT verbal score is instrumentally defined as 25 sentence improvement questions, 18 error identification questions, 6 paragraph improvement questions, and 1 essay. Possible scores range from 200 to 800. Sample questions could not be obtained since the researcher did not have access to the instruments. 


\section{Writing Self-Regulatory Efficacy (WSRE)}

In this study, following the work of Zimmerman and Bandura (1994), Writing Self-Regulatory Efficacy (WSRE) is conceptually defined as "perceived capability (a) to execute strategic aspects of the writing process such as planning, organizing, and revising compositions; (b) to realize the creative aspects of writing such as generating good topics, writing interesting introductions and overviews; (c) to execute behavioral selfmanagement of time, motivation, and competing alternative activities” (p. 849). This concept will be operationalized using the scores of Zimmerman \& Bandura’s (1994) Writing Self-Regulatory Efficacy Scale. A summation of all the items yields possible scores from 25 to 175 . Higher numbers indicate higher writing self-regulatory efficacy. This variable was entered as continuous data.

\section{Self-Efficacy for Writing Tasks (SEFWT)}

Following the work of Pajares, Hartley \& Valiante (2001), Self-Efficacy for Writing Tasks (SEFWT) is conceptually defined as students' “judgments of their capability to successfully perform various writing skills appropriate to their academic level” (p. 214). This construct will be operationalized using the scores of Jones (2008) Writing Tasks Scale. A summation of all the items yields possible scores from 8 to 48 . Higher numbers indicate higher writing efficacy. This variable was entered as continuous data.

\section{Frequency of Writing Center Visits (FWCV)}

Following the work of Williams \& Takaku (2011), the variable Frequency of Writing Center Visits (FWCV), is conceptually defined as cumulative writing center visits. It is instrumentally defined as "How many times did you go the writing center this 
semester?” It is operationally defined as Arabic numerals. This variable was entered as continuous data.

\section{Frequency of Instructor-Student Conferences (FISC)}

The variable Frequency of Instructor-Student Conferences (FISC) is conceptually defined as cumulative instructor-student conferences. It is instrumentally defined as "How many times did you meet with your instructor to discuss your writing assignments this semester?” This variable is operationally defined as Arabic numerals and was entered as continuous data.

\section{Time on Task (TOT)}

The variable Time-on-Task (TOT) is conceptually defined as the number of hours spent writing outside of the classroom every week. Following the work of Wagner and Schober (2014), it is instrumentally defined as "How many hours did you spend on average per week working on your writing assignments this semester?” This variable is operationally defined as Arabic numerals. It was entered as an ordinal scale ( $1=$ less than one hour, 5 = more than 10 hours).

\section{Gender (GEN)}

Gender (GEN), conceptually defined as an indication of students' male or female gender. It is operationally defined as a dummy variable with values of "0" indicating female gender, and “ 1 ” indicating male gender. This variable was entered as categorical data. 


\section{Language Background (LB)}

Language background (LB), conceptually defined as whether or not a student speaks a first language other than English. It is instrumentally defined as "Is English your first language?” It is operationally defined as a dummy variable as follows: A response of “No” will be assigned a " 0 ”. This indicates that the student's first language is not English. A response of “Yes” will be assigned a “ 1 ”. This indicates that the student's first language is English. This variable was entered as categorical data.

\section{Socioeconomic Status (SES_EDL)}

Socioeconomic status (SES), conceptually defined in this study as "the social standing or class of an individual or group” (American Psychological Association, Children, Youth, Families and Socioeconomic Status section, para. 1) and “differential access (realized and potential) to desired resources” (Oakes \& Rossi, 2003, p. 775). One of two indicators of socioeconomic status used by Arum and Roska (2011) were used in this study: Education Level of Head of Household (SES_EDL).

Education Level of Head of Household is conceptually defined as defined as the highest level of educational attainment of the head of household. It is instrumentally defined as "How much education has the head of household completed?" This variable is operationally following the categories used by the National Center for Education Statistics: “1” Some high school, “2” High School Graduate, “3” Some college, “4” 2 year associate degree, “5” 4 year bachelor’s degree, “6” Master’s degree, “7” Doctorate.

\section{Writing Performance (WP)}

Following the work of Prat-Sala (2012), Writing Performance (WP), is conceptually defined as the grades students obtained on their final persuasive research 
paper. This 4 to 6 page paper is one of three major writing assignments, which, together, contribute $40 \%$ toward the final course grade. Essays were evaluated by the course instructors. Writing performance is instrumentally defined as secondary data obtained from instructors. It is operationally defined as grades on a 12-point scale, as indicated in the course syllabus as follows: $0-59.9=1 ; 60-63.3=2 ; 63.4-66.7=3 ; 66.8-69.9=4$; $70-73.3=5 ; 73.4-76.7=5 ; 76.8-79.9=7 ; 80-83.3=8 ; 83.4-86.7=9 ; 86.8-89.9=10 ; 90-$ $93.3=11 ; 93.4-100=12$.

\section{Instrumentation}

Instrumentation for this study consisted of three questionnaires: The Writing Survey (TWS), developed by Zimmerman and Bandura (1994), Jones (2008) Writing Tasks Scale (WTS), and three researcher-developed measures, The Student Information Form (SIF), and two survey record reviews, the Previous Writing Achievement Spreadsheet (PWAS), and the Writing Performance Spreadsheet (WPS). Appendix A includes a sample of the instruments that will be administered to participants.

\section{Instrument 1: The Writing Survey (TWS)}

The Writing Survey or Writing Self-Regulatory Efficacy Scale (Zimmerman \& Bandura, 1994) is a two-page questionnaire composed of 25 items which were designed to measure the variable writing self-regulatory efficacy, or students' belief in their ability to regulate their writing. A sample item is "When I have a pressing deadline on a paper, I can manage my time efficiently” in a positive direction. A seven- score Likert-type scale (Not well at all to Very well) is used to answer the items. The coefficient from the Cronbach reliability test was .91. 
Instrument 2: The Writing Tasks Scale (TWTS)

The Writing Tasks Scale, developed by Jones (2008), is one-page questionnaire composed of 8 items which were designed to measure the variable writing self-efficacy, or their perceived confidence in their ability to accomplish academic writing tasks. A sample item is, "Write a persuasive essay that incorporates text sources representing points of view different from yours” in a positive direction. A six-score Likert-type scale on a continuum (No chance to Completely certain), is used to answer the items. Jones (2008) reported the Cronbach reliability coefficient for this scale as .94.

Instrument 3: Student Information Form (SIF)

The researcher-developed Student Information Form (SIF) consists of 9 items and includes 9 variables: Participant ID (PID), Gender (GEN), Ethnicity (ETH), Language Background (LB), Socioeconomic status consisting of two separately measured variables: Education Level of the head of household (EDL) and Occupation of Head of Household $(\mathrm{OHH})$, Frequency of Writing Center Visits (FWC), Frequency of Instructor-Student Conferences (FIS), Time-on-task (TOT). A sample item is, "Is English your first language"?

Instrument 4: Structured Record Review

\section{Previous Writing Achievement Form (PWAF)}

The Previous Writing Achievement Form contains two columns: One for students’ name, and the other for their ACT scores.

\section{Writing Performance Form (WPF)}

This spreadsheet contains two columns: One for students' name, and a split column for the letter grade and numerical grade obtained on the research paper. 


\title{
Data Collection Procedures
}

\author{
The Use of the Survey Method
}

The aim of survey research is to make generalizations from a sample to a population (Babbie, 1990, as cited in Creswell, 2009). Fink (2003) has defined a survey as "a system for collecting information from or about people to describe, compare, or explain their knowledge, attitudes, and behavior” (p. 1). Data for this study was collected using self-administered questionnaires and structured record reviews. In a selfadministered questionnaire, respondents fill out the questionnaire independently. A structured record review is a form that is designed to aid in the collection of data from financial, medical, or academic records (Fink, 2003). Data from the survey were collected in two phases during the spring semester of 2015.

\section{Research Involving Human Subjects}

Before collecting data for the study, permission was granted from the Institutional Review Boards of the researcher's home institution and from the community college where the study was conducted (Appendix D).

The cooperation of the department chair of the host institution was solicited in order to facilitate access to instructors and students. Questionnaires were completed during regular class time. After obtaining permission from the participating community college and the Andrews University Institutional Review Board, a recruitment email (Appendix D) was sent to students soliciting their participation. Participants were given the opportunity to read the informed consent form (Appendix C) and ask questions before the questionnaires were administered. Participants were also informed that their participation was voluntary, and that they could withdraw from the study at any time. 


\section{Phase 1: Administration of Surveys}

During the first phase, participants completed three survey instruments over a two-week period from April 6 to April 21, 2015. Three questionnaires were administered: The Writing Survey (TWS), developed by Zimmerman and Bandura (1994), Jones (2008) Writing Tasks Scale (WTS), and the researcher-developed Student Information Form (SIF). Institutional approval was obtained for the questionnaires to be administered during regular class time (See Appendix A for a sample of the research instruments). 233 students received an e-mail inviting them to participate in the study. A recruitment email (Appendix D) was forwarded to students with the collaboration of the Director of the Office of Institutional Research.

Instructor e-mails were obtained from the Communications Department chairperson. The researcher then contacted each instructor to set up appointments for class visits for the purpose of data collection. The researcher visited all 14 sections of English Composition, and administered the questionnaire over a two-week period at the end of the 2015 spring semester.

The researcher was responsible for collecting the data, and for protecting and securing it. Participants were asked to include their names on the questionnaires in order to correlate them with their ACT scores and final exam grades which were collected during phase 2. Only the researcher had access to the completed questionnaires, which were immediately placed into a sealed envelope on completion.

Confidentiality was maintained by coding respondents into the database using their researcher-assigned ID numbers. Participants’ names were erased from the questionnaires and no personal identifiers were entered into the database. The researcher 
maintained a separate document linking respondents’ ID with their names. Only the researcher had access to this document, which was stored in a secure storage area in the researcher’s office. A copy was also stored on the researcher’s password-protected computer.

\section{Phase 2: Administration of Structured Record Reviews}

Phase 2 was conducted over a four-week period during the months of May and June, 2015. Two Excel spreadsheets, the Previous Writing Achievement Form (PWAF) and the Writing Performance Form (WPF) were used to collect data relative to students' previous writing achievement and their performance on the final persuasive essay. ACT English, ACT COMPASS Writing Skills Placement Test, and SAT Writing scores were obtained from the director of the Office of Institutional Research of the participating institution. Grades on the final persuasive essay were obtained from the chairperson of the Department of Communications.

\section{Data Analysis Procedures}

This section describes steps that were taken to prepare the data for analysis. This section also provides a rationale for using data analysis procedures to answer the research questions.

\section{Data Entry}

Variables were named and defined before the data were entered into the Statistical Package for the Social Sciences (IBM SPSS 22) data editor. Scores for each item on the three instruments (The Writing Survey, Writing Tasks Scale, Student Information Form) used in the study were scanned using Scantron form recognition software. Data relative 
to students’ previous writing achievement and writing performance were entered manually into SPSS.

\section{Data Cleaning}

Since values entered into the SPSS data file were transcribed, the data were cleaned in order to ensure that the values are within the boundaries of what would be reasonably expected. Following the recommendations of Meyer et al. (2013), consistency checks were performed to verify the reliability of data collected. Suspect or erroneous data were verified and corrected using the raw scores from the responses to the original items on the questionnaires and spreadsheets. Meyer et al. also recommend using frequency tables in SPSS to identify erroneous or missing data. Frequency tables were then generated to assist in identifying erroneous or missing data. 18 cases with missing data were identified. The decision was made to delete these cases. The final dataset consisted of 125 cases.

\section{Structural Equation Modeling}

\section{Rationale for the Use of Structural Equation Modeling (SEM)}

Structural equation modeling analysis (SEM) using IMB SPSS Amos 21 (Arbuckle, 2012) was used to test the hypothesis. As a data analysis procedure, SEM can be used to analyze both measurement and structural models. This study focused on analyzing the structural model, which can be analyzed independently from the measurement model (Meyers et al., 2013). The following criteria are generally used to

measure model fit (Myers et al., 2013): The chi-square $\left(\chi^{2}\right)$ likelihood ratio statistic, the 
goodness-of-fit index (GFI), the normed fit index (NFI), the comparative fit index (CFI), and the root mean square error of estimation (RMSEA).

The chi-square $\left(\chi^{2}\right)$ likelihood ratio statistics is the most important absolute fit index, and tests for the difference between the theoretical model and the empirical model (Meyers et al., 2013). A significant $\chi^{2}$ indicates that the theoretical model does not fit the empirical data, while a non-significant $\chi^{2}$ indicates a good fit. According to Schumacker and Lomax (2004), "the initial (full) model represents the null hypothesis $\left(H_{o}\right)$ " (p. 113).

The GFI shares conceptual similarities with the $R^{2}$ in multiple regression (Khine et al., 2013). It measures the comparative amount of variances and covariances accounted for by the model. Values equal to or greater than .90 indicate good model fit. The NFI analyzes the difference between the chi-square values of the hypothesized and null models. The target value for the NFI is .95 . The CFI analyzes differences between the empirical data and the theoretical model. A value of .95 indicates a good fit. The RMSEA measures approximation error between the observed covariance and the covariance of the hypothesized model (Meyers et al., 2013).

Structural equation modeling (SEM) is a statistical technique used for analyzing structural models which contain latent variables (Meyers, Gamst \& Guarino, 2013). Two types of models can be analyzed using SEM: a measurement model and a structural model. The measurement model evaluates the extent to which the predicted relationships among the variables is reflected in the relationships among the observed variables. The structural model measures the extent of the relationship among latent constructs as well as the relationship among other measured variables. If the data from the hypothesized model and observed models match, the structural equation model can be used to explain 
the hypothesized model. The nature of the research hypothesis provides the rationale for the use of structural equation modeling as a data analysis technique. This study focused on the structural model, and tested the validity of the hypothesized structural model compared to the observed model.

\section{Sample Size Recommendations for the Use of Structural Equation Modeling}

According to Khine et al. (2013), while sample size is a key consideration in SEM, and while there have been many propositions regarding sample size in the research literature, "no consensus has been reached among researchers at present" (p. 10). There is, however, some consensus that structural equation modeling is suitable for analyzing larger sample sizes (e.g. Kline, 2011; Schumacker \& Lomax, 2004), although fewer cases may be used in simpler models with fewer parameters (Kline 2011).

For normally distributed data, Loehlin (2004) has recommended sample sizes of a minimum of 100 cases. According to Loehlin, sample sizes of 100 are adequate in order to evaluate a model, although larger samples of 200 or more are essential for precise parameter estimates and standard errors. Larger sample sizes are also required in order to preserve statistical power (Schumacker \& Lomax, 2004). Sample size is also dependent on the size and characteristics of the model. Larger samples of 400 or more were at times necessary to obtain more precise results and greater accuracy. Sample sizes of between 100-150 respondents have also been recommended (e.g. Ding, Velicer, and Harlow, 1995, as cited in Kline et al., 2013; Schumacker \& Lomax, 2010). Minimum sample sizes of 100 have been recommended for models which contain five or fewer latent variables with three or more measurement variables (Hair, Black, Babin \& Anderson, 2009). 


\section{CHAPTER 4}

\section{RESULTS}

\section{Introduction}

The primary purpose of the study was to test a theoretical model of the influence of personal, behavioral, and environmental factors on the writing performance of firstyear community college students by examining the relationships among the three latent variables specified in the model, as well as their contribution in predicting the independent variable. This chapter reports on the response rate for the paper survey and structured record review, presents descriptive statistics of the sample and the variables used in the study, and presents inferential statistics which address the research hypothesis.

\section{Response Rate}

A total of 147 questionnaires were distributed in a census of all participating students present when the researcher visited each section of English Composition. 143 usable questionnaires were returned, which is a 97\% response rate. A structured record review form was also used to collect participants' scores on the ACT English test, COMPASS Writing Skills Placement Test, SAT Writing Test, and grades on their final persuasive essay. Standardized test scores were reported for 144 out of 147 participants, while grades on the final persuasive essay were reported for all of the participants. 


\section{Description of the Sample}

\section{Participants}

The sample consisted of first-year students from a small, rural, mid-western community college. Participants were enrolled in 14 sections of Freshman English II. Freshman English II is the one of three freshman English courses. Students were placed directly into Freshman English II if they obtained the benchmark score of 18 on the ACT English test, a minimum of 78 on the ACT COMPASS Writing Placement Test, or 470 on the SAT Writing test. A minimum grade of “C” in Freshman English I was also required as a prerequisite for this course. Three hours of instruction per week were provided. The course emphasized academic writing. Students were required to write three major argumentative essays, and were also introduced to college-level research. They were also required to obtain a minimum pass grade of “C” to transfer to Freshman English III.

\section{Descriptive Statistics}

Descriptive statistics were used to obtain a description of the sample. Table 1 shows the demographic characteristics of the participants $(n=125)$. Participants in the study were predominantly White non-Hispanic (66\%). There were more females (53\%) than males (47\%). 11 participants (9\%) reported speaking a first language other than English. The highest educational level reported for approximately one-third of the heads of household (35\%) was “Some college”, while 21\% were high-school graduates. 
Table 1

Demographic Characteristics $(N=125)$

\begin{tabular}{lrr}
\hline \multicolumn{1}{c}{ Variable } & $\mathrm{N}$ & $\%$ \\
\hline Gender & 59 & \\
Male & 66 & 57.2 \\
Female & & \\
\hline Ethnicity & 83 & 66.4 \\
White non-Hispanic & 2 & 1.6 \\
Am. Indian./Al. Native & 3 & 2.4 \\
Asian American & 17 & 13.6 \\
Black/Afr. American & 8 & 6.4 \\
Latino/Hispanic & 12 & 9.6 \\
Two or more & & \\
Language Background & 114 & 91.2 \\
English & 11 & 8.8 \\
Non-English & & \\
\hline Education Level of Head of & 10 & 8.0 \\
Household & 27 & 21.6 \\
Some high school & 44 & 35.2 \\
High school graduate & 16 & 12.8 \\
Some college & 13 & 10.4 \\
2 year associate degree & 11 & 8.8 \\
4 year bachelor's degree & 4 & 3.2 \\
Master's degree & & \\
Doctorate & & \\
& &
\end{tabular}

Note. $N=125 ; \%=100$

\section{Variable Description}

This section presents descriptive statistics of the personal and behavioral variables studied. Personal variables reported are Previous Writing Achievement (PWA_ACTz), Writing Self-Regulatory Efficacy (WSRE) and Self-Efficacy for Writing Tasks (SEFWT). Behavioral variables are Time on Task (TOT), Frequency of Writing Center Visits (FWCV), and Frequency of Instructor-Student Conferences (FISC). 


\section{Previous Writing Achievement}

During the process of data cleaning a new variable to measure previous writing achievement (PWA_ACTz) was created. This new variable was created by converting the raw scores from the ACT English test, the ACT COMPASS Writing Skills Placement Test, and SAT Writing test, into standardized, or z scores. According to Howell (2013), a $z$ score is a representation of the number of standard deviations from the mean. A positive z score denotes the number of standard deviations above the mean, while a negative $\mathrm{z}$ score denotes the number of standard deviations below the mean.

The following procedure was used to convert the ACT English, ACT COMPASS Writing Skills Placement Test and SAT scores into a single standardized score to measure previous writing achievement. SAT Writing scores were first converted into their ACT score equivalent using a concordance table published by the College Board (2009). Secondly, the means and standard deviations of the ACT English $(M=18.2, S D=$ 4.9), and COMPASS Writing Skills Placement Test $(M=69.9, S D=26.2)$ were obtained from a concordance table (Oakton Community College, 2010). The ACT English, converted SAT scores and ACT COMPASS scores were then converted into standardized z scores using the following formula:

$$
\begin{gathered}
X-\text { Mean } \\
Z=\text {---------------------- } \\
\text { Standard deviation }
\end{gathered}
$$

Previous writing achievement $z$ scores ranged from -1.82 to $2.61(M=.09, S D=$ $.16)$. Scores of $-.59, .16$, and .78 represent the $25^{\text {th }}, 50^{\text {th }}$, and $75^{\text {th }}$ percentile respectively. Possible $z$ scores ranged from -3.0 to +3.0 . 


\section{Writing Self-Regulatory Efficacy}

This section presents descriptive statistics of the items on the Writing Survey (Zimmerman \& Bandura, 1994). This scale measured participants' beliefs about their ability to regulate their writing activities and was measured on a 7-point Likert-type scale with responses ranging from "Not well at all" to "Very well".

Descriptive statistics for each item are shown in Table 2. Descriptive analysis of the writing self-regulatory efficacy scale yielded a mean of 116.78 and a standard deviation of 21.29. Mean scores ranged from 3.91 to 5.29. The lowest mean score ( $M=$ 3.91, $S D=1.73$ ) was obtained for item 8, "I can find a way to concentrate on my writing even when there are many distractions around me”. The highest mean score $(M=5.29$, $S D=1.18)$ was obtained for item 25 , "When my paper is written on a complicated topic, I can come up with a short, informative title”. Item 12, "I can rewrite my wordy or confusing sentences clearly", had a mean score of $5.10(S D=1.22)$. Item 13, "When I need to make a subtle or an abstract idea more imaginable, I can use words to create a vivid picture" obtained a mean score of $5.05(S D=1.43)$. A mean score of $5.03(S D=$ 1.37) was obtained for item 11, "I can come up with memorable examples quickly to illustrate an important point”.

These results suggest that students were least confident in their ability to focus on their writing when faced with distractions. The results also suggest that students were most confident in their ability to create titles for their essays, edit wordy or confusing sentences, illustrate their writing with effective examples, and create vivid word pictures. 
Table 2

Mean and Standard Deviation for Writing Self-Regulatory Efficacy $(N=125)$

\begin{tabular}{llll}
\hline No. & Item & $M$ & $S D$
\end{tabular}

1. When given a specific writing assignment, I can come up with a $\quad 4.94 \quad 1.36$ suitable topic in a short time.

$\begin{array}{lll}\text { 2. I can start writing with no difficulty. } & 4.46 & 1.44\end{array}$

$\begin{array}{lll}\text { 3. I can construct a good opening sentence quickly. } & 4.45 & 1.42\end{array}$

$\begin{array}{llll}\text { 4. I can come up with an unusual opening paragraph to capture } & 4.60 & 1.38\end{array}$ readers' attention.

5. I I can write a brief but informative overview that will prepare $\quad 4.57 \quad 1.12$ readers well for the main thesis of my paper.

$\begin{array}{llll}\text { 6. I can use my first attempts at writing to refine my ideas on a } & 4.98 & 1.17\end{array}$ topic.

7. I can adjust my style of writing to suit the needs of any audience. $\quad 4.74 \quad 1.36$

8. I can find a way to concentrate on my writing even when there $\quad 3.91 \quad 1.73$ are many distractions around me.

9. When I have a pressing deadline on a paper, I can manage my $\quad 4.54 \quad 1.60$ time efficiently.

10. I can meet the writing standards of an evaluator who is very $\quad 4.53 \quad 1.26$ demanding.

11. I can come up with memorable examples quickly to illustrate an $\quad 5.03 \quad 1.37$ important point.

12. I can rewrite my wordy or confusing sentences clearly. $\quad 5.10 \quad 1.22$

13. When I need to make a subtle or an abstract idea more $\quad 5.05 \quad 1.43$ imaginable, I can use words to create a vivid picture.

14. I can locate and use appropriate reference sources when I need to $4.76 \quad 1.40$ document an important point.

15. I can write very effective transitional sentences from one idea to $4.76 \quad 1.23$ another. 
Table 2 - Continued

Mean and Standard Deviation for Writing Self-Regulatory Efficacy $(N=125)$

\begin{tabular}{llll}
\hline No. & Item & $M$ & $S D$
\end{tabular}

16. I can refocus my concentration on writing when I am worried or $\quad 4.12 \quad 1.63$ find myself thinking about other things.

17. When I write on a lengthy topic, I can create a variety of good $\quad 4.32 \quad 1.31$ outlines for the main sections of my paper.

18. When I want to persuade a skeptical reader about a point, I can $\quad 4.71 \quad 1.44$ come up with a convincing quote from an authority.

19. When I get stuck writing a paper, I can find ways to overcome $\quad 4.90 \quad 1.35$ the problem.

20. I can find ways to motivate myself to write a paper even when the $4.36 \quad 1.62$ topic holds little interest for me.

21. When I have written a long or complex paper, I can write a good $\quad 4.64 \quad 1.41$ concluding section that ties all the parts together.

22. I can revise a first draft of any paper so that it is shorter and better $\quad 4.73 \quad 1.26$ organized.

23. When I edit a complex paper, I can find and correct all of my $\quad 4.30 \quad 1.57$ grammatical errors.

24. I can find other people who will give critical feedback on early $\quad 4.99 \quad 1.59$ drafts of my paper.

25. When my paper is written on a complicated topic, I can come up $\quad 5.29 \quad 1.18$ with a short, informative title.

Table 3 shows the mean and standard deviation of the items on the Writing Tasks scale (Jones, 2008). This 8-item scale measured students' confidence in their ability to accomplish writing tasks which are generally expected of first-year composition students. The items in this scale were measured on a 6-point Likert-type scale from "No chance" to 
“Completely certain”. Descriptive statistics for each item are shown in Table 3.

Descriptive analysis of the writing tasks scale yielded a mean of 35.49 and a standard deviation of 6.06. Mean scores ranged from 4.09 to 4.86. The lowest mean score was obtained for item 4, "Write an essay that provides a critique or analysis of another essay" $(M=4.09, S D=1.12)$. The highest mean score was obtained for item 1 , "Write a good paper for a professor in English” $(M=4.86, S D=1.02)$. These results indicate that students were least confident in their ability to engage in the task of critical analysis, but were confident in their overall ability to write good papers for their English courses.

\section{Table 3}

Mean and Standard Deviation for Self-Efficacy for Writing Tasks $(N=125)$

\begin{tabular}{llll}
\hline No. & Item & $M$ & $S D$
\end{tabular}

1. Write a good paper for a professor in English.

2. Write a good paper for a professor in any course.

3. Write an essay that develops an idea by making connections among a variety of textual sources.

4. Write an essay that provides a critique or analysis of another essay.

5. Write a persuasive essay that incorporates text sources representing points of view different from yours.

6. Write a summary of a long essay that effectively captures the essence of it.

7. Write an essay that persuasively analyzes the causes or effects of a particular event, concept, or belief.

8. Write an essay that compares and contrasts two authors, events, pieces of art, or concepts in order to reach a larger conclusion about that subject.
$4.86 \quad 1.02$

$4.54 \quad 0.97$

$4.24 \quad 0.97$

$4.09 \quad 1.12$

$4.50 \quad 1.13$

$4.43 \quad 1.07$

$4.61 \quad 0.98$

4.22 
Time on Task

Responses to the item, "How many hours on average per week did you spend working on your writing assignments outside of class this semester?” are presented in Table 4. More than a third of the respondents (39\%) reported spending on average between three to five hours per week writing outside of class. Approximately a third of the respondents (35\%) also reported that they spent between one to three hours on their writing assignments outside of regularly scheduled class time. Overall, the majority of the participants reported spending on average between 1 and 5 hours working on their assignments outside of class.

\section{Frequency of Writing Center Visits}

Table 4 shows the results of the responses to the item, "How many times did you go the writing center this semester?” 49 participants (39\%) reported that they had never visited the writing center during the semester, while 25 participants (20\%) reported one visit. The number of writing center visits for the remaining 51 participants (41\%) ranged from two to 50 .

\section{Frequency of Instructor-Student Conferences}

In response to the item, "How many times did you meet with your instructor to discuss your writing assignments this semester?” approximately a third of the participants (34\%) reported that they had not met with their instructor during the semester. 60 participants (48\%) reported between one and three instructor-student conferences (see Table 4). 
Table 4

Time on Task, Frequency of Writing Center Visits, Frequency of Instructor Student Conferences $(N=125)$

\begin{tabular}{|c|c|c|}
\hline Variable & $\mathrm{N}$ & $\%$ \\
\hline \multicolumn{3}{|l|}{ TOT } \\
\hline Less than 1 hour & 5 & 4.0 \\
\hline 1-3 hours & 44 & 35.2 \\
\hline 3-5 hours & 49 & 39.2 \\
\hline 5-10 hours & 19 & 15.2 \\
\hline More than 10 hours & 8 & 6.4 \\
\hline \multicolumn{3}{|l|}{ FWCV } \\
\hline 0 & 49 & 39.2 \\
\hline 1 & 25 & 20.2 \\
\hline 2 & 12 & 9.6 \\
\hline 3 & 10 & 8.0 \\
\hline 4 & 5 & 4.0 \\
\hline 5 & 5 & 4.0 \\
\hline 6 & 2 & 1.6 \\
\hline 7 & 1 & 0.8 \\
\hline 10 & 1 & 0.8 \\
\hline 11 & 1 & 0.8 \\
\hline 12 & 3 & 2.4 \\
\hline 15 & 1 & 0.8 \\
\hline 17 & 1 & 0.8 \\
\hline 20 & 3 & 2.4 \\
\hline 28 & 1 & 0.8 \\
\hline 30 & 1 & 0.8 \\
\hline 33 & 1 & 0.8 \\
\hline 50 & 3 & 2.4 \\
\hline \multicolumn{3}{|l|}{ FISC } \\
\hline 0 & 43 & 34.4 \\
\hline 1 & 19 & 15.2 \\
\hline 2 & 20 & 16.0 \\
\hline 3 & 21 & 16.8 \\
\hline 4 & 5 & 4.0 \\
\hline 5 & 10 & 8.0 \\
\hline 6 & 1 & 0.8 \\
\hline 7 & 1 & 0.8 \\
\hline 9 & 1 & 0.8 \\
\hline 10 & 2 & 1.6 \\
\hline 20 & 1 & 0.8 \\
\hline 44 & 1 & 0.8 \\
\hline
\end{tabular}




\section{Writing Performance}

Writing performance was measured by students' scores on the last of three major writing assignments in Freshman English II: A 4 to 6 page persuasive research essay. Scores of $78.00,88.00$, and 93.50 represent the $25^{\text {th }}, 50^{\text {th }}$, and $75^{\text {th }}$ percentiles, respectively. According to the grading scale outlined in the course syllabus, a score of 78 is a " $\mathrm{C}+$ ", 88 is a " $\mathrm{B}+$ ", and 93.5 is an “ $\mathrm{A}$ ”.

\section{Variable Correlation}

Huck (2012) has discussed the subjective nature of selecting adjectives to describe correlation coefficients. He noted that "there are no hard or fast rules that dictate when labels such as strong or moderate or weak should be used” (p. 65). He further observed that the choice of adjectives depends on the discretion of the researcher. As such, the adjectives chosen to describe the correlations in this study were chosen based on reported correlations in the literature reviewed. For the purposes of this study the following rule of thumb was adopted: 0.00 , no correlation., .10 to .30, weak, .30 to .50, weak to moderate, .50 to .70 , moderate, .70 to .90 , strong, .90 to 1.00 , very strong.

The results of the variable correlation, mean, and standard deviation are reported in Table 5. Weak correlations $(r=.26, p<.001)$ were found between self-efficacy for writing tasks $(M=35.49, S D=6.06)$ and writing performance $(M=79.58, S D=24.87)$. Writing self-regulatory efficacy $(M=116.78, S D=21.29)$ and writing performance $(M=$ 79.58, $S D=24.87)$ were weakly correlated $(r=.23, \mathrm{p}<.05)$. Previous writing achievement $(M=.09, S D=.88)$ and writing performance $(M=79.58, S D=24.87)$ were also weakly correlated $(r=.25, p<.001)$.

The results indicate that students with higher scores on the writing self-regulatory 
efficacy scale and self-efficacy for writing tasks scale tended to score higher on the final persuasive essay. Similarly, students with higher previous writing achievement as measured by their ACT, COMPASS, and SAT scores, tended to obtain higher scores on the final persuasive essay.

\section{Hypothesis Testing}

Hypothesis

The research hypothesis tested whether the theoretical model of writing performance was supported by the empirical data, and is presented below:

Hypothesis: The theoretical covariance matrix equals the observed covariance matrix.

The theoretical model suggests bivariate correlations among the latent variables Personal Factors (PF), Environmental Factors (EF), and Behavioral Factors (BF), and direct causal relationships between the latent variables and the dependent variable Writing Performance (WP): The theoretical model represents three proposed bivariate correlations and three predictors as it is in a multiple linear regression.

The structural model was evaluated against five criteria: The chi-square $\left(\chi^{2}\right)$ likelihood ratio statistic, the goodness-of-fit index (GFI), the normed fit index (NFI), the comparative fit index (CFI), and the root mean square error of estimation (RMSEA). The chi-square test of the model was not statistically significant $\chi^{2}(33, N=125)=41.11, p=$ .157, which indicates that the model fit the data. The model yielded acceptable fit indices for all indices except one. The other fit measures attained the recommended target values. The value of the GFI was .94, which indicates a good fit. The NFI was .80, which is below the target value of .95. The CFI was .95, and the RMSEA was .045. 
Table 5

Mean, Standard Deviation, and Correlations among Variables $(N=125)$

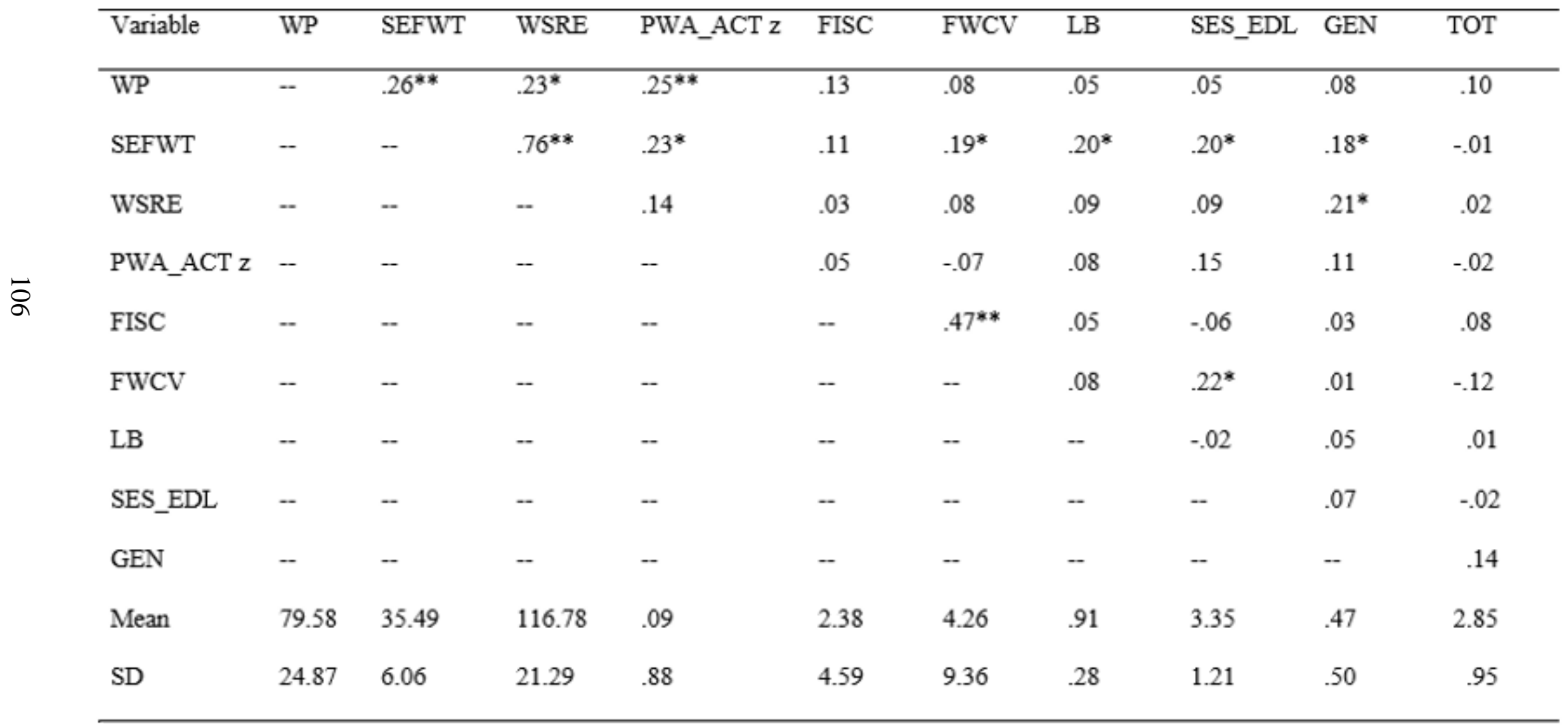

Note. ${ }^{*}$ Correlation is significant at the 0.05 level (2-tailed). ${ }^{* *}$ Correlation is significant at the 0.01 level (2-tailed). 
Hoelter's critical $N$ for the independence model was $37(p=.05)$ and $42(p=.01)$. For the default model, Hoelter's critical $N$ was $143(p=.05)$ and $166(p=.01)$.

Overall, the fit indices indicate an acceptable model fit with the data. Based on these results, the null hypothesis that the theoretical covariance matrix is equal to the observed covariance matrix was retained. The fit indices of the observed model are shown in Table 6. A graphical representation of the results of the structural model is shown in Figure 6.

Table 6

Fit Indices of the Observed Model $(N=125)$

\begin{tabular}{llll}
\hline Fit Index & Observed Model & Recommended Level & References \\
\hline$\chi^{2}$ & $41.11, p=.157$ & Non-significant & Hair et al., 2009 \\
GFI & .94 & $\geq .90$ & Myers et al., 2013 \\
NFI & .80 & .95 & Myers et al., 2013 \\
CFI & .95 & .95 & Hu \& Bentler (1999) \\
RMSEA & .045 & $\leq .05$ & Schumacker \& Lomax, 2004 \\
\hline
\end{tabular}

Table 7 shows the intercorrelations among the variables. Non-significant correlations were found between Personal Factors (PF) and Environmental Factors (EF), $r=.29, p=.359$, Behavioral Factors (BF) and Environmental Factors (EF), $r=.29, p=$ .325, and Personal Factors (PF) and Behavioral Factors (BF), $r=.19, p=.105$.

Table 8 shows the path coefficients for the structural model. Personal Factors was the only significant predictor of writing performance $(\beta=.26, p=.059)$. The path 
coefficient of .26 indicated a large effect size (> .25 Kieth, 2006). Writing performance was influenced by the direct effect of Personal Factors, which accounted for approximately $7 \%$ of the variance in writing performance.

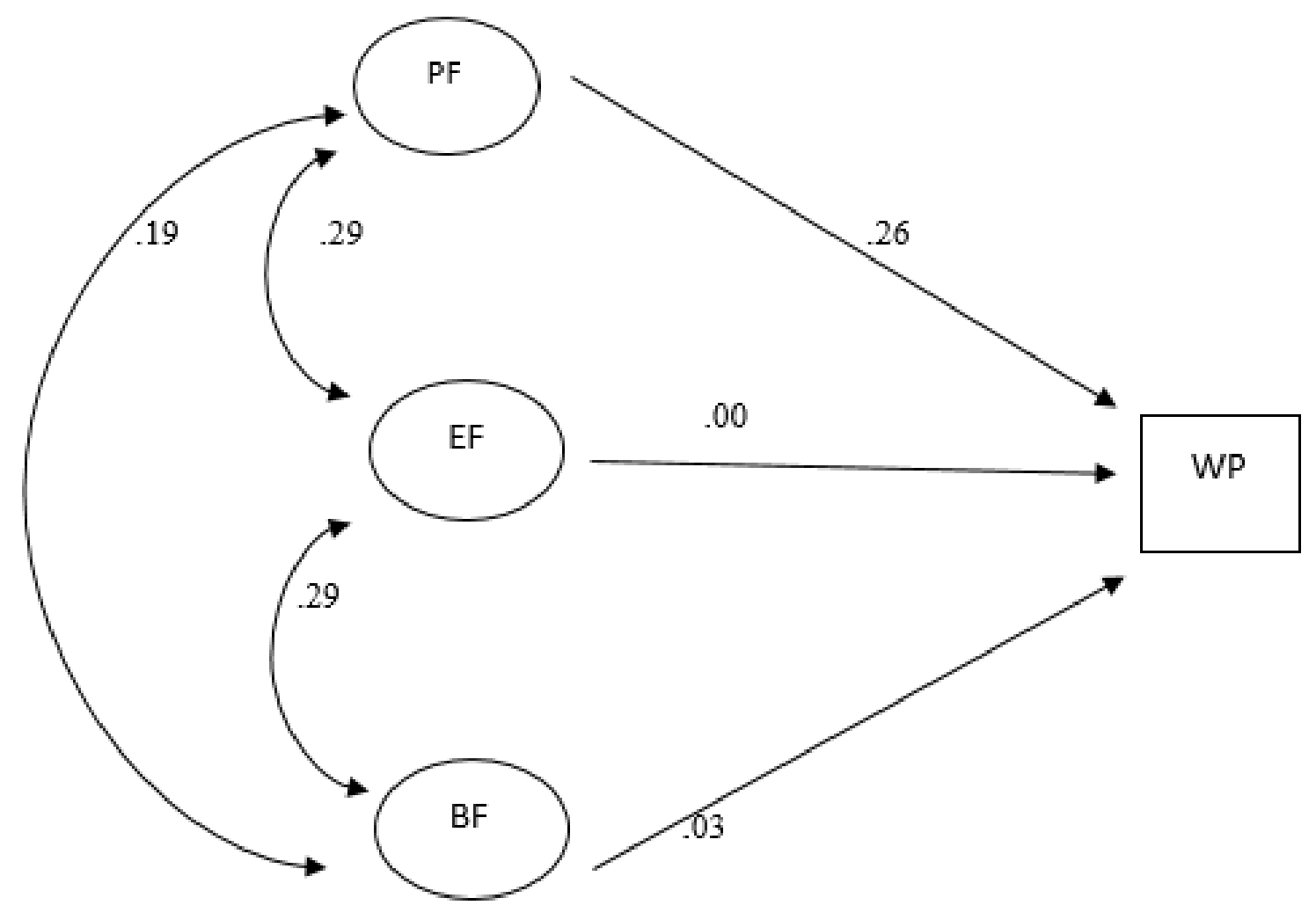

Figure 6. Theoretical model of writing performance. Latent constructs are shown in ellipses. Lines with arrows represent the path or direction of influence. Curved arrows represent correlations among latent variables. The dependent variable is an observed variable represented by a square. 
Table 7

Intercorrelations among Latent Variables in the Structural Model

\begin{tabular}{lccc}
\hline Relationships & $r$ & S.E. & $p$ \\
\hline Personal Factors $\Rightarrow$ Environmental Factors & .29 & .004 & .359 \\
Behavioral Factors $\Rightarrow$ Environmental Factors & .29 & .171 & .325 \\
Personal Factors $\Rightarrow$ Behavioral Factors & .19 & .224 & .105 \\
\hline
\end{tabular}

Table 8

Path Coefficients for the Structural Model

\begin{tabular}{lllll}
\hline Relationships & $\beta$ & $\mathrm{R}^{2}$ & S.E. & $p$ \\
\hline Personal Factors $\Rightarrow$ Writing Performance & .26 & 7.0 & 16.62 & .059 \\
Behavioral Factors $\Rightarrow$ Writing Performance & .03 & 0.0 & .249 & .773 \\
Environmental Factors $\Rightarrow$ Writing Performance & .00 & 0.0 & 51.07 & .995 \\
\hline
\end{tabular}

\section{Summary of Major Findings}

This chapter presented the results of the structural equation model for the influence of personal, behavioral, and environmental factors on writing performance. The validity of the theoretical model was tested using data collected from community college students $(n=125)$ enrolled in a first-year composition course. Overall, the hypothesized model was well-fitted with the observed model. Based on these results, the null 
hypothesis was retained. However, while correlations were found between Personal Factors and Behavioral Factors, Personal Factors and Environmental Factors, and Environmental Factors and Behavioral Factors, they did not reach statistical significance. The latent variable Personal Factors was the only significant predictor of the dependent variable, Writing Performance.

The final chapter which follows recapitulates the major sections of the dissertation. It includes the purpose of the study, a summary of the study problem and methodology, and a discussion of the major findings and conclusions that were drawn from these findings. The chapter concludes with a discussion of recommendations for practice and further research. 


\section{CHAPTER 5}

\section{SUMMARY, DISCUSSION, CONCLUSIONS AND RECOMMENDATIONS}

\section{Introduction}

Despite the importance of writing in academic and professional settings, there is evidence that significant numbers of college-aged students lack proficiency in writing. The results of the American College Testing (ACT) standardized test over the last five years indicate considerable variation in writing proficiency among entering first-year college students. The results indicate that approximately one-third of entering college students did not achieve the ACT benchmark for entry into college-level writing classes. In the state of Michigan these results are well below the national average (Michigan ACT Profile Report, 2014).

Several national studies (e.g. Graham \& Perin, 2007; National Commission on Writing in America’s Schools and Colleges 2003; 2004; 2005; 2006) have assessed the writing skills of the nation's college students and workers. These studies have found that although most students have acquired basic writing skills, they do not meet college writing expectations, and that two-thirds of the nation's corporate employees and significant numbers of state employees do not meet workplace writing expectations.

Another national study (Arum \& Roska, 2011) analyzed the results of the Collegiate Learning Assessment and found that almost half of college sophomores did not show significant improvement in their critical thinking, analytical reasoning, and 
writing skills during their first two years of college. These studies, along with anecdotal evidence gathered by the researcher of differences in both students' attitudes toward writing, and in their attainment of writing outcomes in the first-year composition classroom have provided a catalyst for this study of the personal, behavioral, and environmental factors which may influence students' writing performance.

Social cognitive theory (Bandura, 1989) has been used as a theoretical framework for past and more recent research on students' writing performance (e.g. Jones, 2008; Sanders-Reio, 2010; Williams \& Takaku, 2011; Zimmerman \& Bandura, 1994). In keeping with this research tradition, the conceptual framework used to explain the relationships among the variables in this study was also drawn from social cognitive theory. Social cognitive theory is based on the premise that humans' ability to play a role in their own development, or human agency is a fundamental aspect of being human (Bandura 2001; 2006).

Social cognitive theory is based on three underlying assumptions (Zimmerman, 1989). The third assumption of social cognitive theory, triadic reciprocal causation, posits that individuals contribute to their own motivation and action. Bandura's concept of triadic reciprocal causation consists of three interacting components: Personal, behavioral, and environmental factors. The conceptual framework used in this study was developed by the researcher based on a review of relevant theoretical literature and empirical studies, and applied Bandura's (1989) model of triadic reciprocal causation to explain the relationships among the variables. 


\section{Purpose of the Study}

The primary purpose of the study was to test a theoretical model of the influence of personal, behavioral, and environmental factors on the writing performance of firstyear community college students, by examining the relationships among the three latent variables specified in the model - personal factors, behavioral factors, and environmental factors - as well as their contribution in predicting the independent variable, writing performance.

\section{Summary of the Problem}

The writing research literature has been enriched by contributions from the field of educational psychology, which has considered the role of both social and cognitive factors in students' attainment of writing outcomes. Previous studies have been conducted within a social cognitive theoretical framework, which allows for the consideration of multiple variables contributing to students’ writing performance. These studies have investigated the role of motivational variables such as previous writing achievement (e.g. Zimmerman \& Bandura, 1994) self-efficacy (eg. Pajares \& Johnson, 1994) self-efficacy for self-regulation (e.g. Sanders-Reio, 2010), beliefs about writing and writing apprehension (e.g. Sanders-Reio, Alexander, Reio, \& Newman, 2010), and locus of control (e.g. Jones, 2008) in students’ writing performance.

While these studies have examined a range of motivational variables, they have tended to exclude certain contextual variables, and variables related to current writing pedagogy and practice. This has resulted in gaps in the research literature. There is a need to enlarge the scope of variables considered as contributing factors to the writing performance of undergraduate students. For example, few studies have considered the 
contribution of socioeconomic factors, although socioeconomic status has been studied in relation to overall academic performance within a social cognitive framework (e.g. Bandura, Barbaranelli, Caprara \& Pastorelli, 1996).

In an effort to enlarge the scope of variables considered as contributing factors to the writing performance of first-year community college students, this study departed from prior studies by including the following behavioral and environmental variables: Frequency of instructor conferences, time on task, and parental education level. This study was a further departure from previous studies by using one of the underlying assumptions of social cognitive theory, Bandura's (1989) model of triadic reciprocal causation as a conceptual framework. Based on Bandura's model, a theoretical model was developed by the researcher based on a review of relevant literature.

This theoretical model was tested using structural equation modeling (SEM) as the method of data analysis. This method of hypothesis testing and data analysis was also another departure from previous studies. Previous quantitative studies on writing achievement have tested their theoretical models using multivariate data analysis procedures including hierarchical regression (e.g. Jones, 2008; Prat-Sala \& Redford, 2012; Sanders-Reio, 2010; Tanyer, 2015) and path analysis (e.g. Williams \& Takaku, 2011; Zimmerman and Bandura, 1994). However, to date, no prior studies which have examined writing performance within a social cognitive framework have applied Bandura's theoretical model of triadic reciprocal causation, nor analyzed the data using structural equation modeling (SEM), which allows for the analysis of latent, or underlying constructs. 


\section{Summary of the Literature Review}

The literature review sought to establish a theoretical and empirical basis for the study, and examined prior studies relevant to the influence of personal, behavioral, and environmental factors on writing performance. The literature related to personal factors included studies on previous writing achievement, writing self-regulatory efficacy, and self-efficacy for writing. The section of the review on behavioral factors included studies on frequency of writing center visits, frequency of instructor conferences, and the time spent writing outside of class. The third major section of the review included studies on gender, language background, and socioeconomic status.

\section{Measurement of Writing Performance}

There is inherent difficulty in assessing writing by assigning a quantitative score to an activity that is qualitative in nature. Issues of reliability and validity have persisted in the field of writing assessment (Huot \& O’Neill, 2009). Limitations in both scoring methods and performance measures have been acknowledged. Shortcomings have been identified in holistic and analytic scoring, as well as commonly used performance measures such as timed essays, the single take-home paper, and course grades (e.g. Cherry \& Meyer, 2009; Hayes, Hatch \& Silk, 2000; Jones, 2008; Murphy \& Yancey, 2008; White, 2009).

\section{Personal Factors}

The influence of students’ previous writing achievement on their subsequent writing performance has been investigated in several studies (e.g. Arum \& Roska, 2011; Jones, 2008; Pajares \& Johnson, 1994; Williams \& Takaku, 2011; Zimmerman \& Bandura, 1994). Weak correlations were found between previous writing achievement 
and writing performance in two studies, while a moderate correlation was reported in one study. One national evaluation study reported a positive relationship between students' ACT/SAT scores and their performance on the Collegiate Learning Assessment. One study found that previous writing achievement, as indicated by SAT writing score and a pretest was not related to composition grade.

Higher writing self-efficacy scores were associated with writing performance in several studies reviewed (e.g. Jones, 2008; Prat-Sala, 2012; Sanders-Reio, 2010; SandersReio, Alexander, Reio \& Newman, 2014; Tanyer, 2015; Williams \& Takaku, 2011; Zimmerman \& Bandura, 1994). Bandura recommended that scales measuring selfefficacy be domain-specific. A distinction has been drawn between first- and secondgeneration writing self-efficacy scales based on their conceptual definition of writing self-efficacy (Sanders-Reio, 2010). First-generation writing self-efficacy scales (e.g. McCarthy, Meier, \& Rinderer, 1985; Meier, McCarthy \& Schmeck, 1984; Shell, Murphy \& Bruning, 1989) were constructed to measure mainly mechanical skills. This has been viewed as a short-coming as these scales were not aligned with current composition pedagogy (Jones, 2008). Second-generation writing self-efficacy scales (e.g. Jones, 2008; Sanders-Reio, 2010; Zimmerman \& Bandura, 1994) were constructed to measure both mechanical and substantive skills.

Self- regulation has been studied in relation to academic achievement in attempts aimed at identifying factors beyond students' skills and abilities, which may impact their academic achievement (e.g. Winne \& Hadwin, 2008; Zimmerman \& Schunk, 2008). Selfefficacy has been found to play a mediating role in the self-regulation of academic 
achievement (Zimmerman, 2000). Students' self-efficacy beliefs impact their academic motivation as they engage in self-regulatory processes such as goal-setting.

The role of writing self-regulatory efficacy, or students' belief in their ability to regulate their own writing, has been investigated in relation to their writing performance (e.g. Sanders-Reio, 2010). Zimmerman and Bandura (1994) found a weak, statistically insignificant correlation between writing self-regulatory efficacy and writing performance. Writing self-regulatory efficacy explained a small amount of the variance in writing performance (e.g Sanders-Reio, Alexander, Reio \& Newman, 2014).

\section{Behavioral Factors}

Adaptive help-seeking is a self-regulatory strategy that has been conceptualized as mediating the relationship between challenging academic tasks and successfully completing those tasks (Newman, 1994). Adaptive help-seeking has framed research on writing center visitation, although this research has been sparse. Adaptive help-seeking as a self-regulatory strategy has been extended in this study to include instructor-student writing conferences. Frequency of writing center visits has been found to be related to students' writing performance in the studies reviewed (e.g. Williams \& Takaku, 2011; Williams, Takaku \& Bauman, 2006).

Varied results were also reported in the studies which examined the relationship between frequency of instructor-student conferences and the quality of revisions students made. Several studies on the effectiveness of instructor-student conferences have been conducted. These studies have focused on the effectiveness of the interaction between instructor and student on the quality of students' revisions (e.g. Eksi, 2012; Gulley, 2012; Hewett, 2006), or on developing personal agency in beginning writers (e.g. Strauss \& 
Xiang, 2006), on students’ expectations of the instructor-student conference (e.g. Liu, 2009), and on the role of students’ self-efficacy in instructor-student conferences (e.g. Bayraktar, 2009).

Time-management as a self-regulatory strategy and as a measure of student engagement with writing tasks, was used in this study to examine the relationship between time on task and students’ writing performance. Astin (1993) conducted a fouryear evaluation study of 25,000 undergraduates which found that time on task or the number of hours students spent studying or doing homework, was positively correlated with their overall academic performance.

\section{Environmental Factors}

The concluding section of the review presented studies relevant to the influence of environmental factors on students' writing performance, with regard to gender, language background, and socioeconomic status. The studies presented varied results with regard to the influence of gender on students' writing performance. Some studies reported no significant differences between males and females (e.g. Arum \& Roska, 2011; Pajares \& Johnson, 1994;), while others did (e.g. Villalon, Mateos \& Cuevas, 2013; Williams \& Takaku, 2011). Varied results were also reported regarding the influence of second language background on writing performance in the mainstream composition classroom (e.g. Arum \& Roska, 2011; DeGennaro, 2009; Doolan, 2013; 2014; Williams \& Takaku, 2011).

The literature review concluded by discussing several studies with the aim of arriving at a conceptual definition of socioeconomic status for the present study. Although it is one of the most widely used conceptual variables in educational research, 
there is a lack of consensus among social science researchers regarding its conceptual definition. Socio-economic status has been operationalized in the literature in various ways. Sirin’s (2005) meta-analysis of studies, conducted between 1990 and 2000, found that among four indicators of socioeconomic status - parental education, parental occupation, parental income, and eligibility for free or reduced-lunch programs - the most commonly used indicator was parental education.

There were only a few studies which have investigated socioeconomic status in relation to writing achievement. Parental level of education was found to be related to writing performance (e.g. ACT Annual Report, 2014; Arum \& Roska, 2011). Higher parental levels of education were associated with higher levels of writing performance.

\section{Methodology}

\section{Population and Sample}

The study was conducted at a two-year community college in Michigan, United States. A census was conducted among all 233 students currently enrolled in English Composition on two campuses of the same institution. The sample consisted of 147 participants, based on the number of students present when the survey was administered. After the data were cleaned, the final sample consisted of 125 participants enrolled in 14 sections of a first-semester Freshman English course.

\section{Research Question}

In this exploratory study of the personal, behavioral and environmental factors which may influence the writing performance of first-year community college students, the research question sought to investigate whether the theoretical model of writing performance (see Figure 6), was supported by the empirical data. The following research 
question was answered: Is the theoretical covariance matrix equal to the observed covariance matrix?

\section{Research Design}

A non-experimental, correlational, cross-sectional, ex post facto, survey research design was used to examine the personal, behavioral, and environmental factors that had been identified as being of potential influence to students’ writing performance. Nonexperimental designs are aimed at examining variation among the participants in the sample. Non-experimental designs allow for the investigation of the relationships among variables (McMillan and Schumacher, 2010). A correlational design is appropriate if the goal of the research is to relate two or more variables to examine their influence on each other (Creswell, 2012). This study was also cross-sectional, as data were collected at one point in time. According to Creswell, cross-sectional survey designs are useful in collecting data relative to "current attitudes, opinions, or beliefs" (p. 377). Ex post facto designs are used "to investigate whether one or more pre-existing conditions have possibly caused subsequent differences in the groups of subjects” (McMillan \& Schumacher, 2010). In the present study, ex post facto relates to the possible influence of students’ previous writing achievement on their current writing performance.

\section{Summary of Findings}

Structural equation modeling hypothesis-testing procedures using IBM SPSS Amos 21 (Arbuckle, 2012) indicated an acceptable fit between the theoretical covariance matrix and the observed covariance matrix. The null hypothesis was therefore retained, indicating empirical support for the theoretical model. 
Associations were found among the three latent variables Personal Factors (PF), Behavioral Factors (BF), and Environmental Factors (EF). However, these associations did not achieve statistical significance. In addition, Personal Factors (PF) was the only significant predictor of writing performance. The path coefficient of .26 indicated a large effect size ( $>.25$, Kieth, 2006). Writing performance was influenced by the direct effect of Personal Factors (PF), which accounted for approximately 7\% of the variance in writing performance.

\section{Hypothesis}

\section{Conclusions}

The theoretical model of writing performance, which applied Bandura’s (1989) model of triadic reciprocal causation to the writing performance of first-year composition students, was minimally supported by the findings. Five of the six parameters in the model did not satisfy the expectations of statistical significance.

The causal contribution of Personal Factors, consisting of previous writing achievement, self-regulatory efficacy, and self-efficacy for writing tasks to first-year composition students' writing performance, was validated. The emergence of Personal Factors as the only significant predictor of writing performance achieved both statistical and practical significance. Overall, the findings point to the important predictive role of personal factors in students' writing performance.

\section{Discussion}

The hypothesis proposed that the theoretical covariance matrix equaled the observed covariance matrix. Further, the theoretical model suggested bivariate correlations among the latent variables Personal Factors (PF), Environmental Factors 
(EF), and Behavioral Factors (BF), and direct causal relationships between the latent variables and the dependent variable Writing Performance (WP).

The observed model tested in this study validated the theoretical model that was constructed using a conceptual model based on Bandura's social cognitive theory. However, of the six parameters in the observed model, which consisted of three bivariate correlations and three predictors of writing performance, five did not attain statistical significance. As such, this study’s application of Bandura's (1989) model of triadic reciprocal causation, which posits that personal, behavioral and environmental factors act as “interacting determinants” (p. 1175), was only minimally supported.

This finding suggests that sample size might have been a factor in the failure to of all the parameters in the model to reach statistical significance. Minimal sample sizes of 100 have been recommended for evaluating statistical models using structural equation modeling (e.g. Hair, Black, Babin \& Anderson, 2009; Loehlin, 2004). This sample size for this study was 125 , which places it within the minimum recommended number of cases. However, samples of 200 or as many as 400 have been recommended in order to obtain precise parameter estimates and standard errors (Loehlin, 2004), to preserve statistical power, and to obtain more precise results and greater accuracy (Schumacker \& Lomax, 2004).

The failure of five of the parameters in the theoretical model to reach statistical significance could also be attributed to some measurement issues which might have resulted in unreliable coefficients. Improving these items may make the significance of these correlations more evident. In addition, the small to moderate, non-significant correlations between behavioral factors and personal factors, behavioral factors and 
environmental factors, and environmental factors and personal factors suggests a mediating effect of behavioral and environmental factors on personal factors in the theoretical model.

However, beyond the discussion of statistical significance, the large effect size of personal factors also indicates practical, or theoretical significance. Huck (2012) discussed the importance of attending to both statistical, and practical significance when reporting and interpreting results. Huck observed that "inferential statistics can yield results that are statistically significant without being important in a practical manner” (p. 401). In the present study, the large effect size of personal factors as a predictor of writing performance is indicative of the strength of the relationship between personal factors and writing performance, and thus holds implications for theory.

In the absence of previous writing performance studies which have applied Bandura’s $(1977 ; 1978)$ triadic reciprocal causation model, the discussion will turn to Bandura’s (1997) conceptualization as a possible explanation for the finding of one significant predictor of writing performance. Firstly, Bandura’s conceptualization does not attribute equal weight to the three components of the triadic reciprocal model. He posited that each component may differ in strength, and that their influence may not be exercised in a simultaneous manner. Bandura observed,

Reciprocity does not mean that the three sets of interacting determinants are of equal strength. Their relative influence will vary for different activities under different circumstances. Nor do the mutual influences and their reciprocal effects all spring forth simultaneously as a holistic entity. (p. 6)

An alternative theoretical explanation for the emergence of Personal Factors as the only significant predictor of writing performance in the observed model can be given by examining the variables which make up the latent construct of Personal Factors. The 
latent variable Personal Factors consisted of Previous Writing Achievement, Writing Self-Regulatory Efficacy and Self-Efficacy for Writing Tasks. This discussion is warranted given the important role attributed to self-efficacy beliefs in social cognitive theory. Bandura (1997) posited, "Perceived self-efficacy occupies a pivotal role in social cognitive theory because it acts upon the other classes of determinants... Beliefs of personal efficacy make an important contribution to the acquisition of the knowledge structures on which skills are founded (p. 35).

Zimmerman (2002) situated self-efficacy as a self-motivational belief within the forethought phase of his three-phase model of self-regulation (see Figure 5). According to Zimmerman (2000), self-efficacy interacts with students’ self-regulated learning processes and mediates their academic performance. The presence of two highly correlated measures of self-efficacy within the theoretical model of writing performance, namely self-efficacy for writing tasks, and writing self-regulatory efficacy, may therefore be considered as an explanation for the predictive role of personal factors within the model.

In conclusion, the absence of statistically significant inter-correlations among the latent variables and the emergence of Personal Factors as the only significant predictor of writing performance in the observed model may be explained both empirically and theoretically. Small sample size for using structural equation modeling may have resulted in a lack of sufficient statistical power. In addition, the failure of all the parameters in the model to reach statistical significance could also be attributed to some measurement issues which might have resulted in unreliable coefficients. However, the small to moderate correlations among the latent variables point to a possible mediating effect of 
behavioral and environmental factors on personal factors. Further, Bandura’s (1997) conceptualization of triadic reciprocal causation has made provision for unequal, nonsimultaneous influence within its causal structure. Finally, the influence of self-efficacy beliefs attributed by Bandura in social cognitive theory provides a theoretical explanation for the predominant influence of personal factors in the structural model.

\section{Other Related Findings}

The latent variable personal factors consisted of three observed variables: Previous writing achievement, writing self-regulatory efficacy, and self-efficacy for writing tasks. This study’s finding that previous writing achievement and writing performance were correlated is supported by prior writing performance studies reviewed, with the exception of William \& Takaku (2011), who found no correlation between SAT score and a pretest and final grades in English Composition.

With regard to previous writing achievement, correlations similar to those reported in this study have also been reported between students' pre- and posttest scores on a writing proficiency test, between their self-reported high-school grades and grades in College English (Jones, 2008), and between students’ SAT scores and final English Composition grades (Zimmerman \& Bandura, 1994). A stronger correlation than that found in this study was also found (Pajares \& Johnson, 1994). Arum and Roska’s (2011) finding that students whose ACT/SAT scores were in the top quintile obtained higher mean scores on the Collegiate Learning Assessment than those who scored in the bottom quintile of the ACT and SAT, also corroborates this study's findings.

The significant correlations found between writing self-regulatory efficacy and writing performance in this study are also supported by previous studies. While a weak 
correlation was observed in this study $(r=.23)$, it was stronger than that obtained by Zimmerman \& Bandura (1994), who reported a correlation of $r=.14$, and Sanders-Reio’s (2010) study which reported a correlation of $r=.17$. Further, in Zimmerman and Bandura's study, the correlation did not reach statistical significance. In the Sanders-Reio et al. (2014) study, writing self-regulatory efficacy explained $1.3 \%$ of the variance in writing performance, less than for the total self-efficacy measure consisting of three subscales: substantive, self-regulatory, and mechanical, which accounted for $3.3 \%$ of the variance.

With regard to the correlation between self-efficacy for writing tasks and writing performance, the results of this study $(r=.26)$ are also supported by prior studies reviewed. Sanders-Reio (2010; 2014) reported similar correlations $(r=.24)$, while moderately larger correlations were reported by Zimmerman \& Bandura (1994), PratSala and Redford (2012), and Tanyer (2015) respectively.

Bandura (1997) posited that self-efficacy was an influential mediator of academic performance, predicting, under certain circumstances, students’ academic performance better than their previous academic achievement, knowledge and skills. The findings of this study partially support Bandura's conceptualization, since only one of the two selfefficacy measures was a better predictor of writing performance than previous writing achievement. The correlation between self-efficacy for writing tasks and writing performance was slightly higher than the correlation between previous writing achievement and writing performance. However, the correlation between writing selfregulatory efficacy and writing performance was lower than the correlation between previous writing achievement and writing performance. 
Similar results as those obtained in the current study were also reported by Zimmerman \& Bandura (1994). They also found lower correlations between writing selfregulatory efficacy and writing performance than between previous writing achievement and writing performance. A higher correlation was found between academic self-efficacy for writing and final grade in English Composition.

Mixed results were also obtained by Jones (2008) when comparing the correlation between previous writing achievement and writing performance with the correlation between self-efficacy for writing tasks and writing performance. Jones (2008) analyzed the SAT verbal scores of first-year composition students and found that course grade was predicted by SAT verbal score for those who had scored above the SAT benchmark of 490. More proficient writers' grades were predicted by previous writing ability, while less proficient writers' grades were better predicted by locus of control than by previous writing ability or writing self-efficacy.

Pajares and Johnson (1994) obtained different results than the current study in their study of pre-service teachers. They reported higher correlations between previous writing achievement scores as measured by a timed essay and final essay scores. Lower correlations were reported between writing self-efficacy and writing performance on the final essay.

Given the mixed results of prior studies, tentative conclusions should therefore be drawn regarding their support for Bandura’s (1997) conceptualization that self-efficacy could, under certain circumstances, predict students' academic performance better than their previous academic achievement, knowledge and skills. Tentative conclusions should also be drawn because of the various ways previous writing achievement and final 
writing performance have been measured. For example, Jones (2008) used a pretest and high school GPA as a measure of previous writing achievement, and a posttest and English composition grades to measure final writing performance. Pajares and Johnson (1994) used a pretest and a posttest, while Zimmerman and Bandura (1994) used SAT scores and final course grades in English composition.

In sum, the structural equation model in the current study suggests that first-year composition students' previous writing achievement, writing self-regulatory efficacy, and self-efficacy for writing tasks may predict their writing performance. These findings are consistent with those of previous studies. However, because this study is exploratory in nature, the conclusions drawn from them should be interpreted with several caveats. These limitations are discussed in the following section.

\section{Limitations of the Study}

An inherent limitation of survey research design is its reliance on self-report data. While self-report methods of data collection have the advantage of providing respondents' own perspective, one disadvantage is the potential for producing invalid data. Respondents may not provide accurate information out of a desire for social desirability, for example. According to Barker, Pistrang, and Elliott (2002), the bias introduced by the weaknesses of self-report data can be remedied by using well-designed questionnaires or by supplementing it with data obtained through direct observation.

Another limitation is the use of convenience sampling to select participants. Convenience sampling is "a type of nonprobability sampling in which people are sampled simply because they are "convenient" sources of data for researchers” (Battaglia, 2008. n.p.). According to Fink (2003), one of the limitations of non-probability sampling is its 
susceptibility to selection biases, since all suitable respondents may not stand an equal chance of being selected as part of a sample.

The use of students’ ACT verbal scores, COMPASS Writing Test scores, and SAT scores as a measure of previous writing achievement is also a limitation of this study. These scores are based on students’ responses to multiple-choice type questions, and may not be an accurate reflection of students' writing ability. In addition, students' ACT, SAT, and COMPASS Writing Test scores were converted into standardized $z$ scores, which do not indicate the true scores on their standardized tests.

The final limitation relates to the use of a single take-home essay as a measure of writing performance, since interrater reliability was not assessed. Students' grades were assigned by their respective course instructors, who may not have used common assessment criteria.

\section{Recommendations for Practice}

The following possible recommendations for practice have been drawn from the study:

1. Writing faculty should be made aware, or reminded of the influence of personal factors such as self-beliefs on students’ writing performance.

2. In this study, students reported their lowest levels of self-efficacy for more substantive writing tasks such as critical analysis. Writing instructors can enable students' to develop personal efficacy by providing mastery experiences and opportunities for success, and through corrective modeling, and positive, but realistic feedback (Woods \& Bandura, 1989). 
3. Students also reported their lowest levels of self-regulatory efficacy for concentrating on their writing when faced with distractions. Student success centers can provide training in self-regulatory strategies for refocusing their concentration, structuring their environment, and for effective time-management (Zimmerman \& Kitsantas, 2007).

4. This study found that approximately a third of the students surveyed reported not attending instructor-student conferences and the writing center. Writing program administrators can conduct surveys or focus groups to assess students' attitudes toward seeking help, or their experiences with instructor-student conferences and writing center visits.

\section{Recommendations for Further Research}

This study's main contribution to writing research and scholarship has been the development and testing of a theoretical model of writing performance. This study was exploratory to the extent that it included variables that had not been included in previous writing performance studies, applied Bandura's model of triadic reciprocal causation to writing performance, and used structural equation modeling data analysis procedures. The following recommendations for further research can be drawn from the current study:

1. The study should be replicated using larger samples and random sampling procedures. This is especially important, given that the major writing performance studies with a few exceptions (e.g. Williams \& Takaku, 2011; Arum \& Roska, 2011; Sanders-Reio et al., 2014) tended to use sample sizes which were smaller than 400 cases. Sample sizes ranged from 30 cases (e.g. Pajares \& Johnson, 
1994), 118 (Jones, 2008), 95 (Zimmerman \& Bandura, 1994), 116 (Tanyer, 2015),

145 (Prat-Sala and Redford, 2012), to 286 cases (Sanders-Reio, 2010).

2. The study should also be replicated with a more heterogeneous sample. The current study sample consisted of $66 \%$ white non-Hispanics. Ethnicity was therefore not considered as a variable in the model.

3. The study could also be replicated as a longitudinal study with varying educational levels.

4. The theoretical model of writing performance can be further expanded to include other variables, since personal factors only explained 7\% of variance in writing performance. Possible variables include locus of control, beliefs about writing, outcome expectations, goal orientation, writing apprehension, and task interest.

5. The current study was delimited to investigating student characteristics. A multilevel structural equation model could be developed to include institutional and teacher characteristics.

6. Future studies should develop more adequate instruments to measure writing selfefficacy which are reflective of current composition pedagogy and practice, in accordance with Bandura's (2006) recommendation that self-efficacy scales be domain-specific and conceptually valid. More adequate instruments are also needed to assess writing center visitation, instructor-student conferences, and time on task. In addition, instrument reliability and interrater reliability should be assessed in future studies when essays are graded by multiple raters.

7. Since the hypothesized theoretical model was minimally supported by the findings, the model could be modified in future exploratory studies to investigate 
the mediating effect of behavioral factors and environmental factors on personal factors, and the influence of these factors on students' writing performance. Data could be analyzed using path analysis in order to determine the path of influence of the latent variables in the theoretical model.

This exploratory study of the factors which influence the writing performance of first-year composition students has contributed to the continued interdisciplinary conversation that has characterized this area of writing research and practice over the past four decades. We have come a long way since Daly and Miller's (1975) initial studies on writing apprehension, which have helped to pave the way for future studies integrating the disciplines of English composition and psychology. It is hoped that this study will serve as a catalyst for further investigation into this area of educational research. 
APPENDIX A

RESEARCH INSTRUMENT 


\section{Writing Survey}

This questionnaire is designed to help us get a better understanding of the kinds of writing that are difficult for students. Please tell us how well you can do the things listed below at the present time by shading the number to the right of each question that best represents your ability. The information you provide will be kept strictly confidential, so be as frank as possible in your answers. Use the following scale to show your responses:

Not Well At All

1
2

Not Too Well

3

4

Pretty Well

5

Very Well

7

\begin{tabular}{|c|c|c|c|c|c|c|c|c|}
\hline No. & Item & $\begin{array}{l}\bar{z} \\
\bar{z} \\
\bar{z} \\
3 \\
0 \\
z\end{array}$ & & $\begin{array}{l}\overline{\bar{a}} \\
3 \\
8 \\
\dot{8} \\
\overline{0} \\
z\end{array}$ & & 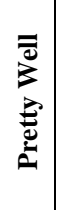 & & $\begin{array}{l}\overline{0} \\
3 \\
3 \\
\frac{0}{0}\end{array}$ \\
\hline 1. & $\begin{array}{l}\text { When given a specific writing assignment, I can come up } \\
\text { with a suitable topic in a short time. }\end{array}$ & 1 & 2 & 3 & 4 & 5 & 6 & 7 \\
\hline 2. & I can start writing with no difficulty. & 1 & 2 & 3 & 4 & 5 & 6 & 7 \\
\hline 3. & I can construct a good opening sentence quickly. & 1 & 2 & 3 & 4 & 5 & 6 & 7 \\
\hline 4. & $\begin{array}{l}\text { I can come up with an unusual opening paragraph to capture } \\
\text { readers' attention. }\end{array}$ & 1 & 2 & 3 & 4 & 5 & 6 & 7 \\
\hline 5. & $\begin{array}{l}\text { I can write a brief but informative overview that will } \\
\text { prepare readers well for the main thesis of my paper. }\end{array}$ & 1 & 2 & 3 & 4 & 5 & 6 & 7 \\
\hline 6. & $\begin{array}{l}\text { I can use my first attempts at writing to refine my ideas on a } \\
\text { topic. }\end{array}$ & 1 & 2 & 3 & 4 & 5 & 6 & 7 \\
\hline 7. & $\begin{array}{l}\text { I can adjust my style of writing to suit the needs of any } \\
\text { audience. }\end{array}$ & 1 & 2 & 3 & 4 & 5 & 6 & 7 \\
\hline 8. & $\begin{array}{l}\text { I can find a way to concentrate on my writing even when } \\
\text { there are many distractions around me. }\end{array}$ & 1 & 2 & 3 & 4 & 5 & 6 & 7 \\
\hline 9. & $\begin{array}{l}\text { When I have a pressing deadline on a paper, I can manage } \\
\text { my time efficiently. }\end{array}$ & 1 & 2 & 3 & 4 & 5 & 6 & 7 \\
\hline 10. & $\begin{array}{l}\text { I can meet the writing standards of an evaluator who is very } \\
\text { demanding. }\end{array}$ & 1 & 2 & 3 & 4 & 5 & 6 & 7 \\
\hline
\end{tabular}




\begin{tabular}{|c|c|c|c|c|c|c|c|c|}
\hline No. & Item & $\begin{array}{l}\bar{z} \\
\bar{z} \\
\bar{z} \\
3 \\
0 \\
\dot{z}\end{array}$ & & $\begin{array}{l}\bar{a} \\
3 \\
0 \\
0 \\
0 \\
\dot{0}\end{array}$ & & 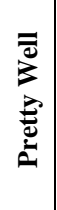 & & $\begin{array}{l}\overline{0} \\
3 \\
3 \\
0 \\
0\end{array}$ \\
\hline 11. & $\begin{array}{l}\text { I can come up with memorable examples quickly to } \\
\text { illustrate an important point. }\end{array}$ & 1 & 2 & 3 & 4 & 5 & 6 & 7 \\
\hline 12. & I can rewrite my wordy or confusing sentences clearly. & 1 & 2 & 3 & 4 & 5 & 6 & 7 \\
\hline 13. & $\begin{array}{l}\text { When I need to make a subtle or an abstract idea more } \\
\text { imaginable, I can use words to create a vivid picture. }\end{array}$ & 1 & 2 & 3 & 4 & 5 & 6 & 7 \\
\hline 14. & $\begin{array}{l}\text { I can locate and use appropriate reference sources when I } \\
\text { need to document an important point. }\end{array}$ & 1 & 2 & 3 & 4 & 5 & 6 & 7 \\
\hline 15. & $\begin{array}{l}\text { I can write very effective transitional sentences from one } \\
\text { idea to another. }\end{array}$ & 1 & 2 & 3 & 4 & 5 & 6 & 7 \\
\hline 16. & $\begin{array}{l}\text { I can refocus my concentration on writing when I am } \\
\text { worried or find myself thinking about other things. }\end{array}$ & 1 & 2 & 3 & 4 & 5 & 6 & 7 \\
\hline 17. & $\begin{array}{l}\text { When I write on a lengthy topic, I can create a variety of } \\
\text { good outlines for the main sections of my paper. }\end{array}$ & 1 & 2 & 3 & 4 & 5 & 6 & 7 \\
\hline 18. & $\begin{array}{l}\text { When I want to persuade a skeptical reader about a point, I } \\
\text { can come up with a convincing quote from an authority. }\end{array}$ & 1 & 2 & 3 & 4 & 5 & 6 & 7 \\
\hline 19. & $\begin{array}{l}\text { When I get stuck writing a paper, I can find ways to } \\
\text { overcome the problem. }\end{array}$ & 1 & 2 & 3 & 4 & 5 & 6 & 7 \\
\hline 20. & $\begin{array}{l}\text { I can find ways to motivate myself to write a paper even } \\
\text { when the topic holds little interest for me. }\end{array}$ & 1 & 2 & 3 & 4 & 5 & 6 & 7 \\
\hline 21. & $\begin{array}{l}\text { When I have written a long or complex paper, I can write a } \\
\text { good concluding section that ties all the parts together. }\end{array}$ & 1 & 2 & 3 & 4 & 5 & 6 & 7 \\
\hline 22. & $\begin{array}{l}\text { I can revise a first draft of any paper so that it is shorter and } \\
\text { better organized. }\end{array}$ & 1 & 2 & 3 & 4 & 5 & 6 & 7 \\
\hline 23. & $\begin{array}{l}\text { When I edit a complex paper, I can find and correct all of } \\
\text { my grammatical errors. }\end{array}$ & 1 & 2 & 3 & 4 & 5 & 6 & 7 \\
\hline 24. & $\begin{array}{l}\text { I can find other people who will give critical feedback on } \\
\text { early drafts of my paper. }\end{array}$ & 1 & 2 & 3 & 4 & 5 & 6 & 7 \\
\hline 25. & $\begin{array}{l}\text { When my paper is written on a complicated topic, I can } \\
\text { come up with a short, informative title. }\end{array}$ & 1 & 2 & 3 & 4 & 5 & 6 & 7 \\
\hline
\end{tabular}




\section{Writing Tasks Scale}

Instructions: One a scale of 1 (no chance) to 6 (completely certain), how confident are you of being able to successfully communicate, in writing, what you want to say in each of the following writing tasks. The information you provide will be kept strictly confidential, so be as frank as possible in your answers.

\begin{tabular}{|c|c|c|c|c|c|c|c|}
\hline No. & Item & 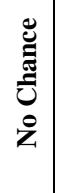 & & & & & نَّ \\
\hline 1. & Write a good paper for a professor in English. & 1 & 2 & 3 & 4 & 5 & 6 \\
\hline 2. & Write a good paper for a professor in any course. & 1 & 2 & 3 & 4 & 5 & 6 \\
\hline 3. & $\begin{array}{l}\text { Write an essay that develops an idea by making connections } \\
\text { among a variety of textual sources. }\end{array}$ & 1 & 2 & 3 & 4 & 5 & 6 \\
\hline 4. & $\begin{array}{l}\text { Write an essay that provides a critique or analysis of another } \\
\text { essay. }\end{array}$ & 1 & 2 & 3 & 4 & 5 & 6 \\
\hline 5. & $\begin{array}{l}\text { Write a persuasive essay that incorporates text sources } \\
\text { representing points of view different from yours. }\end{array}$ & 1 & 2 & 3 & 4 & 5 & 6 \\
\hline 6. & $\begin{array}{l}\text { Write a summary of a long essay that effectively captures } \\
\text { the essence of it. }\end{array}$ & 1 & 2 & 3 & 4 & 5 & 6 \\
\hline 7. & $\begin{array}{l}\text { Write an essay that persuasively analyzes the causes or } \\
\text { effects of a particular event, concept, or belief. }\end{array}$ & 1 & 2 & 3 & 4 & 5 & 6 \\
\hline 8. & $\begin{array}{l}\text { Write an essay that compares and contrasts two authors, } \\
\text { events, pieces of art, or concepts in order to reach a } \\
\text { larger conclusion about that subject. }\end{array}$ & 1 & 2 & 3 & 4 & 5 & 6 \\
\hline
\end{tabular}




\section{Student Information Form}

Instructions: This questionnaire is designed to learn more about you. Please provide the answers to the demographic items below. The information you provide will be kept strictly confidential, so be as frank as possible in your answers.

\begin{tabular}{|c|c|c|}
\hline No. & Item & Responses \\
\hline 1. & Gender & $\begin{array}{l}\square \text { Female } \\
\square \text { Male }\end{array}$ \\
\hline 2. & Ethnicity & $\begin{array}{l}\square \text { White Non-Hispanic } \\
\square \text { American Indian/Alaskan Native } \\
\square \text { Asian American } \\
\square \text { Black/African American } \\
\square \text { Latino/Hispanic } \\
\square \text { Native Hawaiian/Pacific Isl. } \\
\square \text { Two or more }\end{array}$ \\
\hline 3. & Is English your first language? & $\begin{array}{l}\square \text { No } \\
\square \text { Yes }\end{array}$ \\
\hline 4. & $\begin{array}{l}\text { How much education has the head of your } \\
\text { household completed? }\end{array}$ & $\begin{array}{l}\square \text { Some high school } \\
\square \text { High school graduate } \\
\square \text { Some college } \\
\square 2 \text { year associate degree } \\
\square \text { 4 year bachelor's degree } \\
\square \text { Master's degree } \\
\square \text { Doctorate }\end{array}$ \\
\hline 5. & $\begin{array}{l}\text { What is the occupation of the head of your } \\
\text { household? }\end{array}$ & \\
\hline 6. & $\begin{array}{l}\text { How many times did you go the writing center this } \\
\text { semester? }\end{array}$ & \\
\hline 7. & $\begin{array}{l}\text { How many times did you meet with your instructor } \\
\text { to discuss your writing assignments this semester? }\end{array}$ & 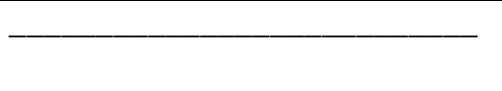 \\
\hline 8. & $\begin{array}{l}\text { How many hours on average per week did you } \\
\text { spend working on your writing assignments outside } \\
\text { of class this semester? }\end{array}$ & $\begin{array}{l}\square \text { less than one hour } \\
\square \text { 1-3 hours } \\
\square \text { 3-5 hours } \\
\square \text { 5-10 hours } \\
\square \text { more than } 10 \text { hours }\end{array}$ \\
\hline
\end{tabular}


APPENDIX B

TABLE OF SPECIFICATIONS 
Table of Specifications

\begin{tabular}{|c|c|c|c|c|}
\hline 1. & $\begin{array}{l}\text { Participant ID } \\
\text { Number (ID) }\end{array}$ & $\begin{array}{l}\text { The researcher- } \\
\text { assigned number } \\
\text { used to identify } \\
\text { each questionnaire } \\
\text { collected from } \\
\text { student } \\
\text { participants. }\end{array}$ & Participant ID Number & $\begin{array}{l}\text { Consecutive Arabic } \\
\text { numerals. } \\
\text { This variable was } \\
\text { measured as categorical } \\
\text { data, and was used to } \\
\text { organize the data. }\end{array}$ \\
\hline 2. & $\begin{array}{l}\text { Previous } \\
\text { Writing } \\
\text { Achievement } \\
\text { (PWA_ACTz) }\end{array}$ & $\begin{array}{l}\text { Following the } \\
\text { work of } \\
\text { Zimmerman \& } \\
\text { Bandura (1994), } \\
\text { Previous Writing } \\
\text { Achievement } \\
\text { (PWA), is } \\
\text { conceptually } \\
\text { defined as ACT } \\
\text { verbal aptitude } \\
\text { scores, ACT } \\
\text { COMPASS } \\
\text { Writing Skills } \\
\text { Placement Test, } \\
\text { and SAT verbal } \\
\text { scores }\end{array}$ & $\begin{array}{l}\text { The ACT verbal aptitude score is instrumentally defined as } \\
\text { consisting of } 75 \text { multiple choice questions. The maximum } \\
\text { score possible to be obtained on the ACT English Test is } \\
\text { 36. Benchmark is } 18 \\
\text { The ACT COMPASS Writing Skills Placement Test is } \\
\text { instrumentally defined as multiple choice questions which } \\
\text { test students' ability to identify and correct errors in } \\
\text { sentences and paragraphs in eight areas. The ACT } \\
\text { COMPASS test is scored on a scale from zero to } 100 \text {. } \\
\text { The SAT verbal score is instrumentally defined as multiple } \\
\text { choice questions. SAT verbal aptitude is measured on a } \\
200-800 \text { scale. }\end{array}$ & $\begin{array}{l}\text { PWA_ACTz is } \\
\text { operationally defined as } \\
\text { the converted raw ACT } \\
\text { English, ACT COMPASS } \\
\text { Writing Skills Placement, } \\
\text { and SAT Verbal test } \\
\text { scores into standardized } z \\
\text { scores. Standard } z \text { scores } \\
\text { range from }-3 \text { to }+3\end{array}$ \\
\hline
\end{tabular}




\begin{tabular}{|c|c|c|c|c|}
\hline No. & Variable & $\begin{array}{l}\text { Conceptual } \\
\text { Definition }\end{array}$ & Instrumental Definition & Operational Definition \\
\hline 3. & $\begin{array}{l}\text { Writing Self- } \\
\text { Regulatory } \\
\text { Efficacy } \\
\text { (WSRE) }\end{array}$ & $\begin{array}{l}\text { "Perceived } \\
\text { capability (a) to } \\
\text { execute strategic } \\
\text { aspects of the } \\
\text { writing process } \\
\text { such as planning, } \\
\text { organizing, and } \\
\text { revising } \\
\text { compositions; (b) } \\
\text { to realize the } \\
\text { creative aspects of } \\
\text { writing such as } \\
\text { generating good } \\
\text { topics, writing } \\
\text { interesting } \\
\text { introductions and }\end{array}$ & $\begin{array}{l}\text { The following } 25 \text { items will be measured by a scale from } 1 \\
-7 . \\
\text { (1) Not well at all } \\
\text { (7) Very well } \\
\text { This questionnaire is designed to help us get a better } \\
\text { understanding of the kinds of writing that are difficult for } \\
\text { students. Please tell us how well you can do the things } \\
\text { listed below at the present time by entering a number to the } \\
\text { left of each question. The information you provide will be } \\
\text { kept strictly confidential and will not be identified by } \\
\text { name, so be as frank as possible in your answers. Use the } \\
\text { following scale: } \\
\text { 1. When given a specific writing assignment, I can come up } \\
\text { with a suitable topic in a short time. } \\
\text { 2. I can start writing with no difficulty. } \\
\text { 3. I can construct a good opening sentence quickly. } \\
\text { 4. I can come up with an unusual opening paragraph to } \\
\text { capture my readers' interest. } \\
\text { 5. I can write a brief, informative overview that prepares } \\
\text { readers well for the main thesis of my paper. } \\
6 \text {. I can use my first attempts at writing to suit the needs of } \\
\text { my audience. } \\
\text { 7. I can adjust the style of my writing to suit the needs of } \\
\text { any audience. } \\
8 \text {. I can find a way to concentrate on my writing even when } \\
\text { there are many distractions around me. }\end{array}$ & 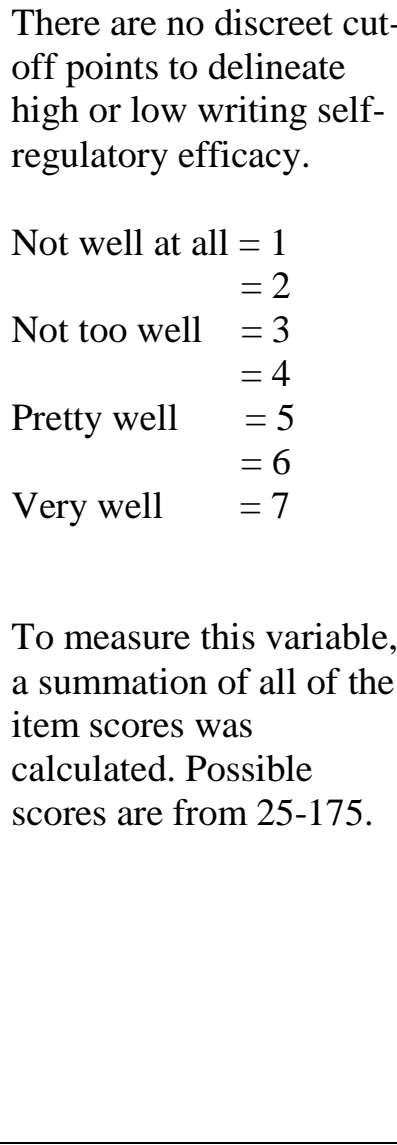 \\
\hline
\end{tabular}




\begin{tabular}{|c|c|c|c|c|}
\hline No. & Variable & $\begin{array}{c}\text { Conceptual } \\
\text { Definition }\end{array}$ & Instrumental Definition & Operational Definition \\
\hline 3. & $\begin{array}{l}\text { Writing Self- } \\
\text { Regulatory } \\
\text { Efficacy } \\
\text { (WSRE) }\end{array}$ & & $\begin{array}{l}\text { 9. When I have a pressing deadline on a paper, I can } \\
\text { manage my time efficiently. } \\
\text { 10. I can meet the writing standards of an evaluator who } \\
\text { is very demanding. } \\
\text { 11. I can come up with memorable examples quickly to } \\
\text { illustrate an important point. } \\
\text { 12. I can rewrite my wordy or confusing sentences } \\
\text { clearly. } \\
\text { 13. When I need to make a subtle or an abstract idea } \\
\text { more imaginable, I can use words to create a vivid } \\
\text { picture. } \\
14 \text {. I can locate and use appropriate reference sources } \\
\text { when I need to document an important point. } \\
\text { 15. I can write very effective transitional sentences from } \\
\text { one idea to another. } \\
16 \text {. I can refocus my concentration on writing when I find } \\
\text { myself thinking about other things }\end{array}$ & \\
\hline
\end{tabular}




\begin{tabular}{|l|l|l|l|}
\hline No. & Variable & $\begin{array}{l}\text { Conceptual } \\
\text { Definition }\end{array}$ & \multicolumn{1}{c|}{$\begin{array}{c}\text { Instrumental Definition } \\
\text { Operational } \\
\text { Definition }\end{array}$} \\
\hline 3. & $\begin{array}{l}\text { Writing } \\
\text { Self- } \\
\text { Regulatory } \\
\text { Efficacy } \\
\text { (WSRE) }\end{array}$ & $\begin{array}{l}\text { 17. When I write on a lengthy topic, I can create a variety of good outlines for } \\
\text { the main my paper. } \\
\text { 18. When I want to persuade a skeptical reader about a point, I can come up } \\
\text { with a convincing quote from an authority. } \\
\text { 19. When I get stuck writing a paper, I can find ways to overcome the problem. } \\
\text { 20. I can find ways to motivate myself to write a paper even when the topic } \\
\text { holds little interest. } \\
\text { 21. When I have written a long or complex paper, I can find and correct all my } \\
\text { grammatical errors. } \\
\text { 22. I can revise a first draft of any paper so that it is shorter and better } \\
\text { organized. } \\
\text { 23. When I edit a complex paper, I can find and correct all my grammatical } \\
\text { errors. } \\
\text { 24. I can find other people who will give critical feedback on early drafts of my } \\
\text { paper. } \\
\text { 25. When my paper is written on a complicated topic, I can come up with a } \\
\text { short, informative title. }\end{array}$ \\
\hline
\end{tabular}




\begin{tabular}{|c|c|c|c|c|}
\hline No. & Variable & $\begin{array}{c}\text { Conceptual } \\
\text { Definition }\end{array}$ & Instrumental Definition & Operational Definition \\
\hline 4. & $\begin{array}{l}\text { Self- } \\
\text { Efficacy } \\
\text { for Writing } \\
\text { Tasks } \\
\text { (SEFWT) }\end{array}$ & $\begin{array}{l}\text { Following the } \\
\text { work of Pajares, } \\
\text { Hartley \& } \\
\text { Valiante (2001), } \\
\text { Self-Efficacy } \\
\text { for Writing Tasks } \\
\text { (SEFWT) is } \\
\text { conceptually } \\
\text { defined as } \\
\text { students' } \\
\text { "judgments of } \\
\text { their } \\
\text { capability to } \\
\text { successfully } \\
\text { perform various } \\
\text { writing skills } \\
\text { appropriate to } \\
\text { their academic } \\
\text { level” (p. 214). }\end{array}$ & $\begin{array}{l}\text { The following } 8 \text { items will be measured by a scale from } 1 \text { - } 6 \\
1=\text { No chance } \\
6 \text { = Completely certain } \\
\text { Instructions: One a scale of } 1 \text { (no chance) to } 6 \text { (completely certain), } \\
\text { how confident are you of being able to successfully communicate, } \\
\text { in writing, what you want to say in each of the following writing } \\
\text { tasks. } \\
\text { 1. Write a good paper for a professor in English. } \\
\text { 2. Write a good paper for a professor in any course. } \\
\text { 3. Write an essay that develops an idea by making connections } \\
\text { among a variety of textual sources. } \\
\text { 4. Write an essay that provides a critique or analysis of another } \\
\text { essay. } \\
\text { 5. Write a persuasive essay that incorporates text sources } \\
\text { representing points of view different from yours. } \\
\text { 7. Write a summary of a long essay that effectively captures the } \\
\text { essen it. } \\
\text { of a particular event, concept, or belief. } \\
\text { events, pieces of art, or concepts in order to reach a larger } \\
\text { conclusion about that subject. }\end{array}$ & 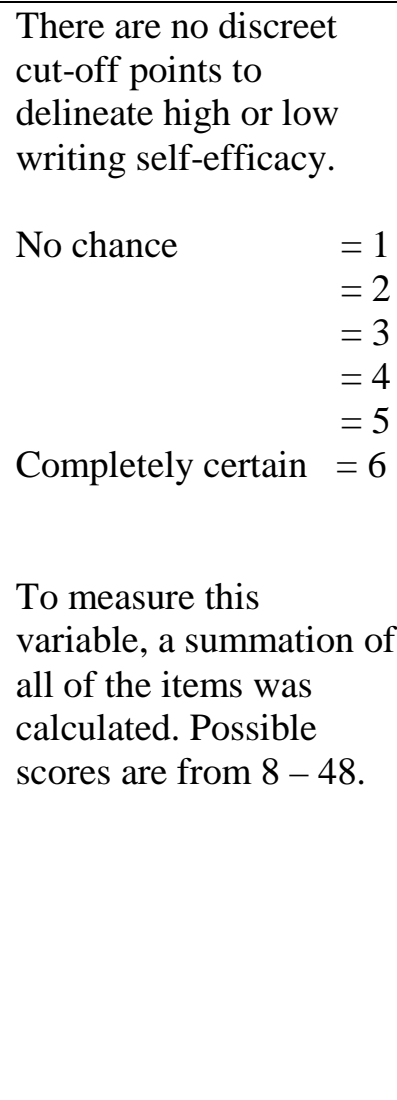 \\
\hline
\end{tabular}




\begin{tabular}{|c|c|c|c|c|}
\hline No. & Variable & $\begin{array}{l}\text { Conceptual } \\
\text { Definition }\end{array}$ & Instrumental Definition & Operational Definition \\
\hline 5. & $\begin{array}{l}\text { Frequency of } \\
\text { Writing } \\
\text { Center Visits } \\
\text { (FWCV) }\end{array}$ & $\begin{array}{l}\text { Cumulative } \\
\text { writing center } \\
\text { visits. }\end{array}$ & How many times did you go the writing center this semester? & $\begin{array}{l}\text { Arabic numerals. } \\
\text { Following Williams \& } \\
\text { Takaku (2011) the number } \\
\text { of times each student } \\
\text { visited the writing center } \\
\text { was entered individually. } \\
\text { This variable was entered } \\
\text { as continuous data. }\end{array}$ \\
\hline 6. & $\begin{array}{l}\text { Frequency of } \\
\text { Instructor- } \\
\text { Student } \\
\text { Conferences } \\
\text { (FISC) }\end{array}$ & $\begin{array}{l}\text { Cumulative } \\
\text { instructor- } \\
\text { student } \\
\text { conferences. }\end{array}$ & $\begin{array}{l}\text { How many times did you meet with your instructor to discuss } \\
\text { your writing assignments this semester? }\end{array}$ & $\begin{array}{l}\text { Arabic numerals. } \\
\text { This variable will be } \\
\text { entered as continuous data. }\end{array}$ \\
\hline
\end{tabular}




\begin{tabular}{|c|l|l|l|l|}
\hline No. & \multicolumn{1}{|c|}{ Variable } & \multicolumn{1}{|c|}{ Conceptual Definition } & \multicolumn{1}{c|}{$\begin{array}{c}\text { Instrumental Definition } \\
\text { Operational } \\
\text { Definition }\end{array}$} \\
\hline 8. & $\begin{array}{l}\text { Gender } \\
\text { (GEN) }\end{array}$ & $\begin{array}{l}\text { Indicates student's male or female } \\
\text { gender. }\end{array}$ & $\begin{array}{l}\text { Gender } \\
\text { (0) Female } \\
\text { (1) Male }\end{array}$ & $\begin{array}{l}\text { Female }=0 \\
\text { Male }=1 \\
\text { This variable was } \\
\text { recoded as a dummy } \\
\text { variable and entered as } \\
\text { categorical data. The } \\
\text { number assigned is the } \\
\text { gender of the student. }\end{array}$ \\
\hline 9. & $\begin{array}{l}\text { Ethnicity } \\
\text { (ETH) }\end{array}$ & $\begin{array}{l}\text { Indicates the student's ethnic group, } \\
\text { following the guidelines of the U.S. } \\
\text { Department of Education for } \\
\text { collecting and reporting ethnic data } \\
\text { by educational institutions. }\end{array}$ & $\begin{array}{l}\text { Ethnicity } \\
\text { (0) Other } \\
(1) \text { White Non-Hispanic }\end{array}$ & $\begin{array}{l}\text { Other }=0 \\
\text { White Non-Hispanic }= \\
\text { This variable was } \\
\text { measured as categorical } \\
\text { data. The number } \\
\text { assigned is the } \\
\text { student's ethnic group. }\end{array}$ \\
\hline
\end{tabular}




\begin{tabular}{|c|l|l|l|l|}
\hline No. & \multicolumn{1}{|c|}{ Variable } & \multicolumn{1}{|c|}{ Conceptual Definition } & \multicolumn{1}{c|}{$\begin{array}{c}\text { Instrumental Definition } \\
\text { Operational } \\
\text { Definition }\end{array}$} \\
\hline 10. & $\begin{array}{l}\text { Language } \\
\text { Background } \\
\text { (LB) }\end{array}$ & $\begin{array}{l}\text { Indicates whether or not the student } \\
\text { speaks a first language other than } \\
\text { English. }\end{array}$ & $\begin{array}{l}\text { Is English your first language? } \\
\text { (0) No } \\
\text { (1) Yes }\end{array}$ & $\begin{array}{l}\text { No }=0 \\
\text { Yes }=1 \\
\text { A response of "No" } \\
\text { was assigned a "0". } \\
\text { This indicates that the } \\
\text { student's first language } \\
\text { is not English. } \\
\text { A response of "Yes" } \\
\text { was assigned a "1". } \\
\text { This indicates that the } \\
\text { student's first language } \\
\text { is English. } \\
\text { This variable was } \\
\text { recoded as a dummy } \\
\text { variable and entered as } \\
\text { categorical data. }\end{array}$ \\
\hline
\end{tabular}




\begin{tabular}{|c|c|c|c|c|}
\hline No. & Variable & Conceptual Definition & Instrumental Definition & Operational Definition \\
\hline 11. & $\begin{array}{l}\text { Writing Performance } \\
\text { (WP) }\end{array}$ & $\begin{array}{l}\text { Students' grades on their final } \\
\text { persuasive research paper, as } \\
\text { evaluated by their instructor. }\end{array}$ & $\begin{array}{l}\text { The researcher does not have } \\
\text { access to the primary data, or } \\
\text { instruments used by course } \\
\text { instructors. }\end{array}$ & 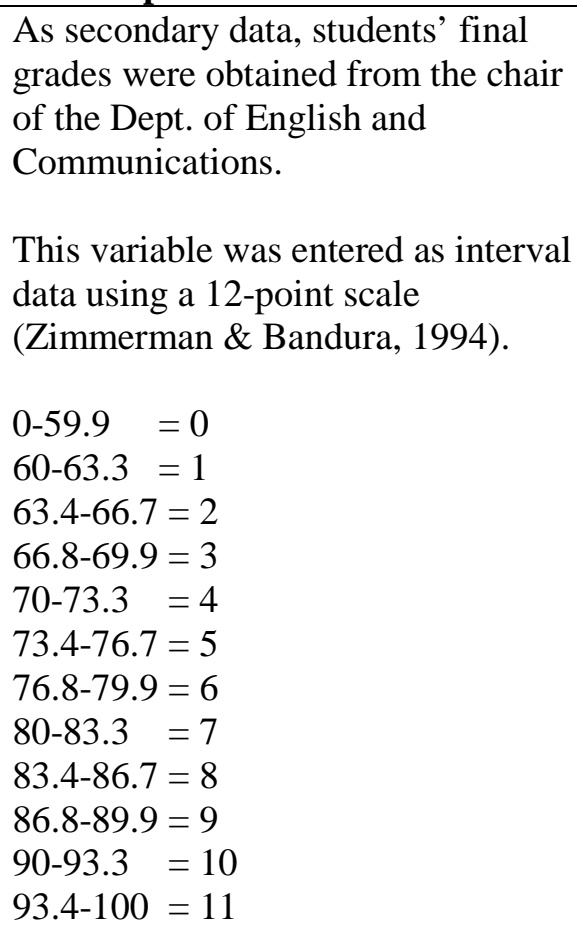 \\
\hline
\end{tabular}


APPENDIX C

INFORMED CONSENT FORM 


\section{Informed Consent}

This study seeks to identify factors which contribute to the writing performance of students enrolled in English Composition at Michigan community colleges. My completion of this questionnaire will benefit the educational community as a result of the outcomes of the study.

There are no risks, stressors, or discomforts associated with my completion of this questionnaire.

You are asked to answer several questions that should take no more than 15 minutes to complete. There are no right or wrong answers. We only asked that you answer honestly and candidly. To participate in this study, you must be at least 18 years old. You may withdraw from answering the questions in this survey at any time.

You will be asked to include your name in the survey because it will be correlated with your ACT English score and grade on the final writing assignment in English Composition. However, the information that identifies you will be coded as soon as the results are received. Only the coded information will be used to analyze the data. Only the researcher will have access to your individual survey responses and the results. The records will be kept in a locked safe, and password protected computer for a period not less than 3 years. After completing this survey, you will be given an opportunity to participate in a drawing for one of five $\$ 25$ gift vouchers.

If you have any questions about this study, please contact the following:

Researcher:

Thula I. Lambert, PhD Student

thulalambert@gmail.com

Academic Advisor

Elvin Gabriel, PhD

gabriel@andrews.edu

\section{Informed Consent:}

By signing this form, I am indicating that I am voluntarily participating in this study. I have read the contents of this Consent and received verbal explanations to questions I had. My questions concerning this study have been answered satisfactorily. I understand that I am giving permission for my institution to release my ACT English score and grade on the final writing assignment in English Composition. I understand that the information gathered in this study will be kept completely confidential, and that no references will be made in written or oral materials that could link me personally to this study.
Signature
(Subject)
Date

Researcher Signature

Phone

Date 
APPENDIX D

CORRESPONDENCE 
Thula I. Lambert

4461 International Ct. Apt. 50

Berrien Springs, MI 49103

Email: thulalambert@gmail.com

March 17, 2015

Institutional Review Board

A Michigan Community College*

Dear Members of the Institutional Review Board,

Re: Permission to Conduct Research at A Michigan Community College

I am currently completing requirements for the Doctor Philosophy degree in Curriculum and Instruction at Andrews University in Berrien Springs, Michigan. I am seeking your permission to conduct research for my dissertation at a Michigan College between April 1 and April 30, 2015. College is one of two community colleges which, once permission is granted, will participate in this study.

The topic of my dissertation is An Investigation of the Influence of Personal, Behavioral, and Environmental Factors on the Writing Performance of First-Year Students at Selected Michigan Community Colleges. Data will be collected from students enrolled in English Composition (ENGL 103). A copy of the completed IRB application, the research proposal, and supporting documents have been included along with this request for permission.

My research application has been screened by the IRB of my home institution, and I have obtained provisional approval to conduct this study. If you grant institutional consent, and after final approval by the Andrews University IRB, a recruitment letter will be sent out to students soliciting their participation. The cooperation of the Chair of the Department of Communication will be sought in order to facilitate access to students, and the data collection process.

Once the dissertation is completed, a copy will be provided to your institution. I believe that the findings from this study will be beneficial to students, faculty, and administration.

Sincerely,

Tula I Lavente

Thula Lambert

Attachments (7)

- A Michigan Community College is a pseudonym 


\section{Invitation to Participate in a Research Project}

\section{Dear Student:}

You are invited to participate in a research survey that examines students' writing performance in a first-year English Composition course. The study is being conducted by a doctoral candidate in Curriculum and Instruction at Andrews University. The study hopes to identify factors which influence students' writing performance. The findings should be beneficial to the educational community.

The study involves completing a paper survey, and should require no more than 15 minutes of your time. The study will necessitate obtaining your ACT English scores and your grade on your final major writing assignment. If you are willing to participate in this research project, you will be asked to give your informed consent. The information you provide will be treated with the strictest confidentiality.

If you complete the survey, you will be given an opportunity to participate in a drawing for one of five $\$ 25$ gift vouchers.

If you are under the age of 18, or not enrolled in a first-year English Composition course, please disregard this e-mail.

Thank you for your participation in this very important research! 


\section{English 103 Research Study}

Dear Professor

My name is Thula Lambert, and I have been granted permission by the Institutional Review Board to conduct research for my dissertation among students currently enrolled in English Composition 103. I will be collecting data during the month of April at two area community colleges, including A Michigan Community College.

The topic of my dissertation is 'An Investigation of the Influence of Personal, Behavioral, and Environmental Factors on the Writing Performance of First-Year Students at Selected Michigan Community Colleges'. Students will sign an informed consent form and complete a paper survey, which should require no more than 15 minutes to complete. I may also need about 5 minutes to answer any questions students might have. I am aware that this is a very busy time of the semester, and your willingness to accommodate me is greatly appreciated. Please let me know the best date and time for me to visit your class to administer the surveys. If you teach multiple sections of English 103, I would like to visit all of them. Thank you for your kind consideration.

Sincerely,

Thula Lambert 
Permission to Use the Writing Self-Regulatory Efficacy Scale

thula lambert <thulalambert@gmail.com>

to bzimmerman, bandura

Dear Professors Zimmerman and Bandura,

I am in the process of writing my dissertation proposal and I would like to use your instrument, the Writing Self-Regulatory Efficacy Scale as one of the instruments in my study. Would you be willing to share your instrument and the method of data analysis? If yes, what are your conditions?

Sincerely,

Thula Lambert

PhD Candidate

Andrews University, Berrien Springs, MI

Barry Zimmerman <bzimmerman@gc.cuny.edu>

to me, bandura

Hi Thula:

I will attach a copy of the Writing Self-regulatory Efficacy Scale. You have my permission to use it in your research. The best source for administering the scale and for analyzing your results is our published article. Good luck with your research.

Barry Zimmerman 


\section{Permission to Use Writing Self-Efficacy Scales}

\section{thula lambert <thulalambert@gmail.com>}

Dear Professor Jones,

I am in the process of writing my dissertation proposal and I would like to use the writing selfefficacy scales from your 2008 study. Would you be willing to share your instrument and code book? If yes, what are your conditions?

Sincerely,

Thula Lambert

PhD Candidate in Curriculum and Instruction

Andrews University, Berrien Springs, MI 


\section{Edmund $\mathrm{H}$ Jones <Edmund.Jones@shu.edu>}

to me

Thula,

I'd be happy to let you use the scales I modified/developed. Attached is the instrument. All items are coded positively on the tasks and skills scales. On the behavior scale, the valence of each item is indicated by a plus or minus after the item. There is nothing magical about the 6point Likert scale, though I chose it to make it impossible for students to choose a neutral response that is possible with the middle point of, say, a 5- of 7-point scale. If you have any question, feel free to write back.

My only condition is that you cite my article in your dissertation and any further publication of your work. Best of luck!

Ed Jones

Associate Professor of Writing

Director of Basic Writing and Assessment

English Department

Seton Hall University 


\section{APPENDIX E}

OBSERVED MODEL DATA (IBM SPSS AMOS 21) 


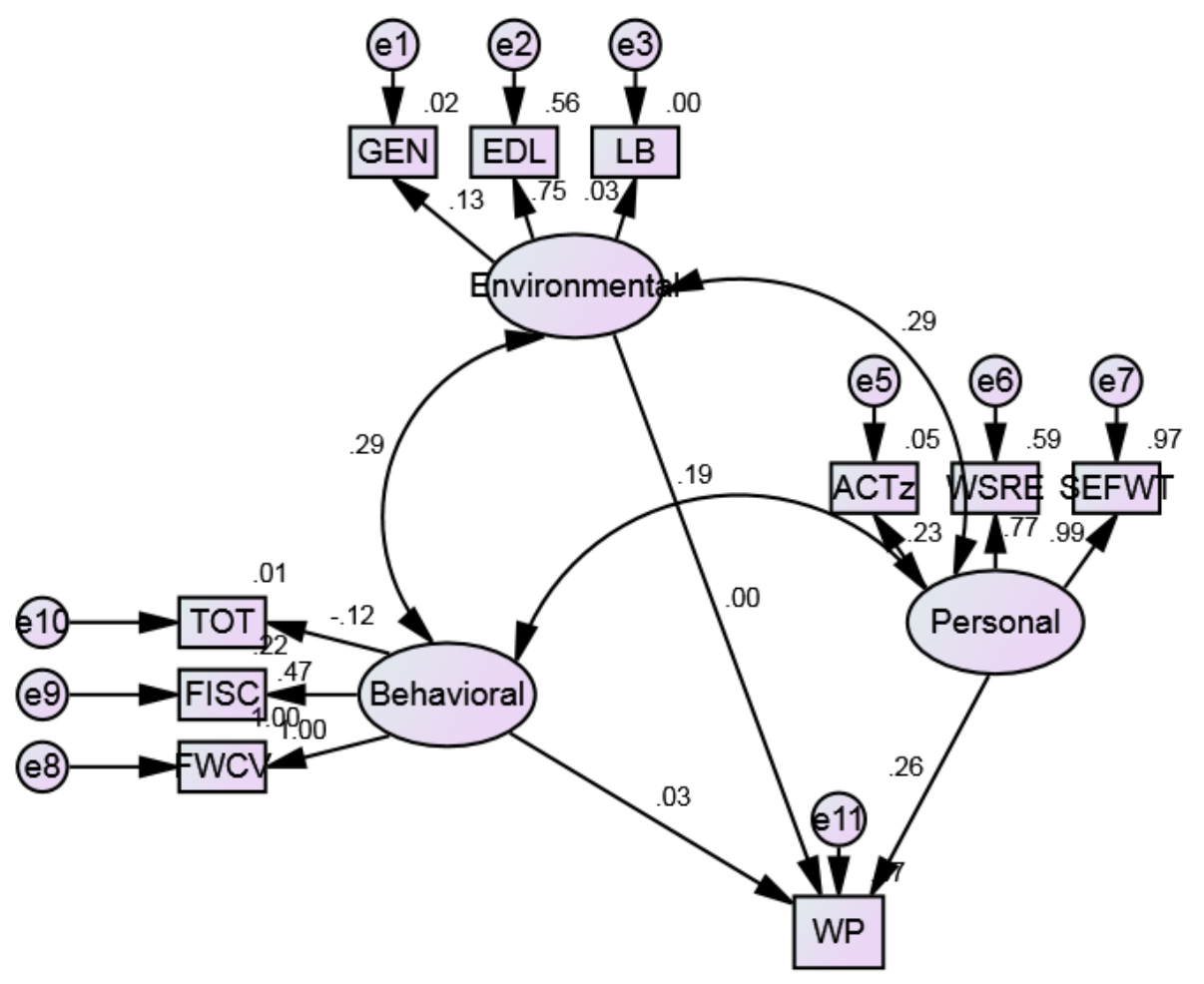




\section{Model Fit Summary}

\section{CMIN}

\begin{tabular}{|l|rrrrr|}
\hline Model & NPAR & CMIN & DF & P & CMIN/DF \\
\hline Default model & 22 & 41.110 & 33 & .157 & 1.246 \\
Saturated model & 55 & .000 & 0 & & \\
Independence model & 10 & 209.666 & 45 & .000 & 4.659 \\
\hline
\end{tabular}

\section{RMR, GFI}

\begin{tabular}{|l|rrrr|}
\hline Model & RMR & GFI & AGFI & PGFI \\
\hline Default model & 3.102 & .940 & .899 & .564 \\
Saturated model & .000 & 1.000 & & \\
Independence model & 21.950 & .772 & .722 & .632 \\
\hline
\end{tabular}

\section{Baseline Comparisons}

\begin{tabular}{|l|rrrrr|}
\hline Model & $\begin{array}{r}\text { NFI } \\
\text { Delta1 }\end{array}$ & $\begin{array}{r}\text { RFI } \\
\text { rho1 }\end{array}$ & $\begin{array}{r}\text { IFI } \\
\text { Delta2 }\end{array}$ & $\begin{array}{r}\text { TLI } \\
\text { rho2 }\end{array}$ & CFI \\
\hline Default model & .804 & .733 & .954 & .933 & .951 \\
Saturated model & 1.000 & & 1.000 & & 1.000 \\
Independence model & .000 & .000 & .000 & .000 & .000 \\
\hline
\end{tabular}

Parsimony-Adjusted Measures

\begin{tabular}{|l|rrr|}
\hline Model & PRATIO & PNFI & PCFI \\
\hline Default model & .733 & .590 & .697 \\
Saturated model & .000 & .000 & .000 \\
Independence model & 1.000 & .000 & .000 \\
\hline
\end{tabular}

NCP

\begin{tabular}{|l|rrr|}
\hline Model & NCP & LO 90 & HI 90 \\
\hline Default model & 8.110 & .000 & 28.606 \\
Saturated model & .000 & .000 & .000 \\
Independence model & 164.666 & 123.374 & 213.500 \\
\hline
\end{tabular}

\section{FMIN}

\begin{tabular}{|l|rrrr|}
\hline Model & FMIN & F0 & LO 90 & HI 90 \\
\hline Default model & .332 & .065 & .000 & .231 \\
Saturated model & .000 & .000 & .000 & .000 \\
Independence model & 1.691 & 1.328 & .995 & 1.722 \\
\hline
\end{tabular}


RMSEA

\begin{tabular}{|l|rrrr|}
\hline Model & RMSEA & LO 90 & HI 90 & PCLOSE \\
\hline Default model & .045 & .000 & .084 & .552 \\
Independence model & .172 & .149 & .196 & .000 \\
\hline
\end{tabular}

AIC

\begin{tabular}{|l|rrrr|}
\hline Model & AIC & BCC & BIC & CAIC \\
\hline Default model & 85.110 & 89.393 & 147.333 & 169.333 \\
Saturated model & 110.000 & 120.708 & 265.557 & 320.557 \\
Independence model & 229.666 & 231.613 & 257.949 & 267.949 \\
\hline
\end{tabular}

\section{ECVI}

\begin{tabular}{|l|rrrr|}
\hline Model & ECVI & LO 90 & HI 90 & MECVI \\
\hline Default model & .686 & .621 & .852 & .721 \\
Saturated model & .887 & .887 & .887 & .973 \\
Independence model & 1.852 & 1.519 & 2.246 & 1.868 \\
\hline
\end{tabular}

HOELTER

\begin{tabular}{|l|rr|}
\hline \multirow{2}{*}{ Model } & HOELTER & HOELTER \\
& .05 & .01 \\
\hline Default model & 143 & 166 \\
Independence model & 37 & 42 \\
\hline
\end{tabular}

Scalar Estimates (Group number 1 - Default model)

Maximum Likelihood Estimates

Regression Weights: (Group number 1 - Default model)

\begin{tabular}{|c|c|c|c|c|c|c|c|}
\hline & & & Estimate & S.E. & C.R. & $\mathrm{P}$ & Label \\
\hline GEN & $<---$ & F1 & 1.000 & & & & \\
\hline EDL & $<---$ & $\mathrm{F} 1$ & 17.812 & 16.654 & 1.070 & .285 & \\
\hline LB & $<---$ & $\mathrm{F} 1$ & .150 & .547 & .274 & .784 & \\
\hline PWA_ACTz & $<---$ & F2 & 1.000 & & & & \\
\hline WSRE & $<---$ & $\mathrm{F} 2$ & 79.686 & 31.051 & 2.566 & .010 & \\
\hline SEFWT & $<---$ & $\mathrm{F} 2$ & 29.166 & 11.155 & 2.615 & .009 & \\
\hline FWCV & $<---$ & Behav & 1.000 & & & & \\
\hline FISC & $<---$ & Behav & .231 & .039 & 5.950 & $* * *$ & \\
\hline TOT & $<---$ & Behav & -.012 & .009 & -1.290 & .197 & \\
\hline
\end{tabular}




\begin{tabular}{|c|c|c|c|c|c|c|}
\hline & & Estimate & S.E. & C.R. & $\mathrm{P}$ & Label \\
\hline WP & $\begin{array}{l}<-- \\
\end{array}$ & 31.385 & 16.621 & 1.888 & .059 & \\
\hline WP & $<---\quad$ F1 & -.291 & 51.070 & -.006 & .995 & \\
\hline WP & $<---$ Behav & .072 & 249 & .289 & .773 & \\
\hline
\end{tabular}

Standardized Regression Weights: (Group number 1 - Default model)

\begin{tabular}{|lll|r|}
\hline & & & Estimate \\
\hline GEN & $<---$ & F1 & .126 \\
EDL & $<---$ & F1 & .745 \\
LB & $<---$ & F1 & .033 \\
PWA_ACTz & $<---$ & F2 & .232 \\
WSRE & $<---$ & F2 & .767 \\
SEFWT & $<---$ & F2 & .986 \\
FWCV & $<---$ & Behav & 1.000 \\
FISC & $<---$ & Behav & .471 \\
TOT & $<---$ & Behav & -.115 \\
WP & $<---$ & F2 & .259 \\
WP & $<---$ & F1 & -.001 \\
WP & $<---$ & Behav & .027 \\
\hline
\end{tabular}

Covariances: (Group number 1 - Default model)

\begin{tabular}{|ll|rrrrr|}
\hline & & Estimate & S.E. & C.R. & P & Label \\
\hline F1 <--> & Behav & .169 & .171 & .984 & .325 & \\
F1 <--> & F2 & .004 & .004 & .918 & .359 & \\
F2 <--> & Behav & .363 & .224 & 1.620 & .105 & \\
\hline
\end{tabular}

Correlations: (Group number 1 - Default model)

\begin{tabular}{|c|c|}
\hline & Estimate \\
\hline F1 <--> Behav & .288 \\
\hline$F 1<-->\quad F 2$ & .286 \\
\hline F2 <--> Behav & .191 \\
\hline
\end{tabular}

Variances: (Group number 1 - Default model)

\begin{tabular}{|l|rrrrr|}
\hline & Estimate & S.E. & C.R. & P & Label \\
\hline F1 & .004 & .007 & .538 & .591 & \\
F2 & .042 & .032 & 1.291 & .197 & \\
Behav & 86.850 & 11.030 & 7.874 & $* * *$ & \\
e2 & 1.000 & & & & \\
e7 & 1.000 & & & & \\
\hline
\end{tabular}




\begin{tabular}{|l|rrrrr|}
\hline & Estimate & S.E. & C.R. & P & Label \\
\hline e8 & .000 & & & & \\
e1 & .245 & .032 & 7.785 & $* * *$ & \\
e3 & .080 & .010 & 7.868 & $* * *$ & \\
e5 & .735 & .093 & 7.862 & $* * *$ & \\
e6 & 184.994 & 24.437 & 7.570 & $* * *$ & \\
e9 & 16.240 & 2.063 & 7.874 & $* * *$ & \\
e10 & .885 & .112 & 7.874 & $* * *$ & \\
e11 & 570.450 & 72.588 & 7.859 & $* * *$ & \\
\hline
\end{tabular}

Squared Multiple Correlations: (Group number 1 - Default model)

\begin{tabular}{|l|r|}
\hline & Estimate \\
\hline WP & .070 \\
TOT & .013 \\
FISC & .222 \\
FWCV & 1.000 \\
SEFWT & .973 \\
WSRE & .589 \\
PWA_ACTz & .054 \\
LB & .001 \\
EDL & .555 \\
GEN & .016 \\
\hline
\end{tabular}




\section{REFERENCE LIST}

ACT. (2015). The condition of college and career readiness 2015: National. Retrieved from https://www.act.org/research/policymakers/cccr15/pdf/CCCR15NationalReadinessRpt.pdf

ACT. (2014). Michigan ACT profile report: State. Retrieved from https://www.act.org/newsroom/data/2014/pdf/profile/Michigan.pdf

ACT, \& Council for Opportunity in Education. (2015). The condition of college and career readiness 2014: First-generation students. Retrieved from http://www.act.org/newsroom/data/2014/states/pdf/FirstGeneration.pdf

ACT, \& United Negro College Fund. (2015). The condition of college and career readiness 2014: African American Students. Retrieved from https://www.act.org/newsroom/data/2014/states/pdf/AfricanAmerican.pdf

American Psychological Association (n.d.). Education and socioeconomic status. Retrieved from http://apa.org/pi/ses/resources/publications/factsheeteducation.pdf

Arbuckle, J. L. (2012). Amos (Version 21.0) [Computer Program]. Chicago, IL: IBM SPSS.

Arter, J. \& McTighe, J. (2000). Scoring rubrics in the classroom: Using performance criteria for assessing and improving student performance. Thousand Oaks, CA: Corwin Press.

Arum, R. \& Roska, J. (2011). Academically adrift: Limited learning on college campuses. Chicago, IL: University of Chicago Press.

Astin, A. (1993). What Matters in College? Four Critical Years Revisited. The Journal of Higher Education, 65(5), 615-622.

Astin, A. (1999). Student involvement: A developmental theory for higher education. Journal of College Student Development, 40(5), 518-529. Retrieved from https://www.middlesex.mass.edu/ace/downloads/astininv.pdf

Bandura, A. (1977). Self-efficacy: Toward a unifying theory of behavioral change. Psychological Review, 84(2), 191-215. Retrieved from http://citeseerx.ist.psu.edu/viewdoc/download?doi=10.1.1.315.4567\&rep=rep1\&t ype $=$ pdf

Bandura, S. (1977). Social learning theory. Englewood Cliffs, NJ: Prentice-Hall. 
Bandura, A. (1978). The self-system in reciprocal determinism. American Psychologist, 33(4), 344-358.

Bandura, A. (1989). Human agency in social cognitive theory. American Psychologist, 44(9), 1175-1184.

Bandura, A. (1997). Self-efficacy: The exercise of control. New York: W. H. Freeman.

Bandura, A. (2001). Social cognitive theory: An agentic perspective. Annual Review of Psychology, 52, 1-26. doi: 10.1146/annurev.psych.52.1.1

Bandura, A. (2006). Toward a psychology of human agency. Perspectives on Psychological Science, 1(2), 164-180. doi: 10.1111/j.1745-6916.2006.00011.x

Bandura, A. (2006). In F. Pajares \& T. Urdan (Eds.), Self-efficacy beliefs of adolescents (pp. 307-337). Greenwich, CT: Information Age Publishing.

Bandura, A., Barbaranelli, C., Caprara, G. V., \& Pastorelli, C. (1996). Multifaceted impact of self-efficacy beliefs on academic functioning. Child Development, 67(3), 1206-1222. doi: 10.2307/1131888

Barker, C., Pinstrang, N., \& Elliot, R. (2002). Research methods in clinical psychology: An introduction for students and practitioners. Chichester, West Sussex: John Wiley \& Sons.

Battaglia, M. (2008). Convenience sampling. In Paul J. Lavrakas (Ed.), Encyclopedia of survey research methods. Thousand Oaks, CA: Sage Publications. doi: http://dx.doi.org/10.4135/9781412963947

Bayraktar, A. (2009). An exploration of the teacher-student writing conference and the potential influence of self-efficacy (Doctoral dissertation). Retrieved from Proquest Dissertation Publishing. (Accession No. 3373970).

Beach, R. (1989). Demonstrating techniques for assessing writing in the writing conference. College Composition and Communication, 37(1), 56-65. Retrieved from http://www.jstor.org/stable/357382

Borman, K., Halperin, R., and Tyson, W. (Eds.), (2010). Becoming an engineer in public universities: Pathways for women and minorities. Retrieved from http://www.palgraveconnect.com/pc/doifinder/10.1057/9780230106826

Boscolo, P. \& Hidi, S. (2007). The multiple meanings of motivation to write. In G. Rijlaarsdam (Series Ed.) and P. Boscolo \& S. Hidi (Volume Eds.), Studies in Writing, Volume 19, Writing and Motivation (pp. 1-14). Oxford: Elsevier.

Bradley, H. \& Corwyn, R. (2002). Socioeconomic status and child development. Annual Review, 53, 371-399. Retrieved from http://www.opleidingjgz.be/bestanden/2012-2013/annurev.psychol.Bradley.pdf

Braine, G. (1996). ESL students in first-year writing classes: ESL versus mainstream classes. Journal of Second Language Writing, 5(2), 91-107. doi:10.1016/S10603743(96)90020-X 
Brown, S. D., Lent, R. W., \& Larkin, K. C. (1989). Self-efficacy as a moderator of scholastic aptitude-academic performance relationships. Journal of Vocational Behavior, 35(1), 64-75. doi: 10.1016/0001-8791(89)90048-1

Byrne, B. M. (1994). Structural equation modeling with EQS and EQS/Windows. Thousand Oaks, CA: Sage Publications.

Caprara, G. V., Vecchione, M., Alessandri, G., Gerbino, M., \& Barbaranelli, C. (2011). The contribution of personality traits and self-efficacy beliefs to academic achievement: A longitudinal study. British Journal of Educational Psychology, 81(1), 78-96. doi: 10.1348/2044-8279.002004

Carino, P. (1995). Early writing centers: Toward a history. The Writing Center Journal, 15(2), 103-115. Retrieved from http://casebuilder.rhet.ualr.edu/wcrp/publications/wcj/wcj15.2/wcj15.2_carino.pdf

Carroll, L. (2002). Rehearsing new roles: How college students develop as writers. Carbondale, IL: Southern Illinois University Press. Retrieved from http://wac.colostate.edu/books/carroll/roles.pdf

Center for Community College Student Engagement (2015). Engagement rising: A decade of CCSSE data shows improvement across the board [Report supplement and methodology]. Retrieved from http://www.ccsse.org/center/resources/docs/publications/Engagement_Rising_Me thodology.pdf

Center for Community College Student Engagement (2015). Engagement rising: A decade of CCSSE data shows improvement across the board. Retrieved from http://www.ccsse.org/docs/Engagement_Rising.pdf

Charney, D. (1984). The validity of using holistic scoring to evaluate writing: A critical overview. Research on the Teaching of Writing, 18(1), 65-81. Retrieved from http://www.jstor.org/stable/40170979

Cherry, R. \& Meyer, P. (2009). Reliability issues in holistic assessment. In B. Huot and P. O’Neill, (Eds.), Assessing writing: A critical sourcebook (pp. 29-56). Boston, MA: Bedford St. Martins.

Coker, D. \& Lewis, W. (2008). Beyond writing next: A discussion of writing research and instructional uncertainty. Harvard Educational Review, 7(1), 231-250.

College Board (2003). The neglected ' $R$ ': The need for a writing revolution. Report of the National Commission on Writing in America's Schools and Colleges. Retrieved from http://www.collegeboard.com/prod_downloads/writingcom/neglectedr.pdf

College Board. (2009). ACT and SAT concordance tables. Office of Research and Development (Research Note No. 40). Retrieved from http://research.collegeboard.org/sites/default/files/publications/2012/7/researchnot e-2009-40-act-sat-concordance-tables.pdf

Common Core State Standards Initiative. (2014). Key shifts in English language arts. Retrieved from http://www.corestandards.org/other-resources/key-shifts-in- 
english-language-arts/

Community College Research Center, Teachers College Columbia University (n.d.). The role of the community college. Retrieved from http://ccrc.tc.columbia.edu/TheRole-of-the-Community-College.html

Conference on College Composition and Communication (2001). CCCC statement on second language writing and writers. Retrieved from http://www.ncte.org/cccc/resources/positions/secondlangwriting

Conference on College Composition and Communication (2006). Writing assessment: A position statement. Retrieved from http://www.ncte.org/cccc/resources/positions/writingassessment

Council of Writing Program Administrators, the National Council of Teachers of English, $\&$ the National Writing Project (2011). Framework for success in postsecondary writing. Retrieved from http://files.eric.ed.gov/fulltext/ED516360.pdf

Council of Writing Program Administrators (2014). Writing outcomes statement for firstyear composition. Retrieved from http://wpacouncil.org/positions/outcomes.html

Creswell, J. (2009). Research design: Qualitative, quantitative, and mixed methods approaches. Los Angeles, CA: Sage Publications.

Creswell, J. (2012). Educational research: Planning, conducting, evaluating. Boston, MA: Pearson. Retrieved from http://basu.nahad.ir/uploads/creswell.pdf

Cutolo, A. (2007). The relationship(s) among learning-style preferences, age, college grade point average, ethnic background, gender, major discipline, and socioeconomic status of undergraduate students at a large private metropolitan university. (Doctoral dissertation). Retrieved from Proquest Dissertation Publishing. (Accession No. 3237781).

Daly, J. \& Miller, M. (1975). The empirical development of an instrument to measure writing anxiety. Research in the Teaching of English, 9(3), 242-249.

Davis, T. (2008). Socioeconomic status, selective college admissions, and the first-year college experience (Doctoral dissertation). Retrieved from Proquest Dissertation Publishing. (Accession No. 3316946).

De Bernardi, B. \& Antolini, E. (2007). Fostering students’ willingness and interest in argumentative writing: An intervention study. In G. Rijlaarsdam (Series. 183202). Oxford: Elsevier.

Di Gennaro, K. (2009). Investigating differences in the writing performance of international and Generation 1.5 students. Language Testing, 26(4), 533-559. doi: $10.1177 / 0265532209340190$

Devonport, T. J., \& Lane, A. M. (2006). Relationships between self-efficacy, coping and student retention. Social Behavior \& Personality: An International Journal, 34(2), 127-138. Retrieved from http://search.proquest.com/docview/209898913?accountid=8313 
Doolan, S. (2013). Generation 1.5 writing compared to L1 and L2 writing in first-year composition. Written Communication, 30(2) 135-163.

doi:10.1177/0741088313480823

Doolan, S. (2014). Comparing language use in the writing of developmental generation 1.5, L1, and L2 tertiary students. Written Communication, 31(2), 215-247. doi: $10.1177 / 0741088314526352$

Dougherty, K. \& Townsend, B. (2006). Community college missions: A theoretical and historical perspective. New Directions for Community College, (136), 5-13. doi: $10.1002 / \mathrm{cC}$

Dubow, E., Boxer, P., \& Huesmann, L. (2009). Long-term effects of parents’ education on children's educational and occupational stress: Mediation by family interactions, child aggression, and teenage aspirations. Merril Palmer Q (Wayne State University Press) 55(3): 224-249. doi:10.1353/mpq.0.0030.

Ekholm, E., Zumbrunn, S., \& Conklin, S. (2015). The relation of college student selfefficacy toward writing and writing self-regulation aptitude: Writing feedback as a mediating variable. Teaching in Higher Education, 20(2), 197-207. doi: http://dx.doi.org/10.1080/13562517.2014.974026

Ekși, G. (2012). Peer review versus teacher feedback in process writing: How effective? International Journal of Applied Environmental Science 13(1), 33-48.

Emig, J. (1971). The composing processes of twelfth graders. Urbana, IL: National Council of Teachers of English.

Fink, A. (2003). The survey handbook. Thousand Oaks, CA: Sage Publications.

Fleischer, C. (2012). A case for collaboration: Intertwined roots, interwoven futures. In P. Stock (Ed.), Composition's roots in English education (pp. 160-163). Portsmouth, NH: Heinemann.

Flower, L., \& Hayes, J. R. (1981). A cognitive process theory of writing. College Composition and Communication, 32(4), 365-387. Retrieved from http://www.jstor.org/stable/356600

Fowler, F. (2009). Survey research methods. Los Angeles, CA: Sage Publications.

Gore, P. A. (2006). Academic self-efficacy as a predictor of college outcomes: Two incremental validity studies. Journal of Career Assessment, 14(1), 92-115. doi: $10.1177 / 1069072705281367$

Grbic, D., Jones, D. \& Case, S. (2013). Effective practices for using the AAMC socioeconomic status indicators in medical school admissions. Association of American Medical Colleges. Retrieved from https://www.aamc.org/download/330166/data/seseffectivepractices.pdf

Grinnell, C. (2003). The effect of a writing center on developmental student writing apprehension and writing performance (Doctoral dissertation). Retrieved from Proquest Dissertation Publishing. (Accession No. 3119003). 
Gulley, B. (2012). Feedback on developmental writing students first drafts. Journal of Developmental Education, 36(1), 16-36.

Hahs-Vaughn, D. (2004). The impact of parents' educational level on college students: An analysis using the beginning post-secondary students' longitudinal study 1990-92/94. Journal of College Student Development, 45(5), 483-500.

Hair, J., Black, W., Babin, B., \& Anderson, R. (2009). Multivariate data analysis (7 ed.). Upper Saddle River, NJ: Prentice Hall.

Hammann, L. (2005). Self-regulation in academic writing tasks. International Journal of Teaching and Learning in Higher Education, 17(1), 15-26. Retrieved from http://www.isetl.org/ijtlhe/pdf/ijtlhe14.pdf

Haswell, R. (2008). Teaching of writing in higher education. In C. Bazerman, (Ed.), Handbook of research on writing: History, society, school, individual, text (pp. 331-346). New York: Lawrence Erlbaum Associates.

Hayes, J., Hatch, J., and Silk, C. (2000). Does holistic assessment predict writing performance? Estimating the consistency of student performance on holistically scored writing assignments. Written Communication, 17(1), 3-26. doi: 10.1177/0741088300017001001

Hewett, B. (2006). Synchronous online conference-based instruction: A study of whiteboard interactions and student writing. Computers and Composition, 23, 421. doi:10.1016/j.compcom.2005.12.004

Hidi, S., \& Boscolo, P. (2006). Motivation and writing. In C. MacArthur, S. Graham, \& J. Fitzgerald, (Eds.), Handbook of writing research (pp. 144-157). New York: The Guilford Press.

Howell, D. (2013). Statistical methods for psychology. Belmont, CA: Wadsworth.

Hu, L. \& Bentler, P. (1999). Cutoff criteria for fit indexes in covariance structure analysis: Conventional criteria versus new alternatives. Structural Equation Modeling: A Multidisciplinary Journal, 6(1), 1-55. doi: 10.1080/10705519909540118

Huck, S. (2012). Reading statistics and research ( $6^{\text {th }}$ ed.). Boston, MA: Pearson.

Huot, B. \& O’Neill, P. (2009). (Eds.), Assessing writing: A critical sourcebook (pp. 131149). Boston, MA: Bedford/St. Martin.

IBM Corp. Released 2013. IBM SPSS Statistics for Windows, Version 22.0. Armonk, NY: IBM Corp.

Isaacs, E., \& Knight, M. (2013). Assessing the impact of the Outcomes Statement. In N. Behm, G. Glau, D. Holdstein, D. Roen \& E. White (Eds.), The WPA outcomes statement: A decade later, (pp. 285-309). Anderson, SC: Parlor Press.

Jacobs, S. \& Karliner, A. (1977). Helping writers to think: The effect of speech roles in individual conferences on the quality of thought in student writing. College 
English, 38(5), 489-505. Retrieved from www.jstor.org/stable/376387

Jones, E. (2008). Predicting performance in first-semester college basic writers: Revisiting the role of self-beliefs. Contemporary Educational Psychology, 33(2), 209-238. doi: http://dx.doi.org/10.1016/j.cedpsych.2006.11.001

Khine, M., Ping, L., \& Cunningham, D. (2013). (Eds.). Application of structural equation modeling in educational research and practice. Rotterdam, The Netherlands: Sense Publishers.

Kieth, T. (2006). Multiple regression and beyond: An introduction to multiple regression and structural equation modeling $\left(2^{\text {nd }}\right.$ ed.). New York: Taylor and Francis.

Kirschner, S. \& Poteet, G. (1973). Non-standard English usage in the writing of black, white, and Hispanic remedial English students in an urban community college. Research in the Teaching of English, 7(3), 351-355. Retrieved from http://www.jstor.org/stable/40170723

Kline, R. (2011). Principles and practice of structural equation modeling ( $3^{\text {rd }}$ ed.). New York, NY: The Guilford Press.

Kraska, M. (2010). Quantitative research. In Neil J. Salkind (Ed.), Encyclopedia of Research Design (pp. 1167-1172). doi: http://dx.doi.org/10.4135/978141288.n352

Lent, B., Larkin, K.C. (1984). Relation of self-efficacy expectations to academic achievement and persistence. Journal of Counseling Psychology, 31(3), 356-362. doi: http://dx.doi.org/10.1037/0022-0167.31.3.356

Lent, R. W., Brown, S. D., \& Larkin, K. C. (1986). Self-efficacy in the prediction of academic performance and perceived career options. Journal of Counseling Psychology, 33(3), 265-269. doi: http://dx.doi.org/10.1037/0022-0167.33.3.265

Lerner, N. (2005). The teacher-student writing conference and the desire for intimacy. College English, 68(2), 186-208. Retrieved from http://www.jstor.org/stable/30044673

Liu, Y. (2009). ESL students in the college writing conferences: Perception and participation (Doctoral dissertation). Retrieved from Proquest Dissertation Publishing. (Accession No. 3359771).

Loehlin, J. (2004). Latent variable models: An introduction to factor, path, and structural equation analysis ( $4^{\text {th }}$ ed). Mahwah, NJ: Lawrence Erlbaum Associates.

MacArthur, C. A. (2007). Best practice in teaching evaluation and revision. In S. Graham, C. MacArthur, \& J. Fitzgerald (Eds.), Best practice in writing instruction (pp. 141-162). New York: Guilford.

Marshall, C. \& Rossman, G. (2011). Designing qualitative research. $\left(5^{\text {th }}\right.$ ed.). Thousand Oaks, CA: Sage Publications.

McCarthy, P., Meier, S., \& Rinderer, R. (1985). Self-efficacy and writing: A different view of self-evaluation. College Composition and Communication, 36(4), 465- 
471. doi: $10.2307 / 357865$

McClenney, K., \& Marti, C. (2006). Exploring the relationships between student engagement and student outcomes in community colleges: Report on validation research. (Unpublished Paper). Retrieved from http://www.ccsse.org/center/resources/docs/publications/CCSSE_Validation_Res earch.pdf

McComiskey, B. (2012). Bridging the divide: The (puzzling) framework and the transition from K-12 to college writing instruction. College English, 74(6), 520524.

McGuire, M., Reynolds, A. \& Delahunt, B. (2013). Self-efficacy in academic reading and writing: Authorial identity and learning strategies in first-year students. All Ireland Journal of Teaching and Learning in Higher Education, 5(1), 1111-1117. Retrieved from http://ojs.aishe.org/aishe/index.php/aishe-j/article/view/111/168

McLeod, S. (1987). Some thoughts about feelings: The affective domain and the writing process. College Composition and Communication, 38(4), 426-435. Retrieved from http://www.jstor.org/stable/357635

McMillan, J. \& Schumacher, S. (2010). Research in education: Evidence-based inquiry. Boston, MA: Pearson.

Meece, J., Wigfield, A. \& Eccles, J. (1990). Predictors of math anxiety and its influence on young adolescents' course enrollment intentions and performance in mathematics. Journal of Educational Psychology, 82(1), 60-70.

Meier, S., McCarthy, P., \& Schmeck, R. (1984). Validity of self-efficacy as a predictor of writing performance. Cognitive Therapy and Research, 8(2), 107-120. doi: 10.1007/BF01173038

Meyers, L., Gamst, G., \& Guarino, A. (2013). Applied multivariate research: Design and interpretation. Los Angeles, CA: Sage Publications, Inc.

Michigan Association of Collegiate Registrars and Admissions Officers (2014). The MACRO transfer agreement: The Michigan college student guide for transfer of general education credits within the state of Michigan. Retrieved from https://www.macrao.org/Publications/MACRAOAgreement.asp

Michigan Community College Network. Fall 2013 Enrollment by Community College, Ethnicity, and Gender. Retrieved from http://www.michigancc.net/ccdata/enrollments/ea13/Default.aspx

Michigan Workforce Development Agency (2013). Directory of Michigan Community Colleges. Retrieved from http://www.michigancc.net/resource/2013CommunityCollegeDirectory.pdf

Multon, K., Brown, S. \& Lent, R. (1991). Relation of self-efficacy beliefs to academic outcomes: A meta-analytic investigation. Journal of Counseling Psychology, 
38(1), 30-38.

Murphy, S., \& Yancey, K. B. (2008). Construct and consequence: Validity in writing assessment. In C. Bazerman (Ed.), Handbook of research on writing: History, society, school, individual, text (pp. 365-385.) New York: Lawrence Erlbaum Associates.

Murray, D. (1985). A writer teaches writing. Boston, MA: Houghton Mifflin.

Newkirk, T. (1989). The first five minutes: Setting the agenda in a writing conference. In C. M. Anson (Ed.), Writing and response: Theory, practice and research (pp. 317-331). Urbana, IL: National Council of Teachers of English.

Newman, R. (1994). Adaptive help-seeking: A strategy of self-regulated learning. In D. Schunk and B. Zimmerman (Eds.), Self-regulation of learning and performance: Issues and educational applications (pp. 284-299). Hillsdale, NJ: Erlbaum Associates.

Newman, R. (2008). The motivational role of adaptive help-seeking. In D. Schumk \& B. Zimmerman (Eds.). Motivation and self-regulated learning: Theory, research, and applications (pp. 315-337). Hillsdale, NJ: Erlbaum Associates.

Oakton Community College. (2010). Concordant ACT ${ }^{\circledR}, C O M P A S S \circledR$, and ASSET ${ }^{\circledR}$ Scores February, 2010. Retrieved from http://www.oakton.edu/user/3/cbustama/Developmental\%20English/Concordance \%20for\%20Compass,\%20Act,\%20and\%20Asset.pdf

O’Neill, P., Adler-Kassner, L., Fleischer, C., \& Hall, A. (2012). Creating the framework for success in postsecondary writing. College English, 74(6), 520-524.

Pajares, F. (2008). Motivational role of self-efficacy beliefs in self-regulated learning. In D. Schunk \& B. Zimmerman (Eds.). Motivation and self-regulated learning: Theory, research, and applications (pp. 111-140). Hillsdale, NJ: Erlbaum Associates.

Pajares, F., \& Johnson, M. J. (1996). Self-efficacy beliefs and the writing performance of entering high school students. Psychology in the Schools, 33(2), 163-175. doi: http://dx.doi.org/10.1002/(SICI)1520-6807(199604)33:2<163::AIDPITS10>3.0.CO;2-C

Pajares, F. \& Johnson, M. (1994). Confidence and competence in writing: The role of self-efficacy, outcome expectation, and apprehension. Research in the Teaching of English, 28(3), 313-331.

Pajares, F., \& Urdan, T. (Eds.). (2006). Self-efficacy beliefs of adolescents. Greenwich, CT: Information Age Publishing.

Pajares, F. \& Valiante, G. (2006). Self-efficacy beliefs and motivation in writing development. In C. MacArthur, S. Graham \& J. Fitzgerald (Eds.), Handbook of writing research (pp.158-170). New York: The Guilford Press. 
Pajares, F., Hartley, J., \& Valiente, G. (2001). Response format in writing self-efficacy assessment: Greater discrimination increases prediction. Measurement and Evaluation in Counseling and Development, 33(4), 214-221. Retrieved from http://www.uky.edu/ eushe2/Pajares/PHV2001MECD.html

Perl, S. (1980). Understanding composing. College Composition and Communication, 31(4), 363-369. doi: 10.2307/356586

Piazza, C. \& Seibert, C. (2008). Development and validation of a writing dispositions scale for elementary and middle school students. The Journal of Educational Research, 101(5), 275-286. doi: 10.3200/JOER.101.5.275-286

Prat-Sala, M. \& Redford, P. (2012). Writing essays: Does self-efficacy matter? The relationship between self-efficacy in reading and in writing and undergraduate performance in essay-writing. Educational Psychology: An International Journal of Experimental Educational Psychology, 32(1), 9-20. doi: 10.1080/01443410.2011.621411

Rendleman, E. (2013). Writing centers and mandatory visits. WPA-CompPile Research Bibliographies, No. 22. WPA-CompPile Research Bibliographies. Retrieved from http://comppile.org/wpa/bibliographies/Bib22/Rendleman.pdf

Ryan, A. \& Pintrich, P. (1997). "Should I ask for help?” The role of motivation and attitudes in adolescents' help-seeking in math class. Journal of Educational Psychology, 89(2), 329-341.

Sanders-Reio, J., Alexander, P., \& Reio, T. (2014). Do students' beliefs about writing relate to their writing self-efficacy, apprehension, and performance? Learning and Instruction, 33, 1-11. doi: 10.1016/j.learninstruc.2014.02.001

Sanders-Reio, J. (2010). Investigation of the relations between domain-specific beliefs about writing, writing self-efficacy, writing apprehension, and writing performance in undergraduates (Doctoral dissertation). Retrieved from Proquest. Dissertation Publishing. (Accession No. 3409651)

Schrieber, J., Stage, F., King, J., Nora, A. \& Barlow, E. (2006). Reporting structural equation modeling and confirmatory factor analysis: A review. The Journal of Educational Research, 99(6), 323-338. doi: 10.3200/JOER.99.6.323-338

Schumacker, R., and Lomax, R. (2010). A beginner's guide to structural equation modeling ( $3^{\text {rd }}$ ed.). New York: Taylor and Francis.

Schunk, D. (1991). Self-efficacy and academic motivation. Educational Psychologist, 26, 207-231.

Schunk, D. (1981). Modeling and attributional effects on children's achievement: A selfefficacy analysis. Journal of Educational Psychology, 73(1), 93-105. Retrieved from http://libres.uncg.edu/ir/uncg/f/D_Schunk_Modeling_1981.pdf

Schunk, D. \& Miller, S. (2002). Self-efficacy and adolescents' motivation. In F. Pajares, \& T. Urdan (Eds.), Academic motivation of adolescents (pp. 29-52). Greenwich, $\mathrm{CN}$. Information Age Publishing. 
Shaughnessy, M. (1977). Errors and expectations: A guide for the teacher of basic writing. New York: Oxford University Press.

Shell, D. F., Murphy, C. C., \& Bruning, R. H. (1989). Self-efficacy and outcome expectancy mechanisms in reading and writing achievement. Journal of Educational Psychology, 81(1), 91-100. doi: http://dx.doi.org/10.1037/00220663.81.1.91

Sirin, S. (2005). Socioeconomic status and academic achievement: A meta-analytic review of research. Review of Educational Research, 73(3), 417-453. doi: $10.3102 / 00346543075003417$

Sommers, N. (1980). Revision strategies of student writers and experienced adult writers. College Composition and Communication, 31(4), 378-388.

Strauss, S. \& Xiang, X. (2006). The writing conference as a locus of emergent agency. Written Communication, 23(4), 355-396. doi: 10.1177/0741088306292286

Stock, P. (2012). (Ed.). Composition's roots in English education. Portsmouth, NH: Heinemann.

Sullivan, P. (2006). An essential question: What is college-level writing? In P. Sullivan \& H. Tinberg (Eds.), What is college-level writing? (pp. 1-28). Urbana, IL: National Council of Teachers of English.

Tanyer, S. (2015). The role of writing and reading self-efficacy in first-year pre-service EFL teachers' writing performance. Procedia: Social and Behavioral Sciences, 199, 38-43. doi: 10.1016/j.sbspro.2015.07.484

Troia, G., Shankland, R. \& Wolbers, K. (2012). Motivation research in writing: Theoretical and empirical considerations. Reading and Writing Quarterly, 28(1), 5-28. doi: 10.1080/10573569.2012.632729

Usher, E. \& Pajares, F. (2008). Sources of self-efficacy in school: Critical review of the literature and future directions. Review of Educational Research, 78(4), 751-796. doi:10.3102/0034654308321456

Villalòn, R., Mateos, M. \& Cuevas, I. (2013). High school boys’ and girls’ writing conceptions and writing self-efficacy beliefs: What is their role in writing performance? Educational Psychology: An International Journal of Experimental Educational Psychology. 33(6), 653-674. doi: 10.1080/01443410.2013.836157

Wardle, J., Robb, K., \& Johnson, F. (2001). Assessing socioeconomic status in adolescents: The validity of a home affluence scale. Journal of Epidemiology and Community Health, 56(8), 595-599. doi: 10.1136/jech.56.8.595

White, E. (2009). Holisticism. In B. Huot and P. O’Neill (Eds.), Assessing writing: A critical sourcebook (pp. 19-28). Boston, MA: Bedford/St. Martin.

Willens, J. (1981). The effects of socioeconomic status, verbal ability, locus of control, achievement motivation, and persistence on the writing achievement of two-year college students. (Doctoral dissertation). Retrieved from Proquest Dissertation 
Publishing. (Accession No. 8203781)

Williams, J., \& Takaku, S. (2011). Gender, writing self-efficacy, and help-seeking. International Journal of Business, Humanities, and Technology, 1(3), 46-54. Retrieved from http://www.ijbhtnet.com/journals/Vol_1_No_3_November_2011/5.pdf

Williams, J., \& Takaku, S. (2011). Help-seeking, self-efficacy, and writing performance among college students. Journal of Writing Research, 3(1), 1-18. Retrieved from http://www.jowr.org/articles/vol3_1/JoWR_2011_vol3_nr1_Williams_Takaku.pd $\mathrm{f}$

Williams, J., Takaku, S., \& Bauman, K. (2006). Effects of self-regulatory behavior on ESL student writing. Tohoku Psychological Folia, 65, 24-36.

Wood, R. \& Bandura, A. (1989). Social cognitive theory of organizational management. Academy of Management Review, 14(3), 361-384. Retrieved from http://www.uky.edu/ eushe2/Bandura/Bandura1989AMR.pdf

Winne, P. \& Hadwin, A. (2008). The Weave of motivation and self-regulated learning. In D. Schunk \& B. Zimmerman (Eds.), Motivation and self-regulated learning: Theory, research, and applications (pp. 297-314). Hillsdale, NJ: Erlbaum Associates.

Yancey, K. (2009). Looking back as we look forward: Historicizing writing assessment. In B. Huot \& P. O’Neill (Eds.), Assessing writing: A critical sourcebook (pp. 131149). Boston, MA: Bedford/St. Martin.

Zajacova, A., Lynch, S, \& Espenshade, T. (2005). Research in Higher Education, 46(6), 677-706. doi: 10.1007/s11162-004-4139-z

Zebroski, J. (2012). Hidden from history: English education and the origins of contemporary composition studies, 1960-2000. In P. Stock (Ed.) Composition's roots in English education (pp. 26-50). Portsmouth, NH: Heinemann.

Zimmerman, B. J. (1989). A social cognitive view of self-regulated academic learning. Journal of Educational Psychology, 81(3), 329-339.

Zimmerman, B. J. (1990). Self-regulated learning and academic achievement: An overview. Educational Psychologist, 25(1), 3-17. Retrieved from http://itari.in/categories/ability_to_learn/self_regulated_learnin_g_and_academic_ achievement_m.pdf

Zimmerman, B. J. (1998). Academic studying and the development of personal skill: A self-regulatory perspective. Educational Psychologist, 33(2/3), 73-86. doi: 10.1080/00461520.1998.9653292

Zimmerman, B. J. (2000). Self-efficacy: An essential motive to learn. Contemporary Educational Psychology, 25, 82-91. doi: 10.1006/ceps.1999.1016

Zimmerman, B. J. (2002). Becoming a self-regulated learner: An overview. Theory into Practice, 41(2), 64-70. doi: 10.1207/s15430421tip4102_2 
Zimmerman, B. J., \& Bandura, A. (1994). Impact of self-regulatory influences on writing course attainment. American Educational Research Journal, 31(4), 845-862. doi: 10.3102/00028312031004845

Zimmerman, B. J. \& Kitsantas, A. (2007). A writer's discipline: The development of selfregulatory skill. In G. Rijlaarsdam (Series Ed.) and P. Boscolo \& S. Hidi (Volume Eds.), Studies in Writing, 19, Writing and Motivation (pp. 51-69). Oxford: Elsevier.

Zimmerman, B., Bandura, A., \& Martinez-Pons, M. (1992). Self-motivation for academic attainment: The role of self-efficacy beliefs and personal goal-setting. American Educational Research Journal, 29(3), 663-676. doi: 10.3102/00028312029003663

Zimmerman, B. J., \& Martinez-Pons, M. (1990). Student differences in self-regulated learning: Relating grade, sex, and giftedness to self-efficacy and strategy use. Journal of Educational Psychology, 82(1), 51-59.

Zimmerman, B. \& Schunk, D. (2008). Motivation: An essential dimension of selfregulated learning. In D. Schunk \& B. J. Zimmerman (Eds.), Motivation and selfregulated learning: Theory, research, and applications (pp. 1-30). Hillsdale, NJ: Erlbaum Associates. 
VITA

NAME:

Thula Inetha Norton Lambert

PLACE OF BIRTH:

Georgetown, Guyana, South America

COUNTRY OF CITIZENSHIP: $\quad$ France

EDUCATION:

2015

Candidate, Doctor of Philosophy, Curriculum and Instruction, Andrews University, Berrien Springs, MI

2012

Master of Arts, English with a specialization in

Teaching English to Speakers of Other Languages, Andrews University, Berrien Springs, MI

1997

Graduate Certificate in Teaching English as a

Second Language, Andrews University

1988

Bachelor of Arts, English, Caribbean Union College

(now University of the Southern Caribbean)

PROFESSIONAL EXPERIENCE:

2011; 2013

English Composition Instructor, Department of English, Andrews University, Berrien Springs, MI

2011-2012 English for Academic Purposes Instructor, Center for Intensive English Programs, Andrews University, Berrien Springs, MI

2008-Present Court-Appointed Translator, Court of Appeals, Martinique, French West Indies

2000-2008 English as a Foreign Language Instructor, Chamber of Commerce, Martinique 
